BNL-90967-2009

\title{
National Synchrotron Light Source 2009 Activity Report
}

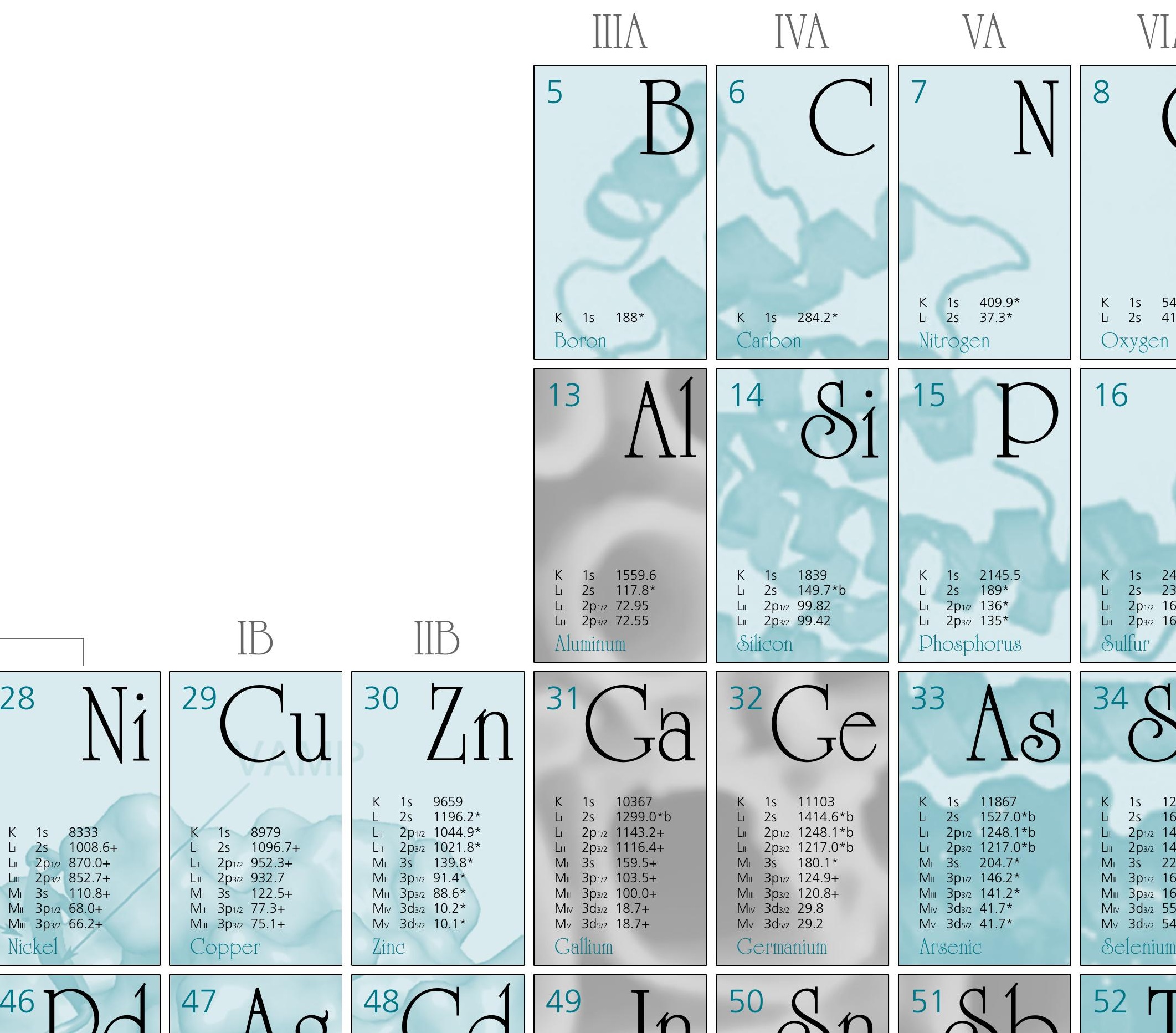




\title{
National Synchrotron Light Source 2009 Activity Report
}

\author{
Kathleen Nasta \\ Managing Editor \\ Kendra J. snyder \\ Science Writer \\ Tiffany $\Lambda$. Bowman \\ Graphic Designer
}

The National Synchrotron Light Source Department is supported by the Office of Basic Energy Sciences, United States Department of Energy, Washington, D.C.

Brookhaven National Laboratory, Brookhaven Science Associates, Inc., Upton, New York 11973 Under contract no. DE-AC02-98CH10886 
BNL-90967-2009

UC400

(General Energy Research)

\section{On the Cover}

Stylized version of the periodic table of the elements with the associated electron binding energies - the energy required to remove an electron from a particular atom. This book's dust jacket can be unfolded and hung up for easy reference.

The 2009 Activity Report is printed on 100\% recycled paper.

\section{Disclaimer}

This report was prepared as an account of work sponsored by an agency of the United States Government. Neither the United States Government nor any agency thereof, nor any of their employees, nor any of their contractors, subcontractors, or their employees, makes any warranty, express or implied, or assumes any legal liability or responsibility for the accuracy, completeness, or usefulness of any information, apparatus, product, or process disclosed, or represents that its use would not infringe privately owned rights. Reference herein to any specific commercial product, process, or service by trade name, trademark, manufacturer, or otherwise, does not necessarily constitute or imply its endorsement, recommendation, or favoring by the United States Government or any agency, contractor, or subcontractor thereof. The views and opinions of authors expressed herein do not necessarily state or reflect those of the United States Government or any agency, contractor, or subcontractor thereof.

Printed in the United States of America

Available from

National Technical Information Service

U.S. Department of Commerce

5285 Port Royal Road

Springfield, VA 22161 


\section{Table of Contents}

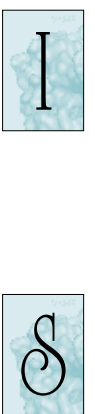

Introduction . . . . . . . . . . . . . . . 4

Chairman's Introduction 4

A Beacon for Research 6

On the Horizon: NSLS-II 7

Science Highlights . . . . . . . . . . . . . . . . . . . . . . . . . . . . 8

Physical and Chemical Sciences Introduction 8

Condensed Matter Physics 10

Materials Sciences 13

Chemical Sciences $\quad 16$

X-Ray Optics and Accelerator Physics 19

Life and Environmental Sciences Introduction 21

Earth and Environmental Sciences 23

Life Sciences $\quad 25$

Soft Condensed Matter and Biophysics 34

Y Year in Review . . . . . . . . . . . . . . . . . . 36

Staff Photo 36

January - April $\quad 38$

May - August $\quad 40$

September - December $\quad 42$

F Facility Report . . . . . . . . . . . . . . . . . 44

Safety Update $\quad 44$

The Accelerator Complex $\quad 46$

Experimental Systems

Facility Facts and Figures . . . . . . . . . . . . . . . . 58

Introduction $\quad 58$

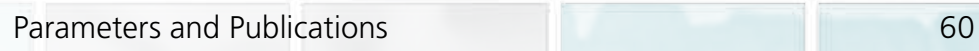

\begin{tabular}{l|l|l} 
User Statistics & 61
\end{tabular}

\begin{tabular}{|l|l|}
\hline Beamline Status & 62 \\
\hline
\end{tabular}

\begin{tabular}{l|l|l}
\hline Beamline Guide & 62
\end{tabular}

\begin{tabular}{l|l} 
Advisory Committees & 68
\end{tabular} 

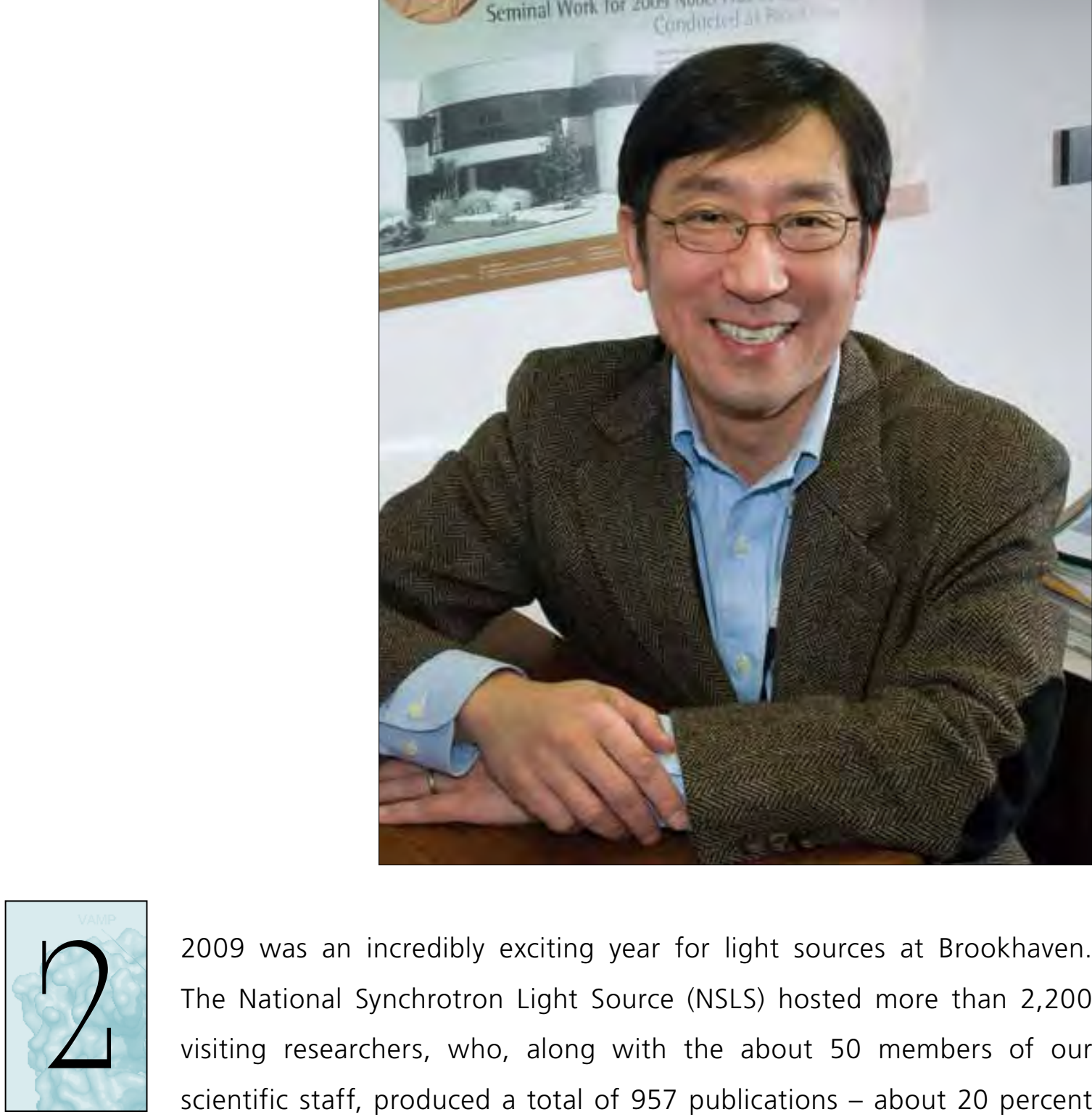

2009 was an incredibly exciting year for light sources at Brookhaven. The National Synchrotron Light Source (NSLS) hosted more than 2,200 visiting researchers, who, along with the about 50 members of our scientific staff, produced a total of 957 publications - about 20 percent of which appeared in premier journals. Covering topics ranging from Alzheimer's disease detection to ethanol-powered fuel cells, a sampling of these findings can be found in this Activity Report.

We've also seen the resurfacing of some of our long-time users' hard work. I was very proud to hear that two of the three recipients of the 2009 Nobel Prize in Chemistry have ties to the NSLS. Venki Ramakrishnan, a former employee in Brookhaven's biology department and long-time user of the NSLS, now at Cambridge University, and Thomas A. Steitz of Yale Uni- versity, also a long-time NSLS user, shared the prize with Ada E. Yonath of the Weizmann Institute of Science for their work on the structure and function of the ribosome. In the late 1990s, Ramakrishnan and Steitz used protein crystallography at the NSLS to gather atomic-level images of two ribosome subunits: 305 (Ramakrishnan) and 50S (Steitz). Both laureates solved the high-resolution 
structures for these subunits based on this data.

After struggling with a rough budget for several years, we received excellent funding, and then some, this year. In addition to NSLS operations funding, we received $\$ 3$ million in funds from the American Recovery and Reinvestment Act

(ARRA). We used that additional money for two exciting projects: construction of a full-field $x$-ray microscope and acquisition of several advanced $x$-ray detectors. The $x$-ray microscope will be able to image objects with a targeted spatial resolution of 30 nanometers. This capability will be particularly important for new initiatives in energy research and will prepare our users for the projected 1-nanometer resolution benchmark at the National Synchrotron Light Source II (NSLS-II). The detectors project is expected to increase the throughput of several high-demand beamlines by an order of magnitude as well as enable new classes of experiments. In addition, a huge chunk of ARRA money - $\$ 150$ million - was put toward accelerating the construction of NSLS-II, which is now taking shape across the street.

Now physically much more than just a pile of dirt, NSLS-II was granted Critical Decision 3 status by the Department of Energy (DOE) early last year, giving the official go-ahead for construction. In July, construction began, marked by a groundbreaking ceremony that attracted elected officials, media,
Research Centers, focused on understanding the underlying nature of superconductivity in complex materials by using techniques at the NSLS and CFN; DOE awarded a $\$ 100,000$ supplemental grant to our detector program to continue the development of a new generation of x-ray detectors that use germanium sensors,

and DOE, Battelle, and Stony Brook University representatives from across the state and the country.

As progress on NSLS-II continues, we're working with Stony Brook University to identify ways to capitalize on the facility's unique capabilities through the Joint Photon Sciences Institute (JPSI). Included in this effort is a series of workshops to encourage the development and application of the photon sciences with collaborative research between industries, universities, and national laboratories. We helped host three of these workshops this year, focusing on microelectronics, energy storage, and materials in next-generation energy systems. The conversation and ideas generated at these meetings has been fresh and valuable and we hope to use this model to organize research opportunities in other scientific fields.

Also this year: Brookhaven was deemed the lead institution for one of DOE's 46 Energy Frontier which, at high energies, are much more efficient than equivalent ones based on silicon; and funding for one of our largest consortia, Case Western Reserve University's Center for Synchrotron Biosciences (CSB), was renewed through the National Institutes of Health. The CSB, which operates five NSLS beamlines and serves more than 550 users, will receive a five-year, \$4-million grant to continue to study the structure and dynamics of proteins and nucleic acids.

Finally, construction of the new $X 9$ beamline and endstation for small angle x-ray scattering (SAXS) and wide angle $x$-ray scattering (WAXS) was completed this year. By July, the beamline and endstation were commissioned and serving general users. This allowed for the relocation of the SAXS and WAXS experimental programs from beamline X21 to X9, providing much-needed beam time for the soft condensed matter physics, life sciences, and nanoscience communities. 

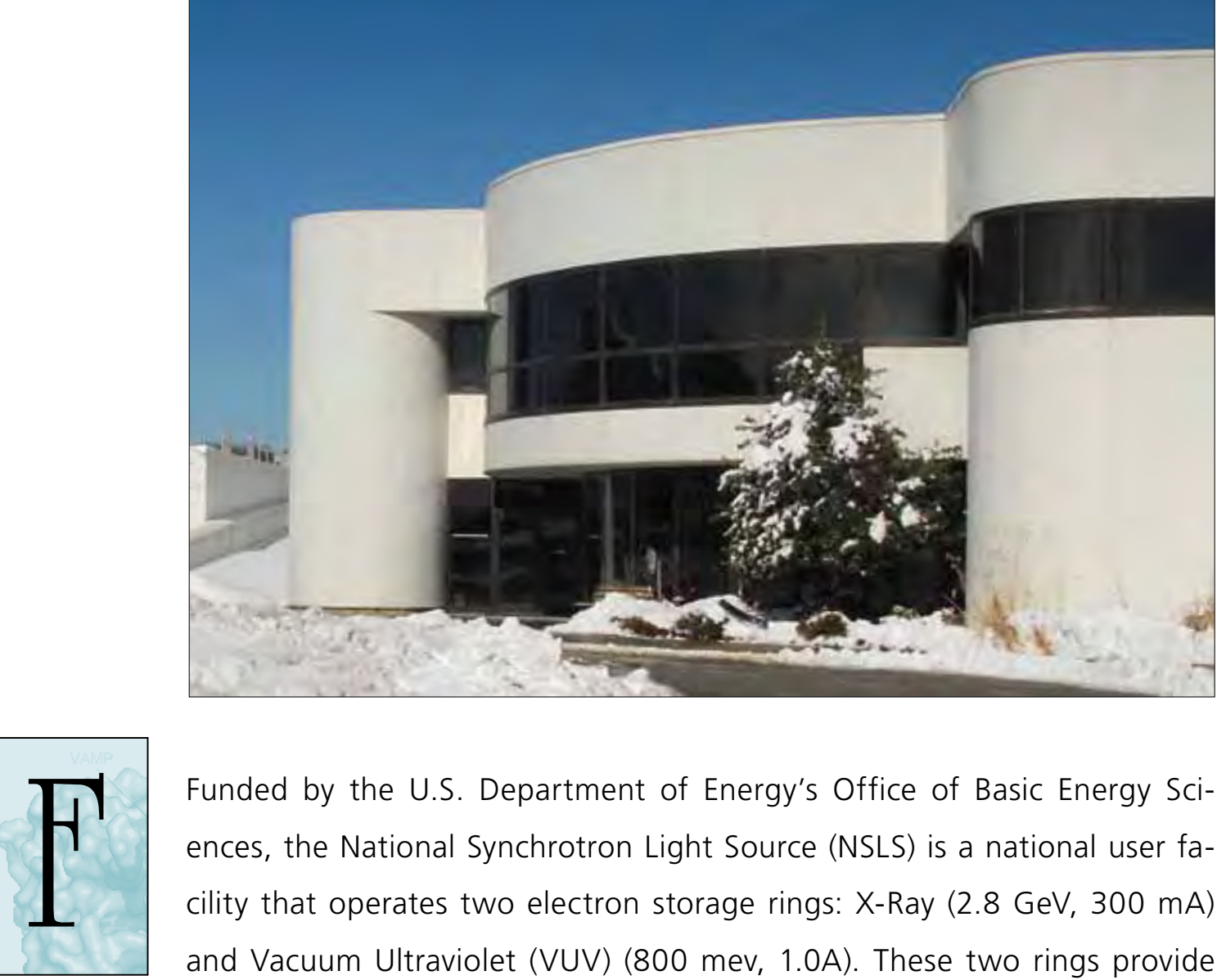

Funded by the U.S. Department of Energy's Office of Basic Energy Sciences, the National Synchrotron Light Source (NSLS) is a national user facility that operates two electron storage rings: X-Ray (2.8 GeV, $300 \mathrm{~mA})$ and Vacuum Ultraviolet (VUV) ( $800 \mathrm{mev}, 1.0 \mathrm{~A})$. These two rings provide intense light spanning the electromagnetic spectrum - from very long infrared rays to ultraviolet light and super-short $\mathrm{x}$-rays - to analyze very small or highly dilute samples. The properties of this light, and the specially designed experimental stations, called beamlines, allow scientists in many diverse disciplines of research to perform experiments not possible at their own laboratories.

Each year, about 2,200 scientists from more than 400 universities and companies use the NSLS for research in such diverse fields as biology, physics, chemistry, geology, medicine, and environmental and materials sciences. For example, researchers have used the NSLS to examine the minute details of computer chips, decipher the structures of viruses, probe the density of bone, determine the chemical composition of moon rocks, and reveal count- less other mysteries of science. The facility has 64 operating beamlines, with 50 beamlines on the X-Ray Ring and 13 beamlines on the VUV-Infrared Ring. It runs seven days a week, 24 hours a day throughout the year, except during periods of maintenance and studies. Researchers are not charged for beam time, provided that the research results are published in open literature. Proprietary research is conducted on a fullcost-recovery basis.
With close to 1,000 publications per year, the NSLS is one of the most prolific scientific facilities in the world. Among the many accolades given to its users and staff, the NSLS has won nine R\&D 100 Awards for innovations ranging from a closed orbit feedback system to the first device able to focus a large spread of high-energy x-rays. In addition, the Nobel Prize in Chemistry has been awarded twice based partially on work coducted at the NSLS: in 2003 and 2009. 

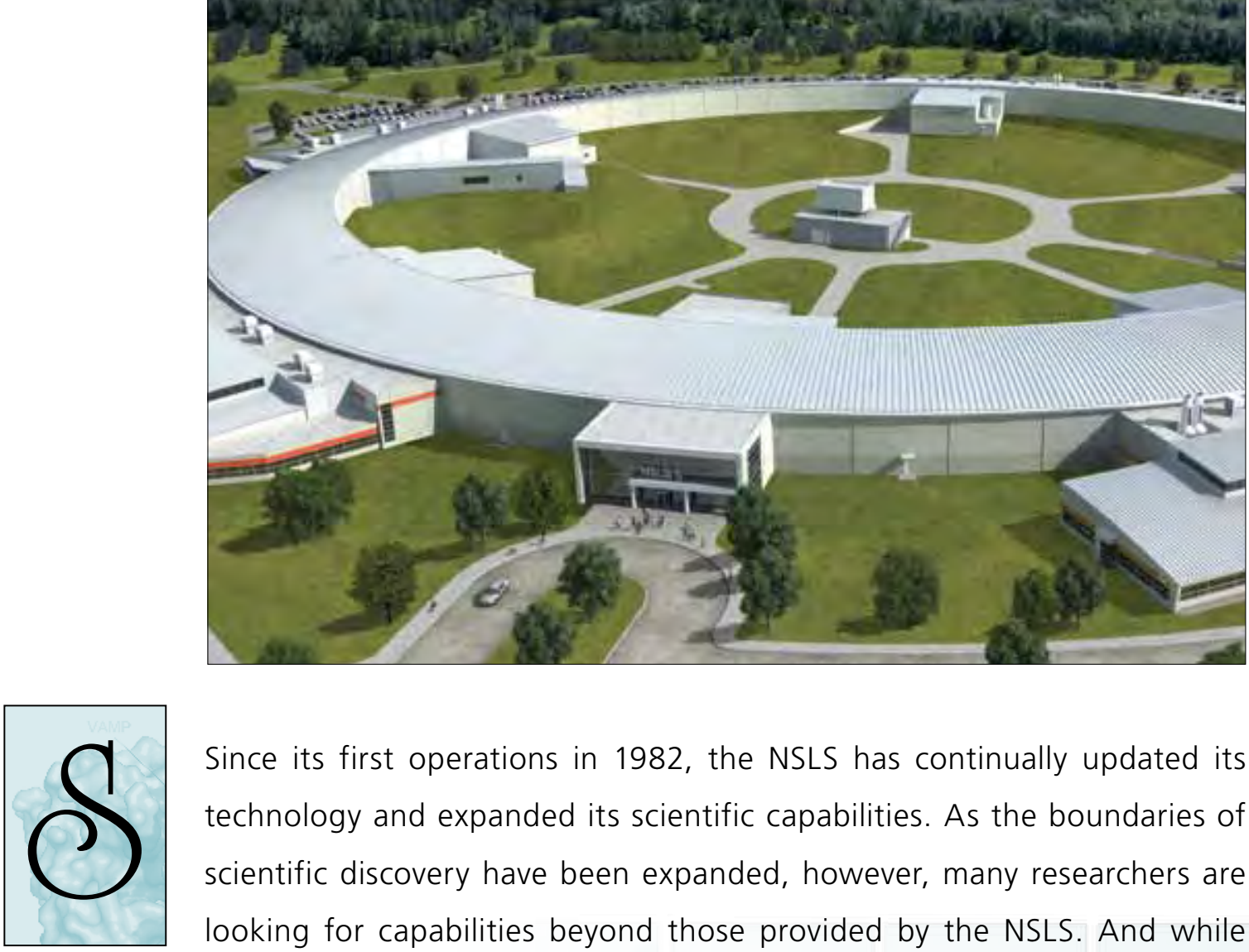

Since its first operations in 1982, the NSLS has continually updated its technology and expanded its scientific capabilities. As the boundaries of scientific discovery have been expanded, however, many researchers are looking for capabilities beyond those provided by the NSLS. And while newer synchrotrons surpass the performance of the present NSLS, no synchrotron anywhere in the world will enable scientists to image and characterize materials down to billionth-of-a-meter (nanometer) resolution.

To address this need, Brookhaven is building the National Synchrotron Light Source II (NSLS-II). The new facility, which will replace the NSLS, will be a mediumenergy storage ring designed to deliver world-leading brightness and flux. It will provide advanced tools for discovery-class science in condensed matter and materials physics, chemistry, and biology. For example, major advances in energy technologies - such as the use of hydrogen as an energy carrier; the widespread, economical uses of solar energy; or the development of the next generation of nuclear power systems - will require scientific breakthroughs in developing new materials with advanced properties.

The combination of capabilities at NSLS-II will have broad impact on a wide range of disciplines and scientific initiatives in the coming decades, including new studies of small crystals in structural biology, the development of probes for nanoscience, coherent imaging of the structure and dynamics of disordered materials, greatly increased applicability of inelastic $x$-ray scattering, and properties of materials under extreme conditions. This high-brightness light source will also foster research in areas such as structural genomics and drug design, as well as extend the studies of early disease detection.

The leading-edge ability of NSLS-II to analyze materials will help guide the development of new materials at Brookhaven's Center for Functional Nanomaterials. The synergy of these two facilities is expected to promote breakthroughs in the use of renewable energy through improved energy conversion, transmission, and storage - science that ultimately will enhance national and energy security and help drive abundant, safe, and clean energy technologies. 
high-temperature superconductors by demonstrating that magnetism is not the driving force for phase transitions within its superconducting phase. The phase diagram of these materials was mapped using $x$-ray powder diffraction. Finally, in measurements carried out using selectedarea angle-resolved photoelectron spectroscopy, a new capability on beamline U5UA, researchers from Brookhaven's Center for Functional Nanomaterials (CFN) studied how graphene behaves when epitaxially prepared on a transition metal surface. The results confirmed the expectation that the novel electronic properties of graphene are disrupted in the first monolayer but further demonstrated that these properties can be recovered in subsequent layers — an important result for the development of graphene-based devices.

In materials science, researchers from Arizona State University and the National Institute of Standards and Technology (NIST) worked on improving material processing for organic photovoltaics. While there are many commercial p-type organic semiconductors, n-type organic semiconductors typically have poor carrier mobility. The researchers used the near-edge $x$-ray absorption fine structure (NEXAFS) technique to demonstrate that this is due to the trapping of electrons at the dielectric/organic semiconductor interface. They further showed that this trapping can be overcome by coating the substrate with a dense hydrophobic organic monolayer that restores the high carrier mobility needed for photovoltaic devices. Another project involving NIST researchers, in collaboration with the NSLS and Intel, was the development of an effective diffusion barrier to prevent the copper atoms in line interconnects from reacting with low-dielectric support substrates. The team explored the introduction of a copper-manganese alloy and showed, using grazing incidence $x$-ray fluorescence spectroscopy, that the manganese atoms migrate to the interface to form an effective diffusion barrier. Improving electronic device performance also was the focus of work by a group from IBM and Ghent University that used in-situ x-ray diffraction to study nickel silicide films during thermal processing. They demonstrated that adding silicon to the nickel changes the phase sequence during thermal annealing and produces more stable films with epitaxial grains.

In the chemical sciences, a research team from the University of South Carolina and Kookmin University in Korea made a breakthrough in the pressurefree synthesis of transition metals in unusually high oxidation states. The high oxidation states with correspondingly smaller radii and potentially different preferences for coordinating with nearest neighbor atoms can lead to new structures with novel properties. X-ray absorption near-edge spectra (XANES) enabled the team to confirm their results. Another unexpected discovery was made by researchers from Northeastern University and NIST, who used the NEXAFS tech- nique to confirm that trace amounts of potassium ions, a by-product of the process used to prepare arrays of titania nanotubes, is responsible for significantly lowering the energy cost when these nanotube arrays are utilized in water-splitting solar cells. Finally, a team of scientists from Brookhaven Lab, the University of Delaware, and Yeshiva University developed a new catalyst that could make ethanol-powered fuel cells feasible. The team used electron microscopy at the CFN together with $x$-ray absorption spectroscopy on beamline $\mathrm{X} 18 \mathrm{~A}$ to confirm the re- 


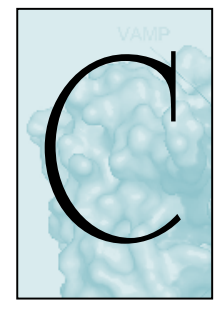

Counting the "Holes" in High-Temperature Superconductors

As part of the effort to better understand how superconductors transport electricity with zero resistance, a team of researchers has demonstrated a new way to count the number of a material's "holes" - locations where electrons are absent. Knowing more about holes, which, like electrons, are thought to interact with each other to produce superconducting current within a material, could help scientists develop superconductors for applications like more-efficient power transmission or magnetic-levitation high-speed trains.

The researchers, from the University of Illinois, Brookhaven National Laboratory, and the University of Paris, focused on copper-oxide compounds, called cuprates. Cuprates normally act as insulators but become superconductors when electrons are removed in a process known as "doping" holes into the material. A material is considered optimally doped when it is superconducting at the highest temperature possible. When the material is doped past this point, the superconductivity often vanishes.

In this study, the researchers built a sandwich of alternating layers of two cuprates: LSCO, which contains lanthanum, strontium, copper, and oxygen; and LCO, which lacks the strontium.
Neither of the two materials used in the study is superconducting by itself - LCO was used in its naturally insulating form and LSCO was overdoped to the point where its superconductivity disappeared. Surprisingly, though, the overall structure is superconducting at 38 Kelvin, about -235 degrees Celsius.

To figure out what was happening, the researchers used resonant soft $x$-ray scattering at NSLS beamline $\mathrm{X} 1 \mathrm{~B}$. By measuring the reflectivity of the structure at different angles, they pinpointed the number of holes in each individual layer.

Their results show that many of the holes actually moved from the overdoped LSCO to the LCO.
This creates optimally doped LCO - the driver of the surprise superconductivity in the multilayered structure.

The results demonstrate the utility of resonant soft $x$-ray scattering for probing the holes near interfaces separately of the atomic structure, as well as provide evidence on the importance of interfaces to novel superconducting materials.

S. Smadici, J.C.T. Lee, S. Wang, P. Abbamonte, G. Logvenov, A. Gozar, C. Deville Cavellin, I. Bozovic, "Superconducting Transition at $38 \mathrm{~K}$ in InsulatingOverdoped $\mathrm{La}_{2} \mathrm{CuO}_{4}-\mathrm{La}_{164} \mathrm{Sr}_{0.36} \mathrm{CuO}_{4}$ Superlattices: Evidence for Interface Electronic Redistribution from Resonant Soft X-Ray Scattering," PRL, 102, 107004 (2009).

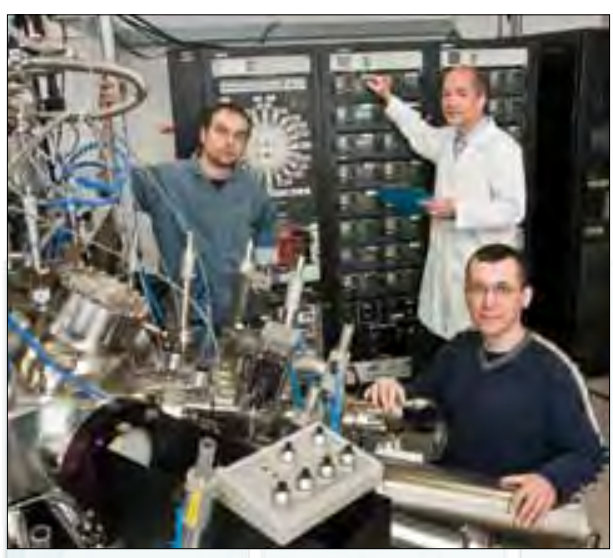

From left, researchers Adrian Gozar, Ivan Bozovic, and Serban Smadici

(left) Layer-resolved hole density in a superconducting $2 x$ LCO - 4 x LSCO superlattice (dots) compared to results of calculations for different screening lengths/lambda (lines). 


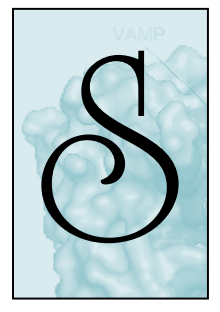

\section{Shining Light on Graphene-Metal Interactions}

By controlling the layered growth of graphene - a relatively "new" form of carbon that's just a single atom thick - researchers at Brookhaven National Laboratory have uncovered intriguing details about the material's superior electrical and optical properties. Their findings could help position graphene as the next-generation material for future computers, digital displays, and electronic sensors.

One of the biggest challenges facing researchers is figuring out how to produce graphene in large quantities. The simplest method is peeling off single sheets of graphene from graphite, a material consisting of many graphene layers, with pieces of tape. But this method yields only small, jagged flakes that aren't useful for most applications.

At Brookhaven, researchers grow graphene on a metal substrate, a technique that can produce single-layer sheets thousands of times larger than the pieces made with the "Scotch tape" method. First, a single crystal of ruthenium is heated while exposing it to a carbon-rich gas. At high temperatures, carbon atoms are able to squeeze into spaces within the metal crystal, similar to water being taken in by a sponge. As the crystal is slowly cooled, these carbon atoms are expelled to the surface of the metal, where they form individual layers of graphene. The number of layers formed can be controlled by the amount of carbon atoms initially absorbed into the ruthenium crystal.

To obtain measurements for the material with different numbers of graphene sheets, the group used micro-angle-resolved photoelectron spectroscopy (mirco-ARPES) at NSLS beamline U5. This technique allows researchers to study the electronic structure of very small regions of interest.
They found that if a single graphene sheet is grown on a metal like ruthenium, the metal binds very strongly to the carbon atoms and disrupts the characteristic properties normally found in isolated graphene. But, those properties re-emerge in subsequent layers grown on the substrate.

The group's findings lay groundwork for future graphene production for advanced technologies, and helps researchers understand how metals - for example in device contacts change the properties of graphene.

P. Sutter, M.S. Hybertsen, J.T. Sadowski, E. Sutter, "Electronic Structure of Few-Layer Epitaxial Graphene on Ru(0001)," Nano Lett., 9(7), 2654 (2009).

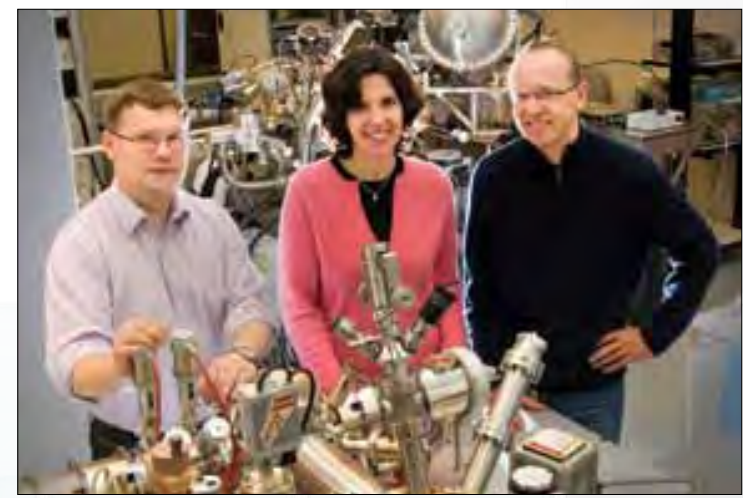

From left, Jurek Sadowski, Eli Sutter, and Peter Sutter

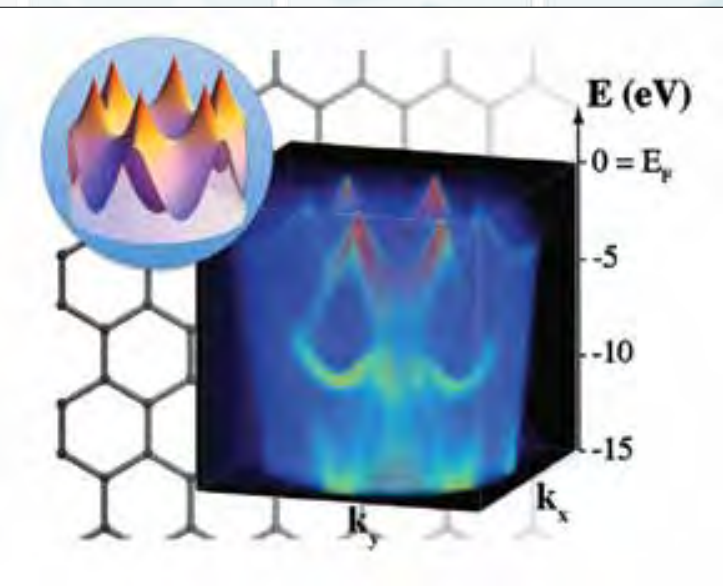

Measurement of the electronic bands of bilayer graphene on ruthenium, which have the characteristics of freestanding monolayer graphene. One of these characteristics is a typical cone-like shape of the bands near the Fermi energy. The inset shows a calculation of these "Dirac cones" for comparison. Shown in the background is a schematic rendering of the lattice structure of graphene.
11

Sh science Highlights 


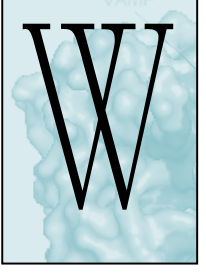

Watching the Tug of War between Structure and Superconductivity

Like Clark Kent, who often forgoes his social life to become Superman, materials that become superconducting must sacrifice at least one of their natural properties to attain the ability to transfer electric current with zero resistance. At the NSLS and Brookhaven's Center for Functional Nanomaterials (CFN), a team of researchers has explored this internal conflict in a class of iron-based superconductors, materials that could be used to develop energy-saving applications such as high-efficient power lines.

Researchers from Princeton, Stony Brook University, Brookhaven, and Johannes Gutenberg University, in Germany, focused their investigations on a particular material made from conducting layers of iron and selenium, called iron selenide.

In order for superconductivity to exist, it must arise as the winner in a "tug of war" between different physical properties. The research community has known that magnetism competes with superconductivity in iron superconductors, but no one had a good idea of how crystal structure competed.

To find out, the group took "snapshots" of superconducting and non- superconducting iron selenide using synchrotron $x$-ray powder diffraction at NSLS beamline X16C. They combined that data with images taken with transmission electron microscopy and electron diffraction at the CFN.

The results show that the superconducting form of iron selenide can be distinguished from the non-superconducting form by a change in its structure. The superconductor gains its power by giving way to a slight structural "distortion," and the nonsuperconductor holds strong.

The researchers also demonstrated that this unique structural change is unrelated to magnetism, as hypothesized in the past. The material's fundamental bonding - the bonding between atoms - stays the same while the angles between the bonds change, similar to the expansion of a baby gate.

But the real surprise is that this structural change actually exists in both the superconducting and non-superconducting forms of the material, just on a very small scale. The challenge now is to figure out over what distance a crystal structure has to be distorted in order to affect its properties.

T.M. McQueen, A.J. Williams, P.W. Stephens, J. Tao, Y. Zhu, V. Ksenofontov, F. Casper, C. Felser, R.J. Cava, "Tetragonal-to-Orthorhombic Structural Phase Transition at $90 \mathrm{~K}$ in the Superconductor $\mathrm{Fe}_{1.01} \mathrm{Se}, "$ PRL, 103, 057002 (2009).

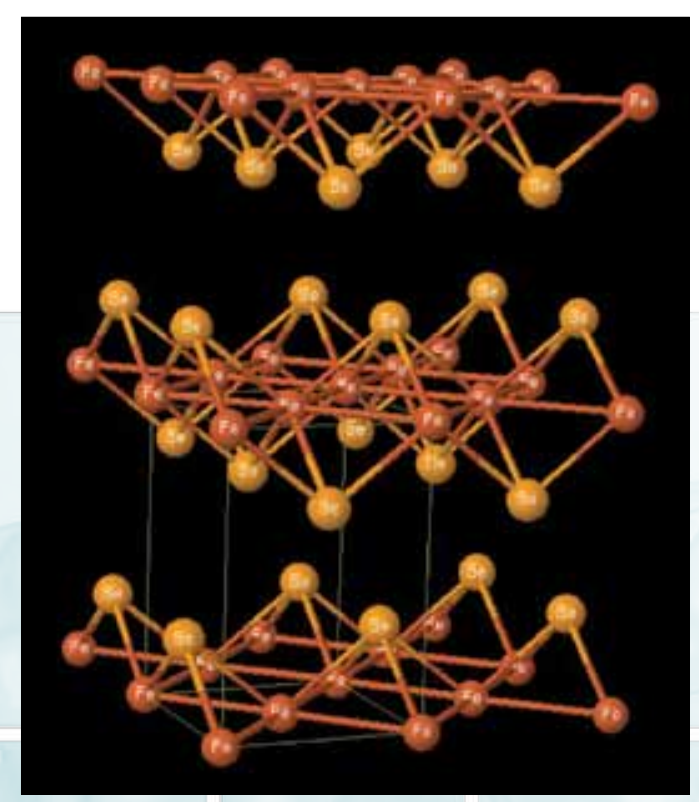

(left) The crystalline structure of the superconductor FeSe has square layers of iron (Fe) atoms that are strongly chemically bonded to layers of selenium (Se) atoms. The superconducting electrons are found in the iron layers. The group's work showed that a deviation of the shape of the iron layers from exactly square geometry at the length scale of thousands of atoms is a critical factor in determining whether superconductivity occurs or doesn't occur.

12 @ 1

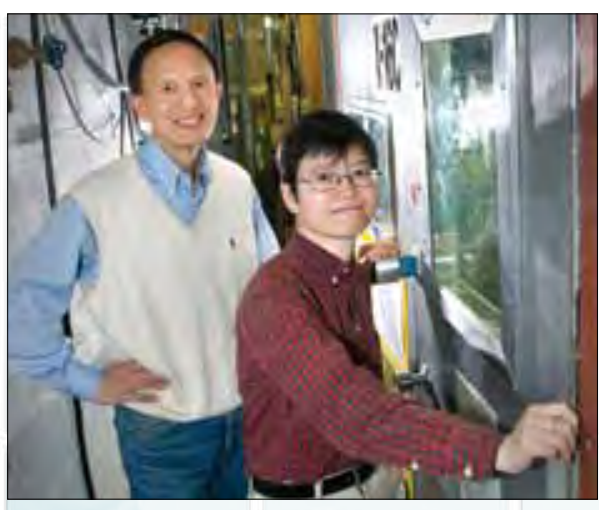

Yimei Zhu (left) and Jing Tao 
E-readers that can be bent and folded, "smart" bandages that signal when they need changing based on oxygen levels, and biodegradable radio frequency identification tags that help companies track and manage stock - these are all real possibilities in the field of organic electronics, which uses carbon-based materials that are intrinsically semiconductors. Using the NSLS, a group of researchers from the National Institute of Standards and Technology (NIST), Arizona State University, and the University of Oulu, Finland, analyzed one promising organic semiconducting material in an effort to bring these technologies, and many more, to the marketplace.

As opposed to conventional electronics, which feature inorganic metal conductors such as silicon or copper, organic electronics - also known as plastic electronics - can be manufactured using technology as common as an ink jet printer. This makes possible the production of lightweight, flexible, and robust electronics at low cost. However, reproducibility and reliability are hard to achieve in organic electronics because the ink dries differently almost every time.

In this study, the researchers analyzed the structure of dried films made from a particular organic semiconductor often used in photovoltaic cells, PTCBI. At NSLS beamline U7A, the researchers used nearedge $\mathrm{x}$-ray absorption spectroscopy and grazing-incidence $x$-ray diffraction to determine the orientation and order of PTCBI as it was formed on different surfaces.

Typically, an organic semiconductor's crystals change size with the dielectric substrate it is deposited on. But, in this case, the researchers found that the PTCBI crystals are actually oriented differently on different dielectrics.
They then linked the orientation of the PTCBI crystals to performance: In general, substrates that allow the crystal's individual molecules to stand up straight - and therefore have a large amount of electronic overlap - exhibit the fastest transport. But substrates that force the molecules to lay down flat exhibit poorer performance.

P. Dhagat, H.M. Haverinen, R.J. Kline, Y. Jung, D.A. Fischer, D.M. DeLongchamp, G.E. Jabbour, "Influence of Dielectric Surface Chemistry on the Microstructure and Carrier Mobility of an n-Type Organic Semiconductor," $A d v$. Funct. Mater., 19, 2365 (2009).
Illustrations of PTCBI films with two different orientations. Researchers found that those laying down (left) exhibit slower transport than those that stand up (right).

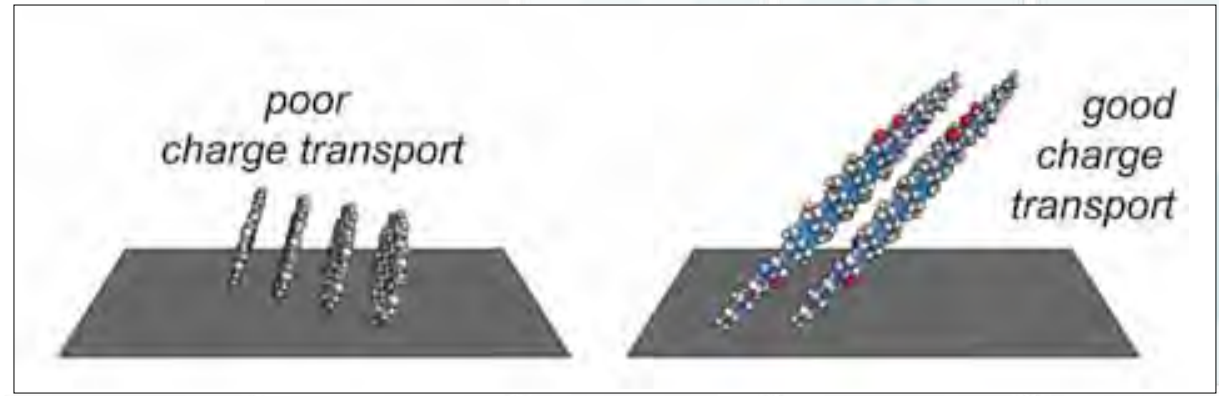

NIST researchers Dan Fischer (left) and Dean DeLongchamp

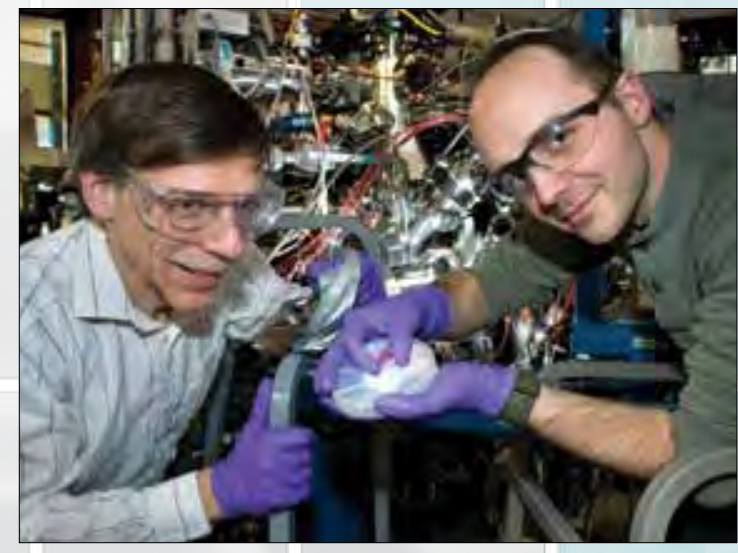


A team of international researchers is the first to uncover the chemical composition and structure of a microelectronics element that is vital to producing ever smaller - and, thus, cheaper and faster - devices.

In order to keep advancing the microelectronics field, major fabrication changes are needed. One of these changes involves the production of "diffusion barriers," which separate the copper metallic lines that connect the various components in an electronic device from the silicon-based insulating material. Silicon and copper are highly reactive and the mixture of the two will ultimately lead to circuit failure. However, current fabrication processes are unable to deliver diffusion barrier films that are conformal (have the same thickness across the entire interface) and thin enough - on the order of one nanometer - to support the next generation of electronic devices.

That's why researchers from Synchrotron SOLEIL in France, the NSLS, the National Institute of Standards and Technology (NIST), IMEC, and Intel, are studying one potential fabrication method that uses coppermanganese alloys. In these systems, the manganese atoms diffuse out of the alloy film upon annealing and form a thin and conformal barrier layer at the silicon interface before copper diffusion can begin.

At NSLS beamlines $X 27 \mathrm{~A}$ and $X 23 \mathrm{~A} 2$, the researchers used grazing incidence $x$-ray fluorescence spectroscopy to study these self-forming barrier layers. They grew the diffusion barrier on two different materials: thermal silicon dioxide $\left(\mathrm{SiO}_{2}\right)$ and one with a lower dielectric constant (k).

The researchers discovered that the diffusion layer is relatively easy to form on the low-k material but substantially more difficult to form on $\mathrm{SiO}_{2}$. These results are promising as low-k dielectrics, which have a lower capacitance - ability to hold charge - than $\mathrm{SiO}_{2}$, will eventually be used in future microelectronic technology, enabling faster and more efficient devices. This is because insulators with a smaller dielectric constant can charge faster, allowing electrical signals to propagate faster through the circuit.

J.M. Ablett, J.C. Woicik, Zs. Tökei, S List, E. Dimasi, "Phase Identification of Self-Forming Cu-Mn Based Diffusion Barriers on $\mathrm{p}-\mathrm{SiOC}: \mathrm{H}$ and $\mathrm{SiO}_{2} \mathrm{Di}-$ electrics Using $X$-Ray Absorption Fine Structure," Applied Physics Letters, 94, 042112 (2009)

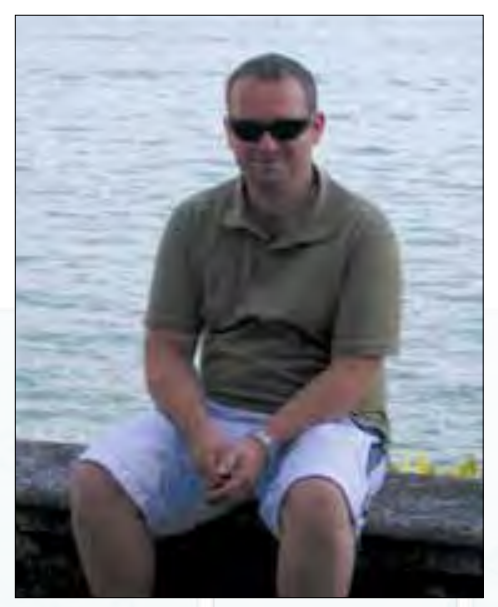

James Ablett
$14 \bigcirc 1$

science Highlights
Cross-sectional transmission electron microscopy image of a barrier layer on a low-k dielectric that was formed by annealing a Cu-Mn alloy for 1 hour at $420^{\circ} \mathrm{C}$.

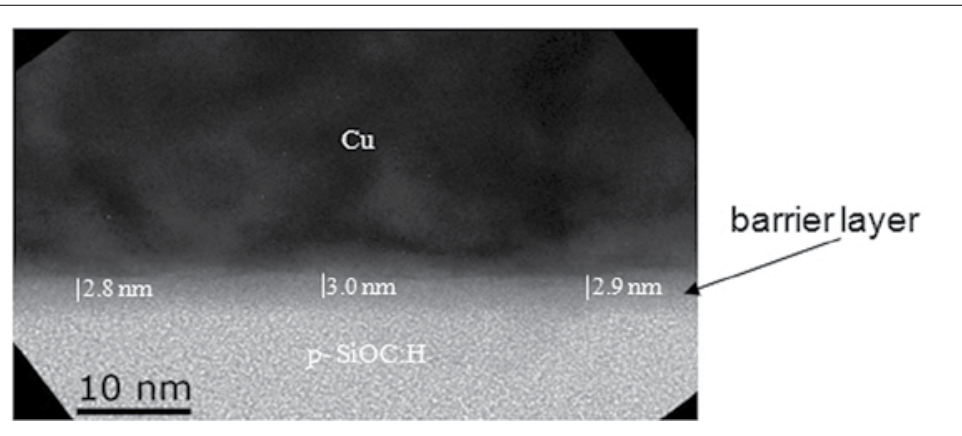




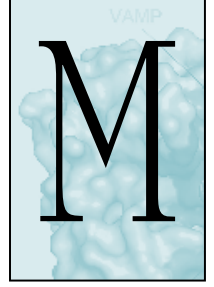

\section{Making Thin Films Stable through Phase-Changing}

In an effort to produce ever-smaller electronics, a team of researchers has used the NSLS to show that slightly changing the way a material is formed can drastically alter its properties. Their findings could help modify the characteristics of silicides, an important class of thin films - layers of material on the order of a millionth of a meter thick - that are crucial to creating the electrical circuits that make devices like handheld computers, cell phones, and digital music players work.

The researchers, from the IBM T.J. Watson Research Center in Yorktown, NY, and Ghent University, in Belgium, focused their study on a thin film of a nickel-silicon compound, called nickel monosilicide, one of the most promising materials for advanced integrated circuits. The problem is, when the layers of nickel monosilicide are on the order of just several nanometers thick, they become unstable.

Thin films of nickel monosilicide typically are produced by depositing a small amount of pure nickel (Ni) on a silicon (Si) substrate and then annealing it. Previous research has shown that the stability of nickel monosilicide can be improved by adding another element to the nickel film. But it wasn't obvious whether these add-ins have a direct or indirect effect on the material's properties.

To find out, the researchers added silicon to the nickel film. By not introducing any ternary elements, they deduced that any changes should be related to the reaction itself.

With use of in-situ x-ray diffraction at NSLS beamline $X 20 C$, the researchers found the formation of silicon-enhanced nickel silicide to be quite different. The film went through a different phase sequence before breaking apart at 800 degrees Celsius - about 150 degrees hotter than observed with the traditional system.

The final result is a nickel monosilicide layer that is much more stable due to the alignment of its crystalline grains in neat, parallel stacks.

C. Van Bockstael, K. De Keyser, R.L. Van Meirhaeghe, C. Detavernier, J.L. Jordan-Sweet, C. Lavoie, "Influence of a transient hexagonal phase on the microstructure and morphological stability of NiSi films," Applied Physics Letters, 94, 033504 (2009).

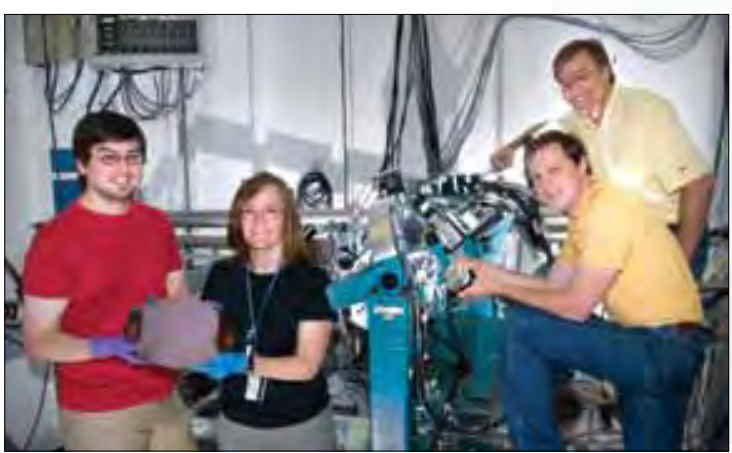

(above) From left, Koen De Keyser, Jean Jordan-Sweet, Christophe Detavernier, and Christian Lavoie

(right) Charlotte Van Bockstael

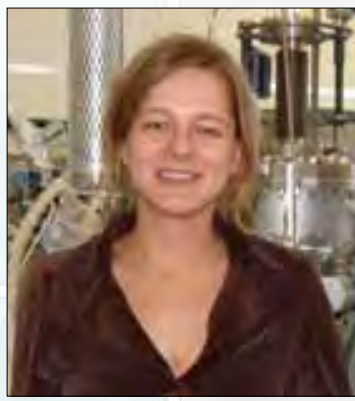

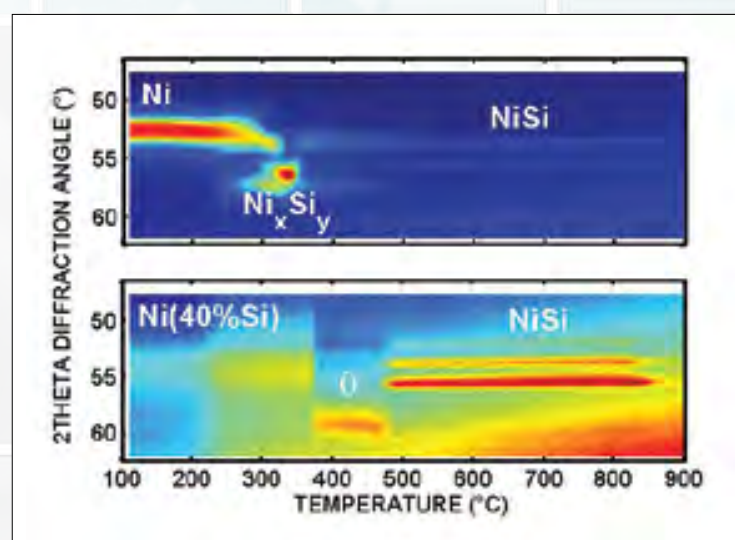

(above) In situ x-ray diffraction as a function of temperature, collected upon heating at a constant rate of (top) a conventional thin nickel film on a silicon substrate, and (bottom) a thin nickel film on a silicon substrate, when extra silicon is added into the nickel film. The measured diffraction angle data, which allows identification of the phases that appear upon annealing, is presented as a color map (red indicating the highest intensity). The addition of silicon strongly affects the conventional phase sequence prior to nickel monosilicide (NiSi) formation, inducing the formation of an unexpected phase at 380 degrees Celsius (labeled as $\theta$ ). 


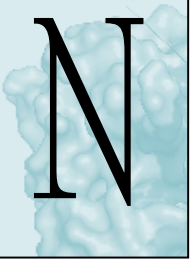

\section{New Catalyst Paves the Path for Ethanol-Powered Fuel Cells}

A team of scientists at Brookhaven National Laboratory, in collaboration with researchers from the University of Delaware and Yeshiva University, has developed a new catalyst that could make ethanol-powered fuel cells feasible. The highly efficient catalyst performs two crucial and previously unreachable steps needed to oxidize ethanol and produce clean energy in fuel cell reactions.

Like batteries that never die, hydrogen fuel cells convert hydrogen and oxygen into water and, as part of the process, produce electricity. However, efficient production, storage, and transport of hydrogen for fuel cell use is not easily achieved. As an alternative, researchers are studying the incorporation of hydrogen-rich compounds, for example, the use of liquid ethanol in a system called a direct ethanol fuel cell.

A major hurdle to the commercial use of direct ethanol fuel cells is the molecule's slow, inefficient oxidation, which breaks the compound into hydrogen ions and electrons that are needed to generate electricity. Specifically, scientists have been unable to find a catalyst capable of breaking the bonds between ethanol's carbon atoms.

But at Brookhaven, scientists have found a winner. Made of platinum and rhodium atoms on carbonsupported tin dioxide nanoparticles, the research team's electrocatalyst is capable of breaking carbon bonds at room temperature and efficiently oxidizing ethanol into carbon dioxide as the main reaction product.

Structural and electronic properties of the electrocatalyst were deter- mined using powerful x-ray absorption techniques at NSLS beamline $\mathrm{X} 18 \mathrm{~B}$, combined with data from transmission electron microscopy analyses at Brookhaven's Center for Functional Nanomaterials. Based on these studies and calculations, the researchers predict that the high activity of their ternary catalyst results from the synergy between all three constituents - platinum, rhodium, and tin dioxide - knowledge that could be applied to other alternative energy applications.

Z. Kowal, M. Li, M. Shao, K. Sasaki, M.B. Vukmirovic, J. Zhang, N.S. Marinkovic, P. Liu, A.I. Frenkel, R.R. Adzic, "Ternary $\mathrm{Pt} / \mathrm{Rh} / \mathrm{SnO}_{2}$ electrocatalysts for oxidizing ethanol to $\mathrm{CO}_{2}, "$ Nature Materials, 8, 325 (2009).

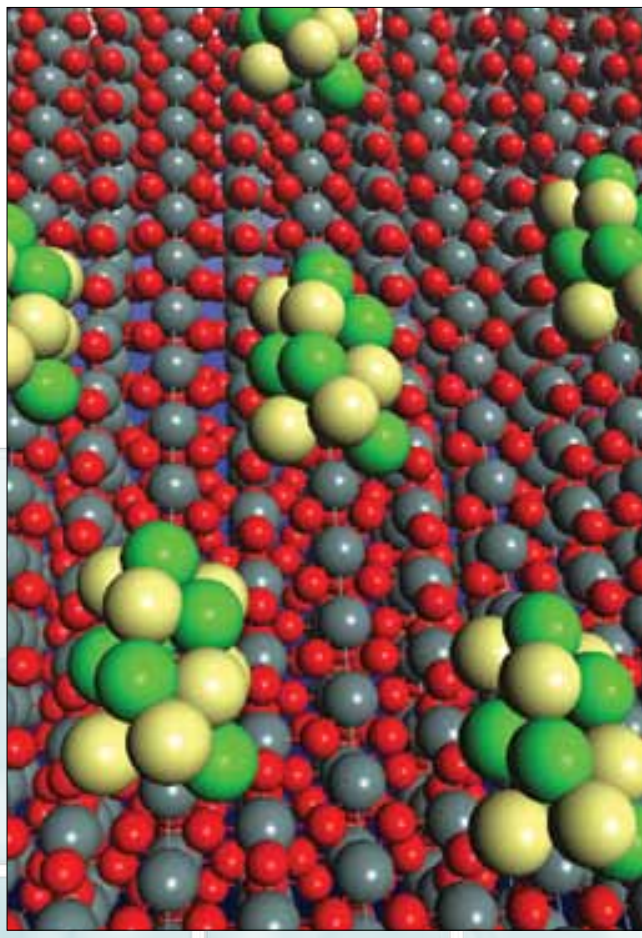

Model of a ternary electrocatalyst for ethanol oxidation consisting of platinum-rhodium clusters on a surface of tin dioxide. This catalyst can split the carbon-carbon bond and oxidize ethanol to carbon dioxide at the fuel cell anode. 


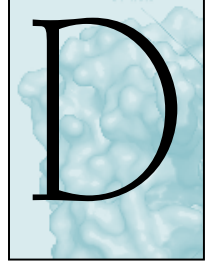

\section{Discovery of an Unexpected Boost for Solar Water-Splitting Cells}

A research team from Northeastern University and the National Institute of Standards and Technology (NIST) has discovered, serendipitously, that a residue of a process used to build arrays of titania nanotubes - a residue that wasn't even noticed before this - plays an important role in improving the performance of the nanotubes in solar cells that produce hydrogen gas from water.

Titania (or titanium dioxide) is a versatile chemical compound found in everything from paint to toothpastes. It also can function as a photocatalyst, producing hydrogen gas from water, electricity, and sunlight. In recent years, researchers have been exploring different ways to optimize the process and create a commercially viable technology that, essentially, transforms cheap sunlight into hydrogen, a pollution-free fuel that can be stored and shipped.

At Northeastern, researchers have been studying how best to incorporate carbon into the nanotubes, because carbon helps titania absorb light in the visible spectrum.

This brought them to the NIST $x$-ray spectroscopy beamline U7A at the

Scanning electron microscope image of typical titania nanotubes for a photocatalytic cell to produce hydrogen gas from water. Nanotubes average roughly 90-100 nanometers in diameter.
NSLS. While making measurements of the carbon atoms, the team noticed spectroscopic data that indicated that the titania nanotubes had small amounts of potassium ions strongly bound to the surface, evidently left by the fabrication process that used potassium salts. This was the first time the potassium has ever been observed on titania nanotubes because previous measurements were not sensitive enough to detect it.

The result was mildly interesting, but became much more so when the research team compared the performance of the potassiumbearing nanotubes to similar arrays deliberately prepared without potassium. The former required only about one-third the electri- cal energy to produce the same amount of hydrogen as an equivalent array of potassium-free nanotubes.

The findings suggest that potassium probably has played an unrecognized role in many experimental water-splitting cells that use titania nanotubes, because potassium hydroxide is commonly used in the cells. By controlling it, hydrogen solar cell designers could use it to optimize performance.

— Michael Baum, NIST

C. Richter, C. Jaye, E. Panaitescu, D.A. Fischer, L.H. Lewis, R.J. Willey, L. Menon, "Effect of Potassium Adsorption on the Photochemical Properties of Titania Nanotube Arrays," J. Mater. Chem., 19, 2963 (2009).

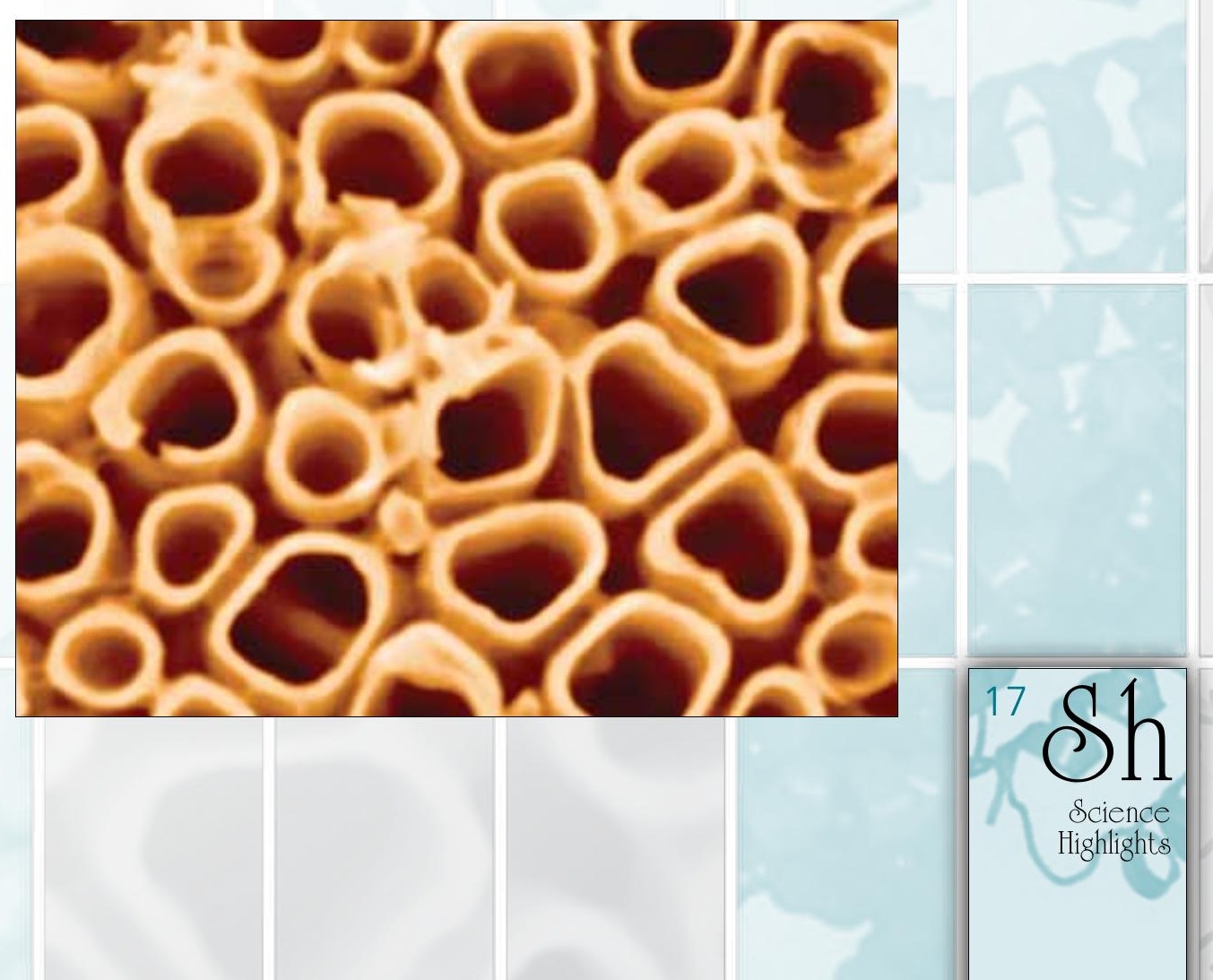




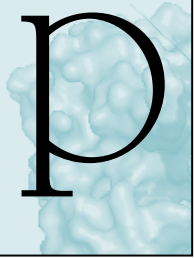

\section{Pressure-Free Preparation for Metal Oxides}

A team of researchers has demonstrated a cheaper and quicker method for preparing a class of metal oxides - materials widely used in applications ranging from hard drives to cell phones with very unusual properties. Without using time-honored high-pressure techniques, the researchers, from the University of South Carolina and Kookmin University, in Korea, produced the mostoxidized iridium oxides to date.

Although it's still the way to go for producing materials with specific structures or high-value products like diamonds, high-pressure techniques can be time-consuming and expensive. And because high-pressure techniques revolve around compression, they're usually not capable of making large quantities of material.

As an alternative, researchers grow crystals - highly ordered atomic structures - of materials from high-temperature solvents. This process can be achieved at ambient pressure with little cost and big results. In this field, the South Carolina group has become known for pushing the production boundaries of complex oxides through the use of one particular group of solvents: molten hydroxides.

In this particular study, the researchers focused on iridium oxides, which normally contain iridium in its most common oxidation state, +IV. Nothing higher than $+V$ has ever been produced at ambient pressure.

First, the group melted potassium hydroxide by heating it to 500 degrees Celsius. In the molten hydroxide, the iridium metal dissolves, reacts, and forms highly oxidized species that assemble into single crystals of two different iridium oxides. In both complexes, iridium is present in the highest oxidation state ever produced, +VI.
After producing these new iridium oxide crystals, the group brought them to the NSLS to confirm their high oxidation states via x-ray absorption spectroscopy (XANES) at beamline X19A.

These particular oxides have very few practical applications, but this research shows the potential to enable the targeted synthesis of other novel oxides containing transition metals in unusually high oxidation states.

S.J. Mugavero III, M.D. Smith, W.-S. Yoon, H.-C. zur Loye, " $\mathrm{Nd}_{2} \mathrm{~K}_{2} \mathrm{IO}_{7}$ and $\mathrm{Sm}_{2} \mathrm{~K}_{2} \mathrm{IrO}_{7}$ : Iridium(VI) Oxides Prepared under Ambient Pressure," Angewandte Chemie, International Edition, 48, 215 (2009).

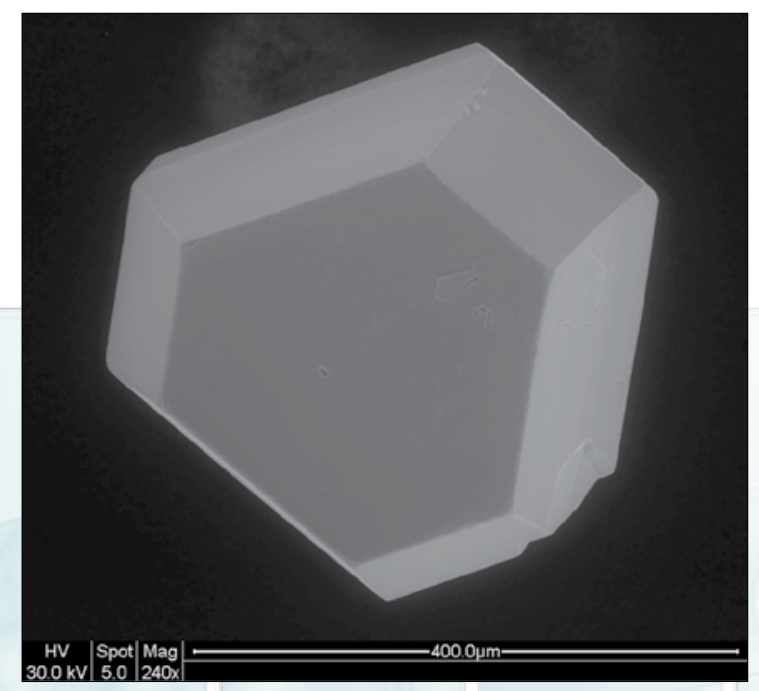

Scanning electron micrograph of a single crystal of $\mathrm{Nd}_{2} \mathrm{~K}_{2} \mathrm{IO}_{7}$.
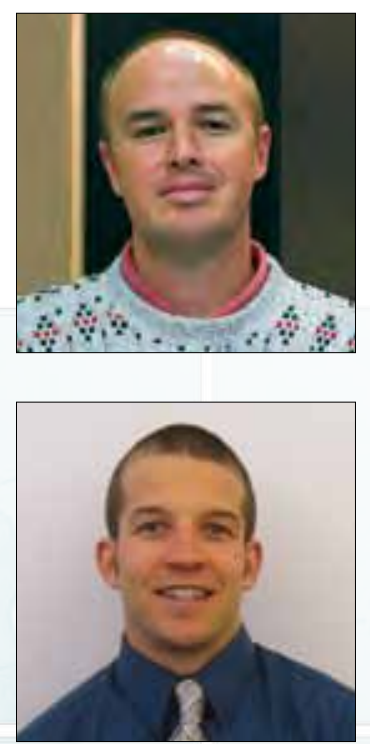

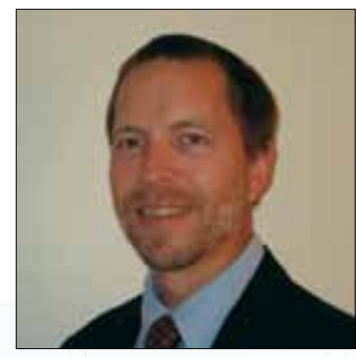

Mark Smith (above left), Hanno zur Loye (above right), and Samuel Mugavero (left)
$18 \bigcirc 1$

Science Highlights 


\section{A Kinoform's Best Friend: Diamond Refractive Lenses for Nanofocusing}

A team of Brookhaven and Argonne National Laboratory researchers has demonstrated a reliable path for sculpting an intricate $x$-ray focusing lens out of diamond. Their technique could prove extremely valuable in the study of nanomaterials at future synchrotron light sources.

Kinoform lenses, a type of refractive lens similar to those found in lighthouses, are being considered by researchers for their ability to efficiently focus $x$-ray light down to very small spots. This feature is vital to the study of molecules, atoms, and advanced materials at the nanoscale. Typically, kinoforms are made from silicon, a material that is easy to shape, but not ideal for handling the intensified photon beams at upcoming synchrotrons like NSLS-II.

Because of its very high thermal conductivity and transparency to $\mathrm{x}$-rays, diamond is an ideal candidate for the job. The problem is its extreme hardness, which makes it very difficult to etch the kinoform's saw-tooth shape.

In order to transfer the kinoform pattern from a numerically generated plate, researchers chemically remove the layers of the material that aren't "masked," or made resistant to the etching process. Through a pulsed, cyclic method with oxygen-argon plasma, the researchers found a way to etch a clean kinoform pattern deep into the diamond at Brookhaven's Center for Functional Nanomaterials.

The lenses were tested on an x-ray beamline at Argonne's Advanced Photon Source. Among other measurements, the team found that the spot size produced by a single diamond lens is about one micrometer, still a ways off from the onenanometer benchmark desired for future synchrotron studies. But multiple kinoforms can be stacked one after another to form a compound kinoform lens, which produces a much smaller spot.

In addition, compared to compound kinoform lenses made from silicon, the compound diamond lenses showed better light transmission and will work in a broader energy range.

A.F. Isakovic, A. Stein, J.B. Warren, S. Narayanan, M. Sprung, A.R. Sandy, K. Evans-Lutterodt, "Diamond Kinoform Hard X-ray Refractive Lenses: Design, Nanofabrication and Testing," J. Synch. Rad., 16, 8 (2009).

The structure of a kinoform lens: (a) single, $11.2 \mathrm{keV}$ kinoform refractive lens made from optical quality artificial diamond using e-beam lithography, metallization, and deep reactive ion etching; (b) a detail (a central portion) of such a lens shown from the tilted perspective of an incoming $x$-ray beam.

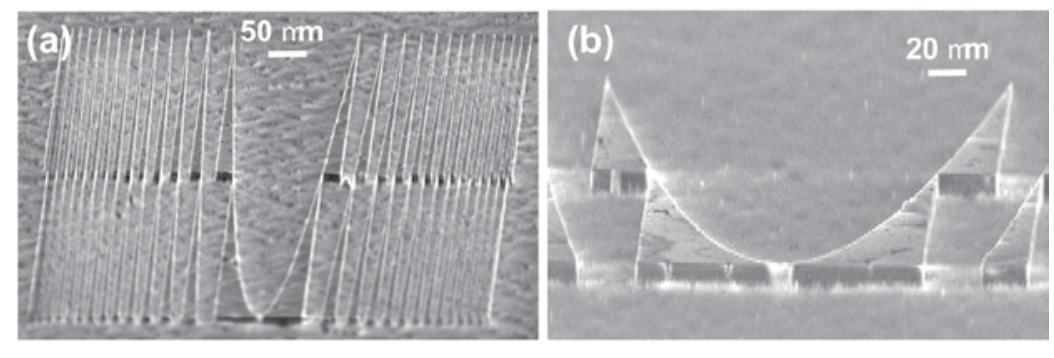

From left, Abdel Isakovic, Kenneth Evans-Lutterodt, John Warren, and Aaron Stein

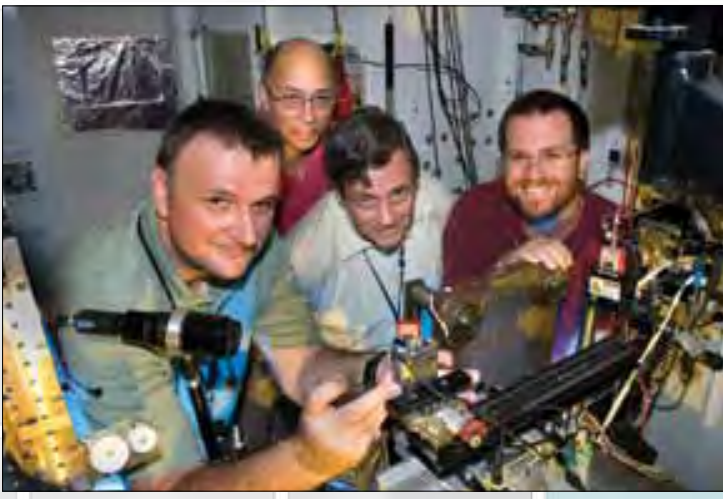




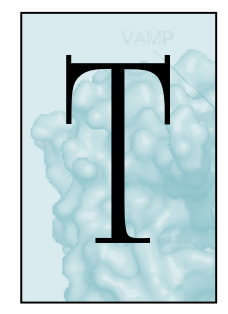

\section{Tapering a Free-Electron Laser to Extract More Juice}

Researchers from the NSLS and Science Applications International Corporation (SAIC) have demonstrated a technique that could be used to significantly improve the quantity and quality of light produced from a free-electron laser (FEL) - a source that provides pulses of light that can be 1,000 times shorter than those at conventional storage ring light sources.

In order to understand how molecules change their structure in chemical and biological systems, scientists need extremely short pulses of light (less than one trillionth of a second) with short wavelengths. This is where FELs shine. Like a stroboscopic flash, the ultra-short bursts of light produced from an FEL allows scientists to take time-resolved images of biological and chemical processes and various other atomic-scale events.

FELs work by shooting a series of ultra-short bunches of electrons through an array of magnets called an undulator, which forces them to oscillate back and forth as though they're zigzagging through a tight slalom course. This oscillatory motion causes the electrons to emit an intense beam of photons (i.e. light) that travels in the same direction as the electron beam. The prolonged interaction between the emitted light and the electron beam along the length of undulator produces ultra-short light pulses of unprecedented brightness.

During a recent novel experiment at the NSLS Source Development Laboratory, the researchers tapered the undulator - slowly increasing the vertical gap in the last few meters of the device. This reduces the magnetic field, which results in an enhanced conversion efficiency of electron energy to FEL light.
In comparison with the results for a uniform undulator, the tapered undulator produced a far-improved FEL beam: the light intensity was increased by 300 percent for the fundamental wavelength and 50 percent for the third harmonic (which has a wavelength that is three times shorter than the fundamental).

This is the first experiment to measure these characteristics in a tapered undulator.

X.J. Wang, H.P. Freund, D. Harder, W.H. Miner, Jr., J.B. Murphy, H. Qian, Y. Shen, X. Yang, "Efficiency and Spectrum Enhancement in a Tapered Free-Electron Laser Amplifier," Phys. Rev. Lett., 103, 154801 (2009).

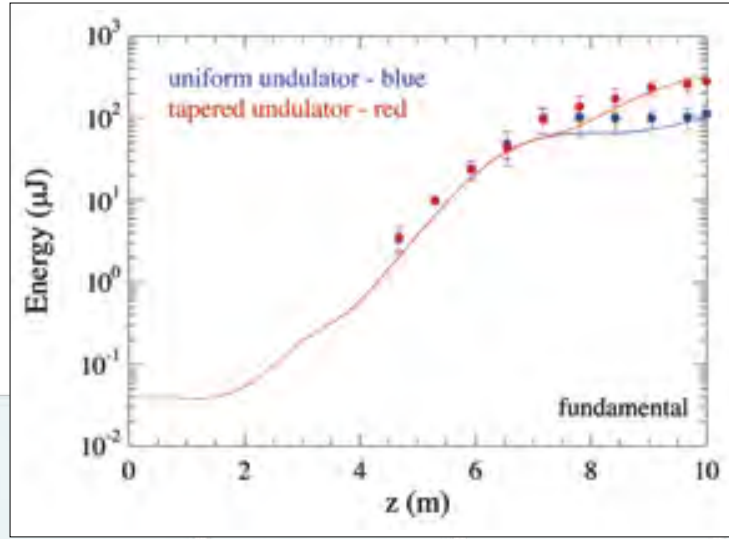

Comparison between the experiment and simulation for the light at the fundamental wavelength for both uniform and tapered undulators.

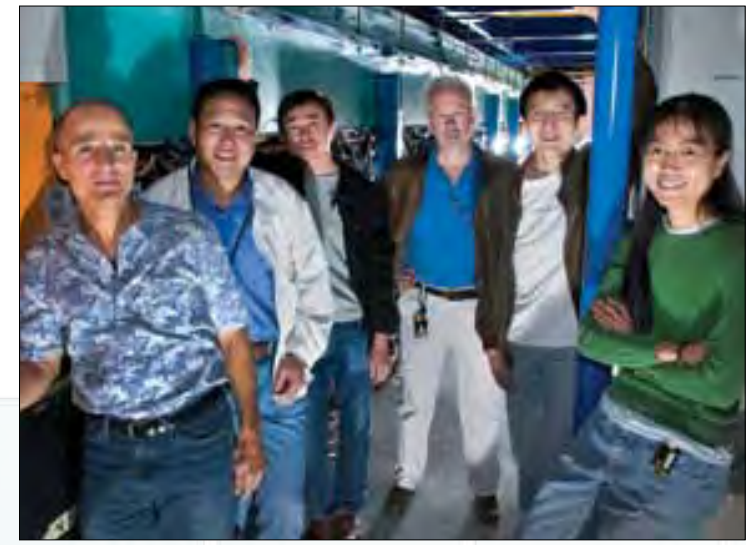

From left, Dave Harder, Xijie Wang, Yuzhen Shen, Jim Murphy, Houjun Qian, and Xi Yang
20 ? 1

science Highlights 
genic bacteria that cause tuberculosis can survive in a human host (Gallagher, et al.), a process that can be blocked by a newly discovered class of inhibitors (Lin, et al.). Several studies revealed a deeper understanding of Alzheimer's disease pathology, including an x-ray fluorescence microscopy study by Leskovjan, et al. that implicated metal ions in the death of brain cells, and a study by Connor, et al. that identified diffraction-enhanced imaging as a possible tool for early diagnosis of the disease. Zinc transport across membranes, which has also been implicated in brainrelated diseases, was another topic highlighted in 2009. For example, the crystal structure of the Yiip Zn transporter provided a proposed mechanism behind the autoregulation of $\mathrm{Zn}$ in cells (Lu, et al.). Moreover, the structure of a Zn-bound domain of the NMDA receptor done by Karakas, et al. showed that $\mathrm{Zn}$ docks to a "clamshell cleft" within the molecule - a site that can now be targeted for the development of inhibitors for the prevention of brain cell death.

In the fields of soft condensed matter and biophysics, a few creative uses of DNA were highlighted in 2009. Published in Nature, a team of researchers led by Ned Seeman at New York University created the world's first 3-D DNA crystals. The importance of this development lies in the ability to organize biological merge - than at mid-ocean ridges, where the plates spread apart

(Kelley and Cottrell). Using $x$-ray absorption spectroscopy with a microscopic $x$-ray beam, the researchers found that the oxidation state of iron in magma increases with the amount of water in the sample, which comes from the subduction zone. This work shows that the oxidized environment

macromolecules by attaching them to these crystals, which can help to crystallize macromolecules that otherwise would not crystallize (Zheng, et al.). In another highlight, DNA was used to link up nanoparticles in various arrangements, including 3-D nano-crystals. The idea is that nanoparticles coated with complementary strands of DNA help the particles find and stick to one another in highly specific ways. Because of its reliability and precision control, this nano-assembly method is high-throughput production that is needed for commercial applications (Maye, et al.).

It was also another productive year for NSLS researchers working in the fields of earth, environmental, and geosciences. Published in Science, researchers from the University of Rhode Island and the Smithsonian Institute helped explain why the Earth's mantle is more oxidized at subduction zones - areas of the ocean floor where tectonic plates also is transferred from the subducting plate to the mantle below.

In another study published in PNAS, Ginder-Vogel, et al. used a technique developed at the NSLS called quick- $x$-ray absorption spectroscopy (Quick-XAS) to study the oxidation rate of arsenic by hydrous manganese oxide, which is a mineral that absorbs heavy metals and nutrients. Understanding these ultrafast reactions is important because the toxicity and availability of arsenic to living organisms depends on its oxidation state.

The following selection of highlights provides a great sampling of some of the outstanding science that was performed using the NSLS in 2009. However, they barely touch the surface of the more than 900 papers published by NSLS staff and users this year and I encourage you to visit the NSLS website for more details on additional publications.
${ }^{22} \mathrm{Sh}$

science Highlights 
A chemical reaction can occur in the blink of an eye. Thanks to a new analytical method employed by researchers at the University of Delaware (UD), scientists can now pinpoint, at the millisecond level, what happens as harmful environmental contaminants such as arsenic begin to react with soil and water under various conditions.

Quantifying the initial rates of such reactions is essential for modeling how contaminants are transported in the environment and predicting risks.

The research method, which uses an analytical technique known as quick-scanning $\mathrm{x}$-ray absorption spectroscopy (Q-XAS), was developed using beamline $\mathrm{X} 18 \mathrm{~B}$ at the NSLS.

In this particular study, the UD researchers made millisecond measurements of the oxidation rate of arsenic by hydrous manganese ox- ide, which is a mineral that absorbs heavy metals and nutrients. Contamination of drinking water supplies by arsenic is a serious health concern in the United States and abroad. The poisonous element occurs naturally in rocks and minerals and is also used in a wide range of products, from wood preservatives and insecticides, to poultry feed.

The toxicity and availability of arsenic to living organisms depends on its oxidation state - in other words, the number of electrons lost or gained by an atom when it reacts with minerals and microbes. For example, arsenite $[\mathrm{As}(\mathrm{III})]$ is more mobile and toxic than its oxidized counterpart, arsenate $[\mathrm{As}(\mathrm{V})]$.

Q-XAS can be looked at as a very early tool that can be incorporated into predictive modeling for the environment.

\section{- Tracey Bryant, University of} Delaware

M. Ginder-Vogel, G. Landrot, J.S. Fischel, D.L. Sparks, "Quantification of Rapid Environmental Redox Processes with Quick-Scanning X-ray Absorption Spectroscopy (Q-XAS)," PNAS, 106(38), 16124 (2009).
Experimental setup used to collect Q-XAS data

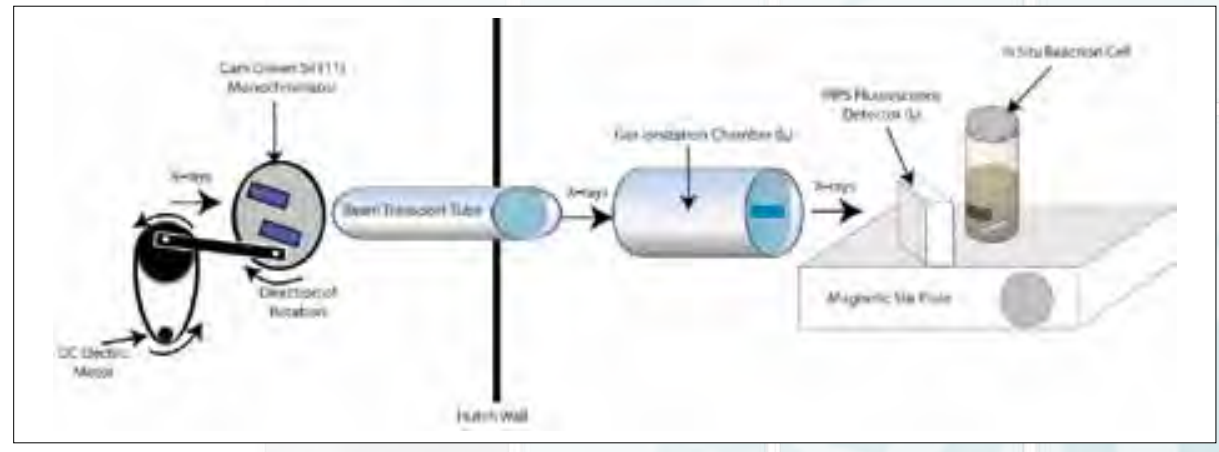

Matthew Ginder-Vogel, left, and Donald Sparks, S. Hallock du Pont Chair of Plant and Soil Sciences and director of the Delaware Environmental Institute at UD (Photo by Kathy F. Atkinson)

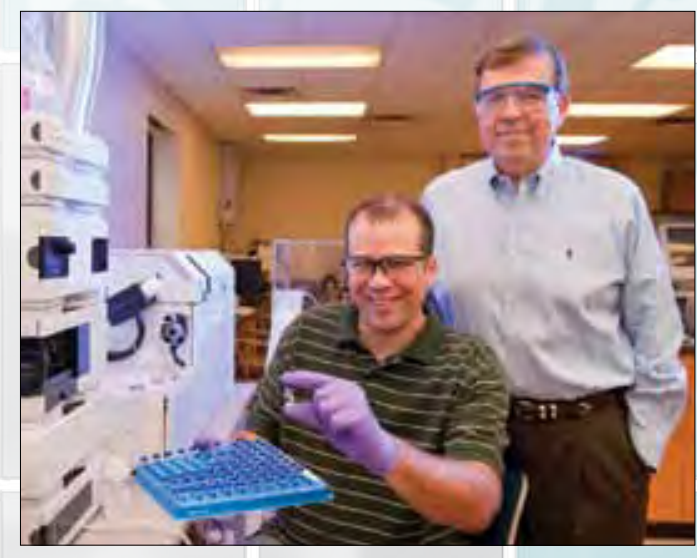




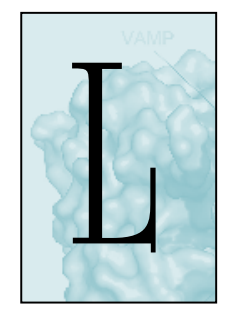

Linking Lava and "Rust" to the Earth's Evolution

By examining microscopic crystals that once lived deep in the Earth, a team of scientists is chipping away at the details of the planet's evolution. Conducted by University of Rhode Island researcher Katherine Kelley and Smithsonian Institution geologist Elizabeth Cottrell, this research helps explain why the Earth's mantle is more oxidized at subduction zones - areas of the ocean floor where tectonic plates merge — than at mid-ocean ridges, where the plates spread apart.

Similar to the metal on a bicycle or a car, iron in the oceanic tectonic plate also can "rust" (oxidize) when it comes into contact with the oxygen in seawater. As this plate moves across the mid-ocean ridge toward the subduction zone over millions of years, the rust builds and builds before slowly being transported into the Earth.

Researchers assume that this process adds oxygen to the mantle buried deep below the surface.
Proof can be found in tiny crystals preserved in magmas, like a prehistoric mosquito frozen in a piece of amber. Inside these crystals is glass with dissolved gases from volcanic eruptions. At the NSLS, Cottrell and Kelley used micro x-ray absorption near-edge structure spectroscopy to determine the oxidation states of iron in a variety of glass samples from different tectonic areas.

The researchers found that the oxidation state of iron in magma in- creases with the amount of water in the sample, which comes from the subduction zone. This work takes that concept a step further, showing that the oxidized environment also is transferred from the subducting plate to the mantle below.

K. Kelley and E. Cottrell, "Water and the Oxidation State of Subduction Zone Magmas," Science, 325, 605 (2009).

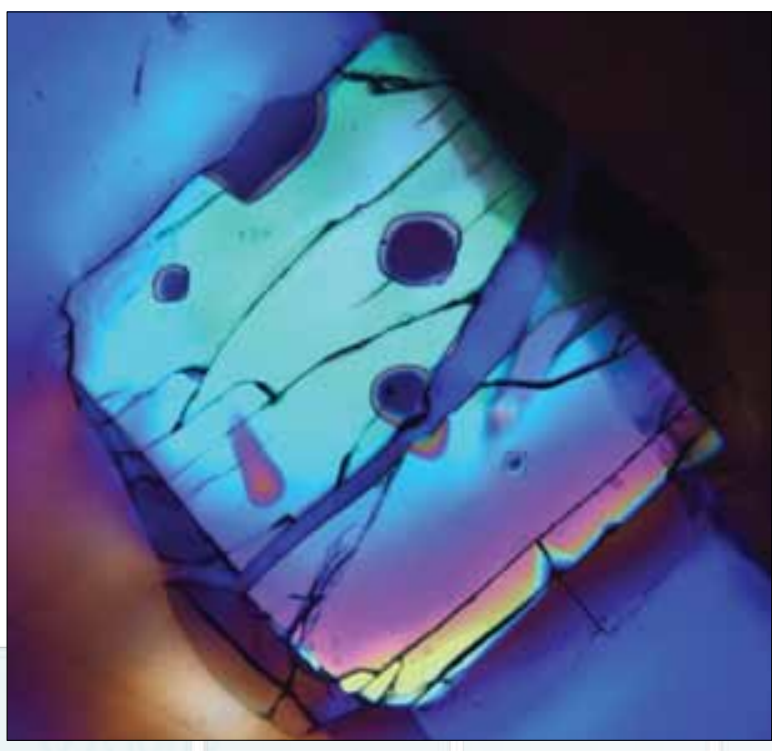

Olivine crystal with glassy melt inclusions from the East Pacific Rise embedded in volcanic glass. Photograph taken in cross-polarized light with a gypsum plate. Field of view is approximately $2 \mathrm{~mm}$.

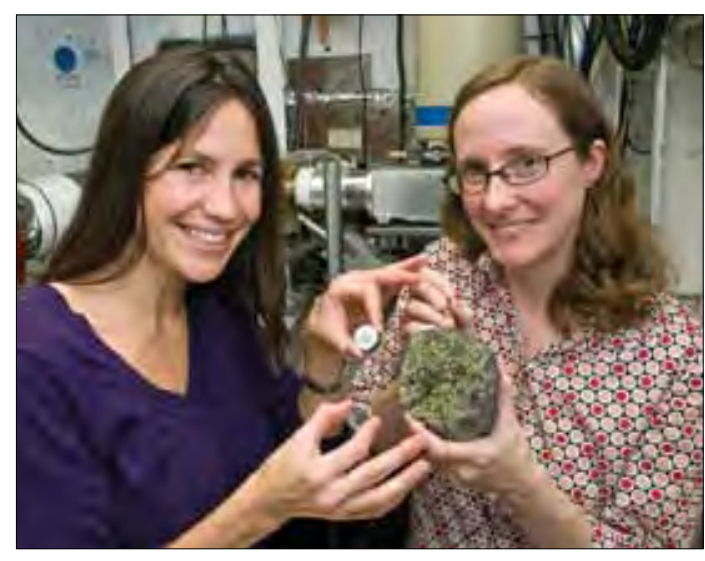

Elizabeth Cottrell (left) and Katherine Kelley
$24 \bigcirc 1$

Science Highlights 


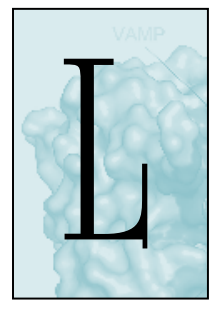

\section{Long-Sought Protein Structure May Help Reveal How 'Gene Switch' Works}

The bacterium behind one of mankind's deadliest scourges, tuberculosis, is helping researchers at the Commerce Department's National Institute of Standards and Technology (NIST) and Brookhaven National Laboratory move closer to answering the decades-old question of what controls the switching on and off of genes that carry out all of life's functions.

The researchers defined - for the first time - the structure of a "metabolic switch" found inside most types of bacteria - the cyclic AMP (CAMP) receptor protein, or CRP - in its "off" state. CRP is the "binding site" (attachment point) for CAMP, a small molecule that, once attached, serves as the signal to throw the switch. This "on" state of CRP then turns on the genes that help a microbe survive in a human host.

Using CRP from the bacterium Escherichia coli, researchers have been able to crystallize the protein in its active ("on") state and examine the structure using a technique called x-ray diffraction. However, the structure of the inactive ("off") E. coli CRP eluded them as attempts to crystallize it repeatedly failed for nearly three decades.

The breakthrough was achieved when the researchers substituted the CRP from Mycobacterium tuberculosis (the pathogen that causes tuberculosis) for the $E$. coli protein. Through x-ray diffraction at NSLS beamline $\times 29$, they discovered that although the $M$. tuberculosis protein in the "off" state consists of two sub- units that are genetically identical, the subunits were not structurally symmetrical as well.

It is believed that the asymmetry in the absence of cAMP prevents the protein from attaching to DNA. This, in turn, keeps CRP from activating genes when they are not needed.

— Michael E. Newman, NIST

D.T. Gallagher, N. Smith, S-K Kim, H. Robinson, P.T. Reddy, "Profound Asymmetry in the Structure of the CAMP-free CAMP Receptor Protein (CRP) from Mycobacterium tuberculosis," Journal of Biological Chemistry 284, 8228-8232 (2009).

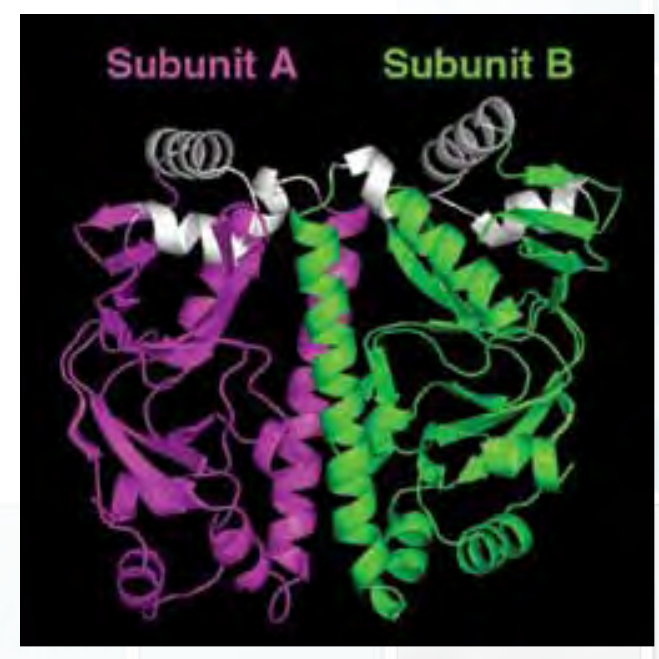

Computer model of the defined structure for the "off" state of the cyclic AMP receptor protein (CRP) found in Mycobacterium tuberculosis. The two subunits of the protein (colored purple on the left and green on the right) are genetically identical but, surprisingly were found to be asymmetric (different in shape) for the areas shown in white (top). This is the state of the CRP that is unable to activate genes necessary for the microbe's survival.

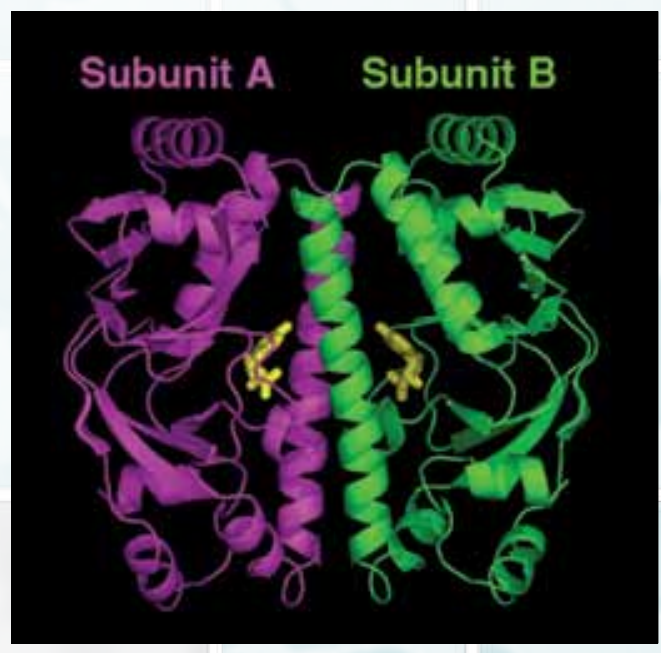

Computer model of the predicted structure for the "on" state of the cyclic AMP receptor protein (CRP) found in Mycobacterium tuberculosis. After binding cyclic AMP molecules (the yellow bodies in the center), the CRP is believed to change its structure so that the two subunits (colored purple on left and green on right) become symmetrical (identical in shape). It is this state of the CRP that binds a gene (DNA) and activates it to carry out functions necessary for the microbe's survival. 


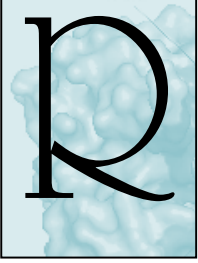

\section{Researchers Find New Protein Function}

A group of Dartmouth researchers has found a new function for one of the proteins involved with chromosome segregation during cell division. Their finding adds to the growing knowledge about the fundamental workings of cells, and contributes to understanding how cell function can go wrong, as it does with cancerous cells.

The researchers studied a protein called NOD, distantly related to the motor proteins called kinesin that power diverse cellular activities, including intracellular transport, signaling, and cell division. They used x-ray crystallography at NSLS beamline X6A to determine its structure, and then they used enzyme kinetics to find out how it performed. While this protein is found in fruit flies, the results are helpful in determining how related proteins work in humans.
The study provides evidence for a new way a kinesin motor could function. Previously, it had been shown that kinesin motors haul chromosomes, neurotransmitters, and other vital cargo by walking along tiny molecular tracks called microtubules. But the researchers discovered that rather than moving on its own, NOD hitches a ride on the ends of microtubules, which results in a dynamic crosslinking between the arms of chromosomes and the cell's growing spindle of microtubules.
If NOD doesn't function properly, then the two cells end up with either both or none of that particular chromosome, which is lethal to the cell and the organism in most cases.

\section{— Susan Knapp, Dartmouth University}

J. C. Cochran, C. V. Sindelar, N. K. Mulko, K. A. Collins, S. E. Kong, R. S. Hawley, F. J. Kull, "ATPase Cycle of the Nonmotile Kinesin NOD Allows Microtubule End Tracking and Drives Chromosome Movement," Cell, 136(1), 110-122 (2009).

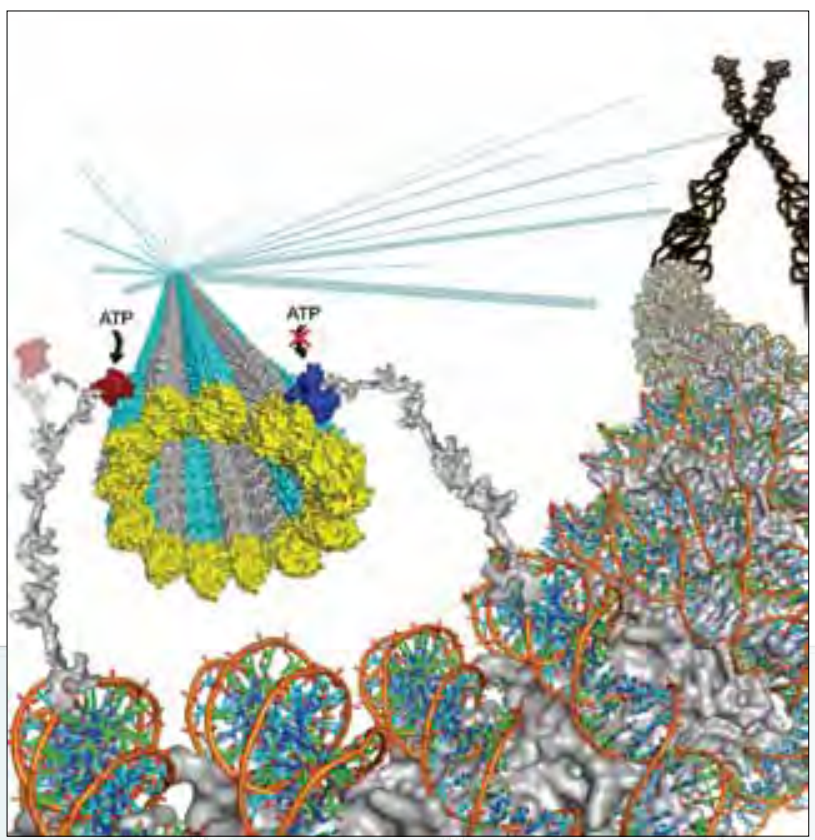

Protein NOD at the end of a microtubule

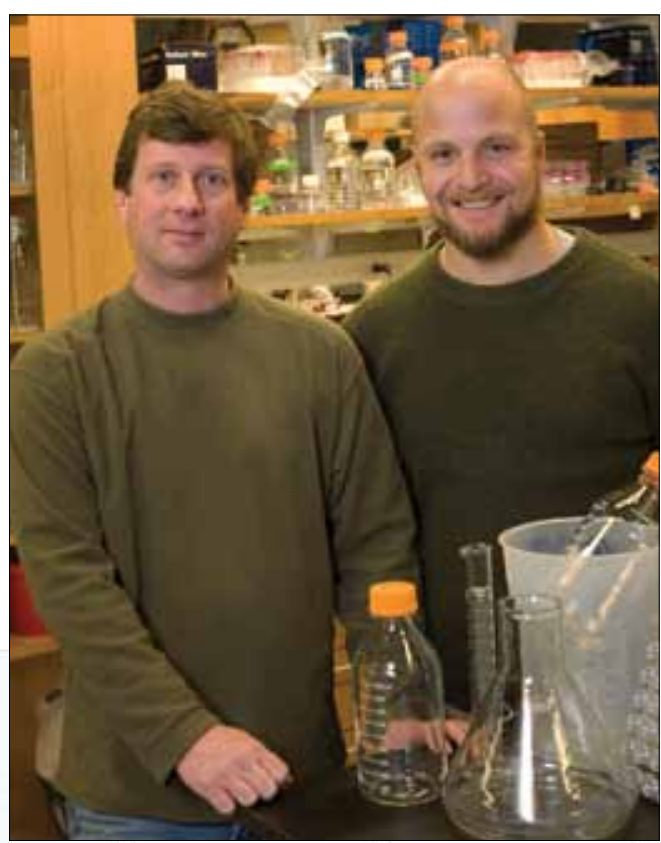

Jon Kull (left) and Jared Cochran (Photo courtesy of Joseph Mehling, Dartmouth) 
Scientists at Burnham Institute for Medical Research have determined the structure of the interactions between proteins that form the heart of the death inducing signaling complex (DISC), which is responsible for triggering apoptosis (programmed cell death).

The research highlights how protein-protein interactions between Fas receptor and Fas-associated death domain protein (FADD) mechanistically control DISC formation. The x-ray crystal structure of the Fas-FADD death domain complex, which was solved at NSLS beamline X29A, revealed a particular arrangement of four FADD death domains bound to four Fas death domains. The structure showed that Fas undergoes a conformational change, creating an open form of the protein that acts as a site for FADD binding and also participates in the as- sociation of other Fas molecules in the clustered complex. The researchers propose that Fas opening itself acts as a control switch for DISC formation and initiation of apoptosis.

Understanding the initiation of DISC is of great interest because if researchers can activate or inhibit cell death they can have a major impact on many diseases such as cancer.

This work sheds the first light on the detailed architecture of this elusive complex. The x-ray crystal structure now provides detailed information about the Fas-FADD complex at a resolution of 2.7 angstroms. Electron microscopy studies additionally revealed that incubation of Fas death domain with full-length FADD resulted in the formation of DISC-like structures that clustered together.

— Josh Baxt, Burnham Institute for Medical Research

F.L. Scott, B. Stec, C. Pop, M. Strokegorzata, K. Dobaczewska, J.J. Lee, E. Monosov, H. Robinson, G.S. Salvesen, R. Schwarzenbacher, S.J. Riedl, "The Fas-FADD Death Domain Complex Structure Unravels Signalling by Receptor Clustering," Nature, 457, 10191022 (2009).

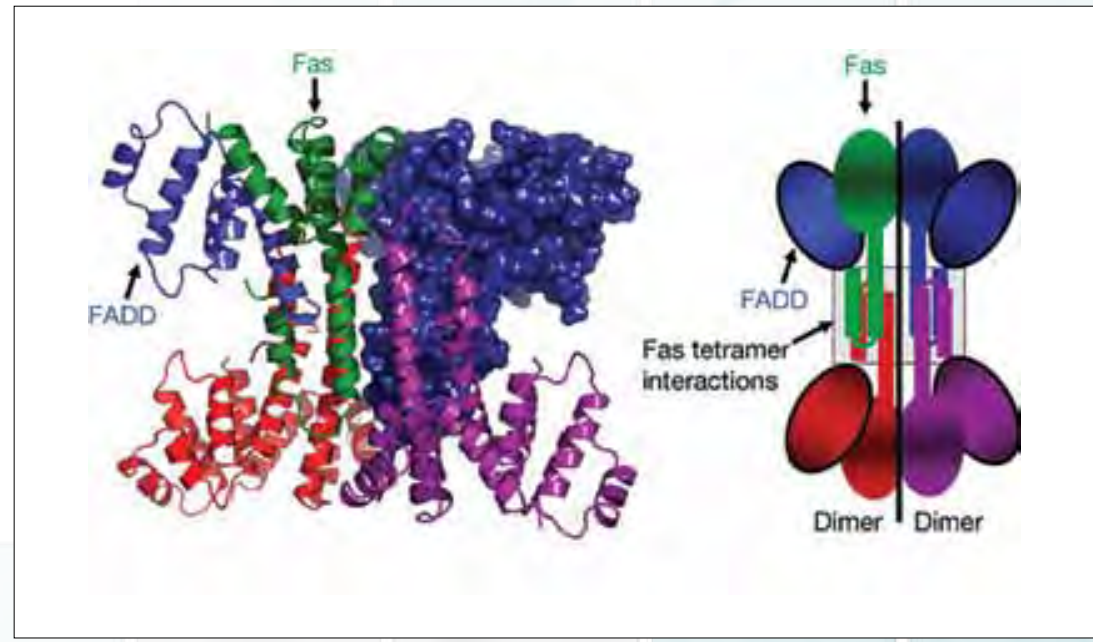

Overall structure of the Fas-FADD death domain complex. The structure (left panel) shows a tetrameric arrangement of Fas-FADD death domain complexes. Contacts between the complexes are solely mediated by Fas molecules. The right panel shows a cartoon representation of the Fas-FADD complex structure. One Fas-FADD death domain complex is displayed in green (Fas) and blue (FADD) ribbons, whereas the remaining three complexes are colored red, magenta and blue (surface representation). 


\section{X-Rays for Early Alzheimer's Disease Detection}

Researchers have demonstrated a new, highly detailed $x$-ray imaging technique that could be developed into a method for early diagnosis of Alzheimer's disease.

Alzheimer's disease is associated with plaques, areas of dense built-up proteins, in the affected brain. Many scientists believe that these plaques, called amyloid beta (Aß) plaques, actually cause the disease. But before anti-plaque drug therapies can be tested, researchers need a non-invasive, safe, and cost-effective way to track the plaques' number and size.

That is no easy task: $A ß$ plaques are extremely small, and conventional techniques such as computed tomography (CT) poorly distinguish between the plaques and other soft tissue such as cartilage or blood vessels.

A technique developed at Brookhaven, called diffractionenhanced imaging (DEI), might provide the extra imaging power researchers crave. DEl, which uses extremely bright beams of synchrotron x-rays, can visualize not only bone, but also soft tissue in a way that is not possible using standard x-rays.

In this study, researchers from Brookhaven and Stony Brook University used $\mathrm{DEI}$ in a high-resolution mode called micro-computed tomography to visualize individual plaques in a mouse-brain model of Alzheimer's disease. The resulting images are similar to those produced by high-resolution magnetic resonance imaging $(\mathrm{MRI})$, with the potential to even exceed MRI pictures in resolution. In addition, they prove that DEI can be used on whole brains to visualize a wide range of anatomical structures without the use of a contrast agent.

The radiation dose used for this study is too high to safely image individual $A B$ plaques in humans - the ultimate goal - but the results provide researchers with promising clues.

D.M. Connor, H. Benveniste, F. Avraham Dilmanian, M.F. Kritzer, L.M. Miller, Z. Zhong, "Computed Tomography of Amyloid Plaques in a Mouse Model of Alzheimer's Disease Using Diffraction Enhanced Imaging," Neurolmage, 46, (4), 908-914 (2009).

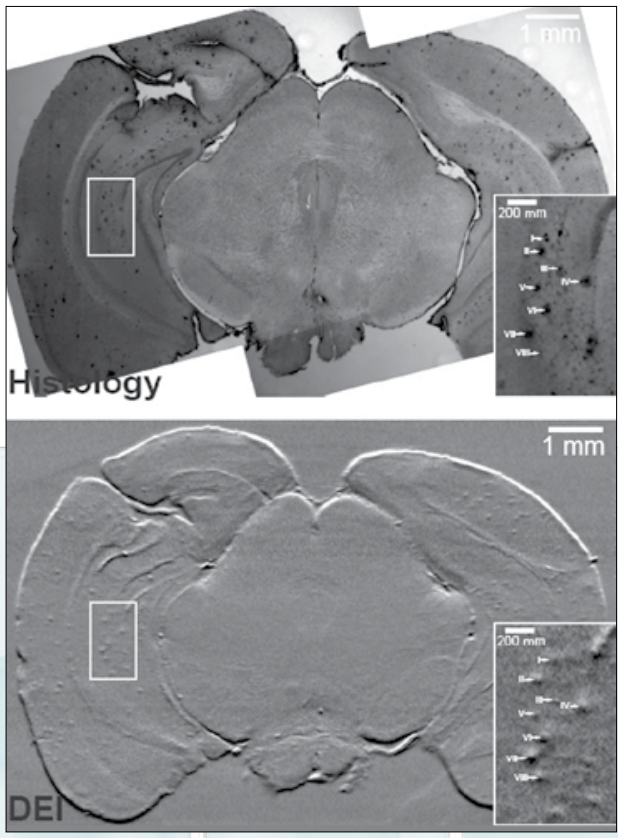

Images of the brain of a transgenic mouse obtained through histology and the corresponding brain region imaged with DEI in computed tomography mode. 


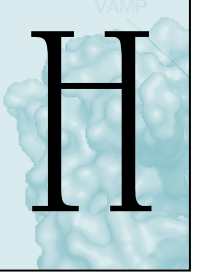

How Botulism Paralyzes Nerve Cells: New Details Revealed

New structures of a botulism toxin interacting with a mimic of the nerve-cell protein it destroys suggest new ways to block this often-fatal interaction.

Botulism toxins are among the deadliest known poisons. The toxins come in seven distinct varieties, but all work the same way: One portion of the toxin binds to a nerve-cell membrane; another portion moves a smaller "catalytic domain" into the cell; then this catalytic domain binds to and cleaves a nerve-cell protein, making it impossible for the nerve cell to "fire," or send signals. The result is paralysis — and often, death.

This study, conducted by scientists from Brookhaven and the U.S. Army Medical Research Institute for Infectious Diseases, looked specifically at how the catalytic domain of neurotoxin $F$ recognizes and binds to its target nerve-cell protein to perform this final, paralyzing step.

The team synthesized two different mimics of the target nerve-cell protein, allowed each to bind to the catalytic domain of the toxin, and

The catalytic domain of Clostridium botulinum neurotoxin type $\mathrm{F}$ (represented as a molecular surface, gray) bound to an inhibitor molecule (colored ribbon) designed to mimic the nerve-cell protein the toxin cleaves. The mimic protein interacts with the toxin at several exosites (purple-, brown-, and green-shaded areas) in addition to the active site (red) that performs the cleaving action, suggesting that blocking these interactions could thwart the toxin's deadly action. analyzed the structures using highintensity $\mathrm{x}$-rays at the NSLS.

The structures reveal that portions of the toxin that are distant from the "active site" that cleaves the nerve-cell protein, called exosites, are crucial to the toxin's ability to bind to and destroy this protein and could serve as additional targets for the development of drugs designed to interfere with the toxin's deadly action.
The scientists are also exploring the possibility that the inhibitor molecules they used in this study as mimics for the nerve-cell protein could themselves serve as anti-toxin drugs.

R. Agarwal, J.J Schmidt, R.G Stafford, S. Swaminathan, "Mode of VAMP Substrate Recognition and Inhibition of Clostridium botulinum Neurotoxin F," Nature Structural \& Molecular Biology, 16, 789 (2009).

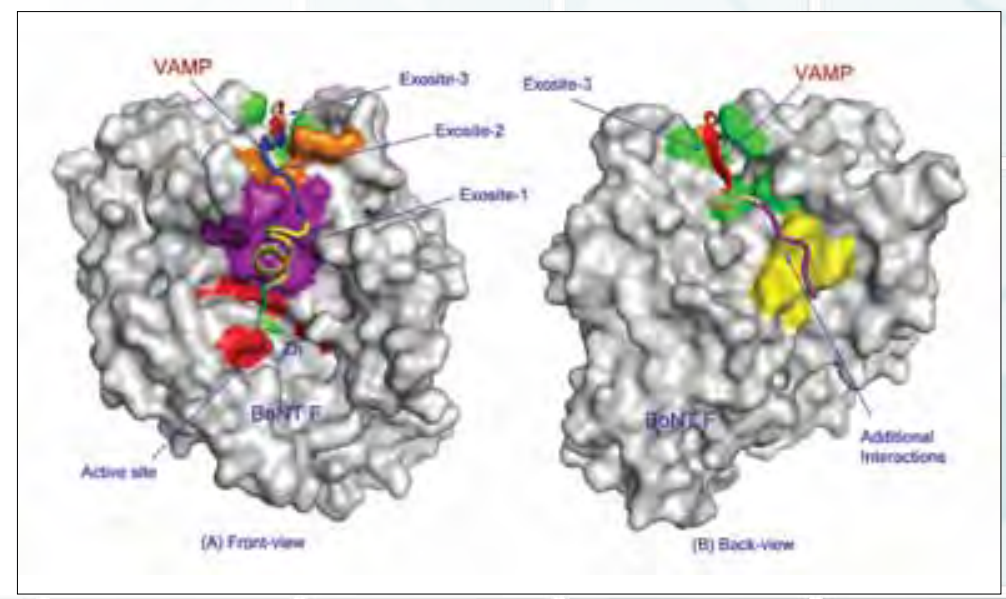

Brookhaven biologists Subramanyam Swaminathan (left) and Rakhi Agarwal

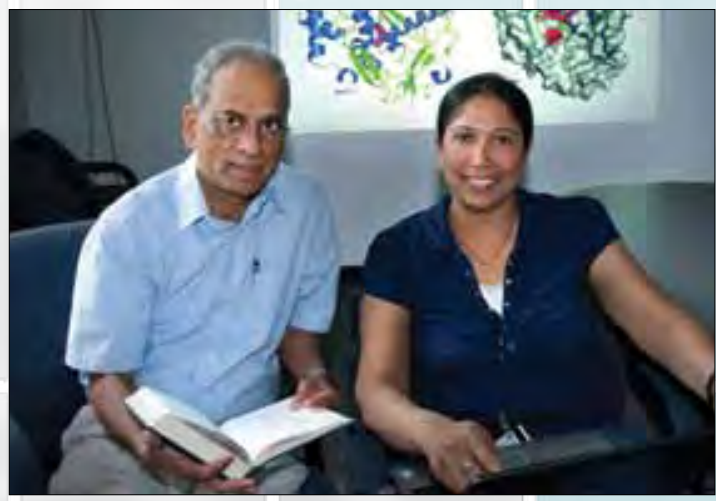




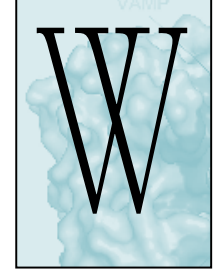

A ribosome is a large particle made of protein and RNA that manufactures the numerous proteins required for living cells. Rapidly growing cells produce thousands of new ribosomes in mere minutes through a series of complicated, and often misunderstood, steps.

In this study, the researchers took "snapshots" of the speedy interactions between ribosomal RNA from the bacteria $E$. coli and the 20 proteins that make up the smaller of the ribosome's two subunits.
First, they mixed together the $E$. coli RNA and proteins in a motorized syringe and then pushed the fluid stream through a flow cell at NSLS beamline X28C while performing a technique called $x$-ray footprinting. In this setup, the $x$-rays create a very reactive chemical that causes the RNA strand to break when it's exposed. However, the RNA is protected when it's tucked inside of the protein structure.

The researchers discovered that the different parts of the subunit start to assemble all at the same time, rather than wait for one part of the structure to finish before proceeding. In addition, they found that the "lock-andkey" model - a popular biological assembly mechanism that describes how one piece perfectly clicks into the other in just one step - is not followed in this process. Instead, in a process referred to as "induced fit," the proteins and RNA continuously adjust their structures, squishing like Play-Doh until they're in place.

T. Adilakshmi, D.L. Bellur, S.A. Woodson, "Concurrent Nucleation of 16S Folding and Induced Fit in 305 Ribosome Assembly," Nature, 455, 1268-1272 (2009).

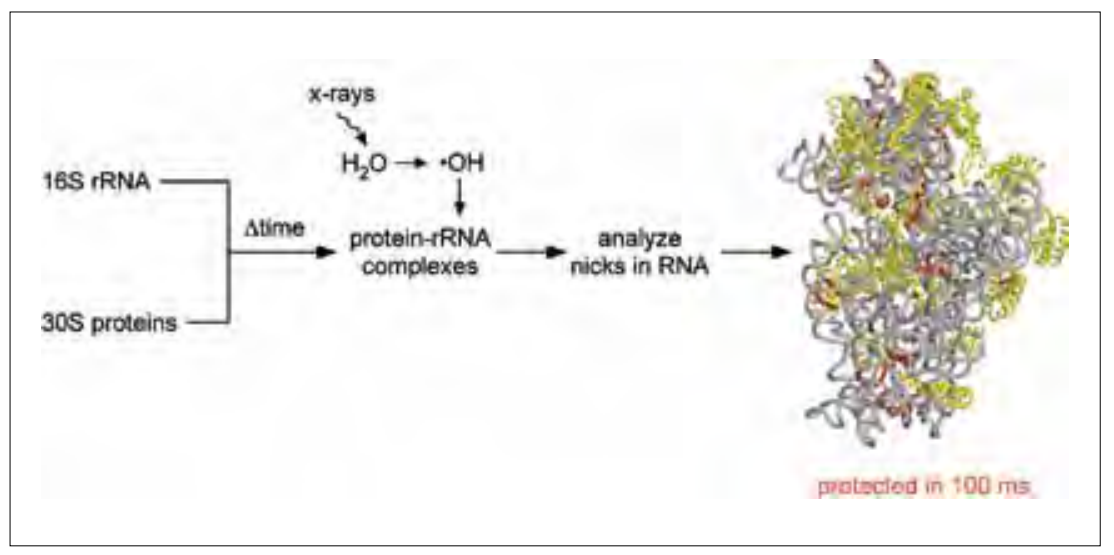

Sarah Woodson
X-ray footprinting of $30 \mathrm{~S}$ ribosome assembly. 16S rRNA was mixed with all 20305 proteins to begin assembly. Exposure to $x$-rays (X28C, NSLS) creates hydroxyl radical $(\bullet \mathrm{OH})$ that nicks the RNA. The absence of nicks at certain locations tells which parts of the rRNA were folded and covered by proteins. Structure of $E$. coli $30 \mathrm{~S}$ ribosome (pdb 2avy) with proteins in yellow and rRNA in gray. RNA regions protected in the first $100 \mathrm{~ms}$ are in red.
30 ค 1

Science Highlights

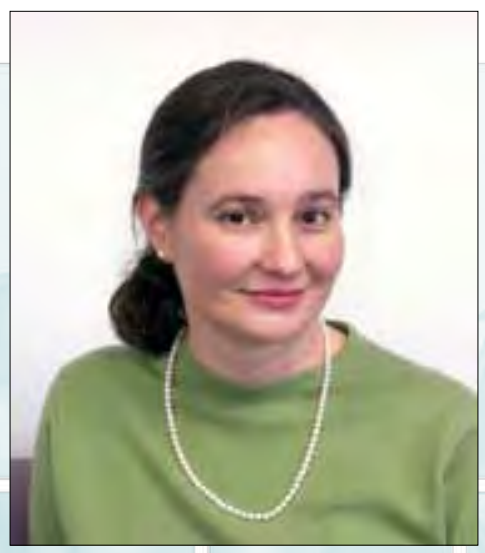


New, improved-resolution views of a zinc transporter protein deciphered at Brookhaven National Laboratory provide not just a structure but also a suggested mechanism for how cells sense and regulate zinc, an element that is essential for life, but which must be kept at a steady state to avoid problems like seizures, diabetes, and possibly Alzheimer's disease.

The structure was revealed using x-ray crystallography at the NSLS, where the researchers had previously solved a zinc transporter protein structure at lower resolution. To achieve the new structure, the scientists added mercury atoms to stabilize protein packing in the crystals. This increased the resolution by a mere angstrom (tenth of a nanometer). But because it brought the overall resolution of their structure to just below 3 angstroms - the point at which atoms begin to become visible it enabled the scientists to see the protein in action.
Using fluorescent probes, the scientists also studied how the protein changed shape in response to zinc binding. And they tested how changes to structural elements of the zinc transporter protein would affect its ability to transport zinc.

Together, these experiments suggest an auto-regulatory mechanism for zinc transport: Zinc binding within the cell triggers hinge-like movements of two electrically repulsive portions of the protein in the cell's interior, which results in a conformational change in the portion of the protein that traverses the cellular membrane. So when zinc levels inside the cell rise too high, this shape shifting pushes zinc ions through the membrane and out of the cell.

The new findings suggest targets for zinc-regulating drugs, and may even advance the understanding of similar zinc-regulating enzymes in plant chloroplasts with possible implications for biofuel production.

M. Lu, J. Chai, D. Fu, "Structural Basis for Autoregulation of the Zinc Transporter YiiP," Nature Structural \& Molecular Biology, 16, 1063 (2009).
Upper panels: Atomic details of zinc binding to the zinc transporter protein, known as YiiP. Lower panel: A cartoon illustrating how zinc binding may change the protein shape to regulate the coordination geometry of the active site for zinc transport (shown as a tetrahedron in upper right panel).

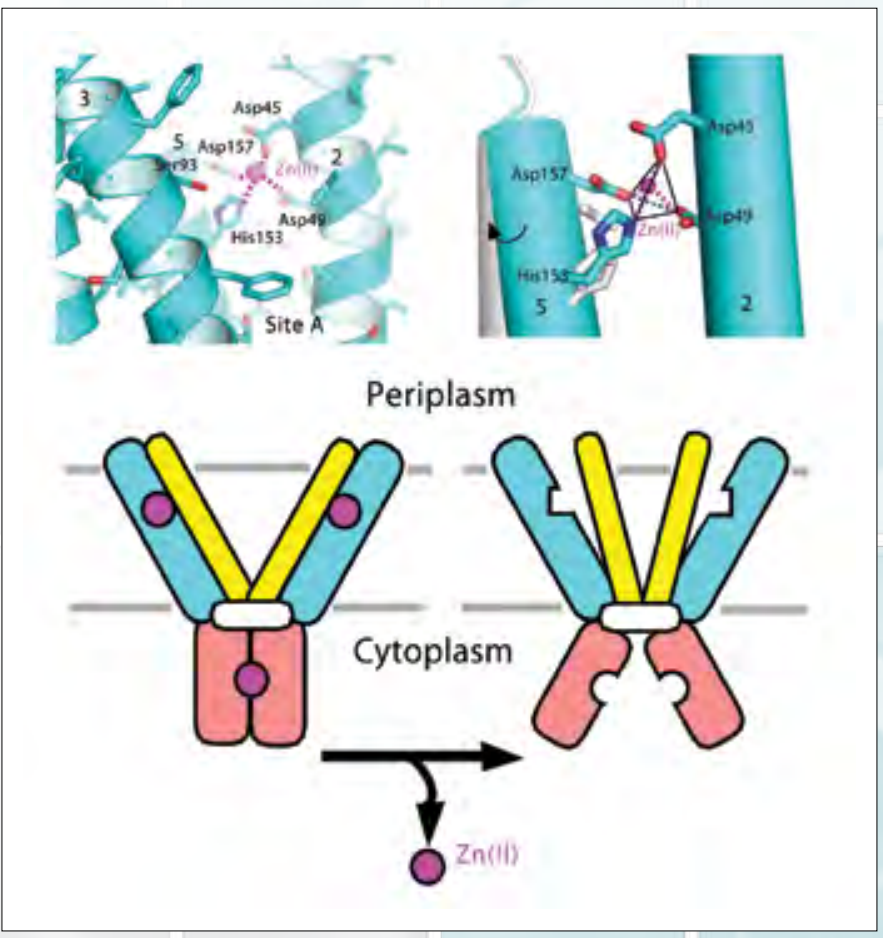


Attempts to eradicate tuberculosis (TB) are stymied by the fact that the disease-causing bacteria have a sophisticated mechanism for surviving dormant in infected cells. Now, a team of scientists including researchers from Brookhaven National Laboratory, Stony Brook University, Weill Cornell Medical College, and The Rockefeller University has identified compounds that inhibit that mechanism — without damaging human cells.

Most people infected with mycobacterium tuberculosis, the bacterium that causes $T B$, remain symptom-free because the bacterium is kept in check within immune system cells. These cells produce compounds such as nitric oxide, which scientists believe damage or destroy the bacteria's proteins. If allowed to accumulate, the damaged proteins would kill the bacteria.

But TB bacteria use a protein-cleaving complex known as a proteasome - identified in earlier research by this same team — to break down damaged proteins. This allows the bacteria to remain dormant, and possibly go on to cause active TB. Finding drugs to disable the protea- some would be a new way to fight TB. However, because human cells also possess proteasomes, the drugs would have to specifically target the TB proteasome without adversely affecting the human protein-cleanup complex.

After screening 20,000 compounds, the researchers identified two inhibitors that are effective against the TB bacteria while showing no toxicity to mammalian cells.

To learn more about the inhibitory mechanism, the group used the NSLS to determine the atomic-level crystal structures of TB proteasomes following exposure to the inhibitors. The studies revealed that the in- hibitor molecules block the proteasome's ability to degrade proteins in more than one way: by producing a direct chemical change to the proteasome active site, and by altering the conformation of the "pocket" into which protein fragments bind before being degraded.

A detailed understanding of the steps by which these inhibitors cause the conformational changes could therefore guide the design of the next generation of anti-TB drugs.

G. Lin, D. Li, L.P. Sorio de Carvalho, H. Deng, H. Tao, G. Vogt, K. Wu, J. Schneider, T. Chidawanyika, J.D. Warren, H. Li, C. Nathan, "Inhibitors Selective for Mycobacterial Versus Human Proteasomes," Nature, 461, 621-626 (2009).
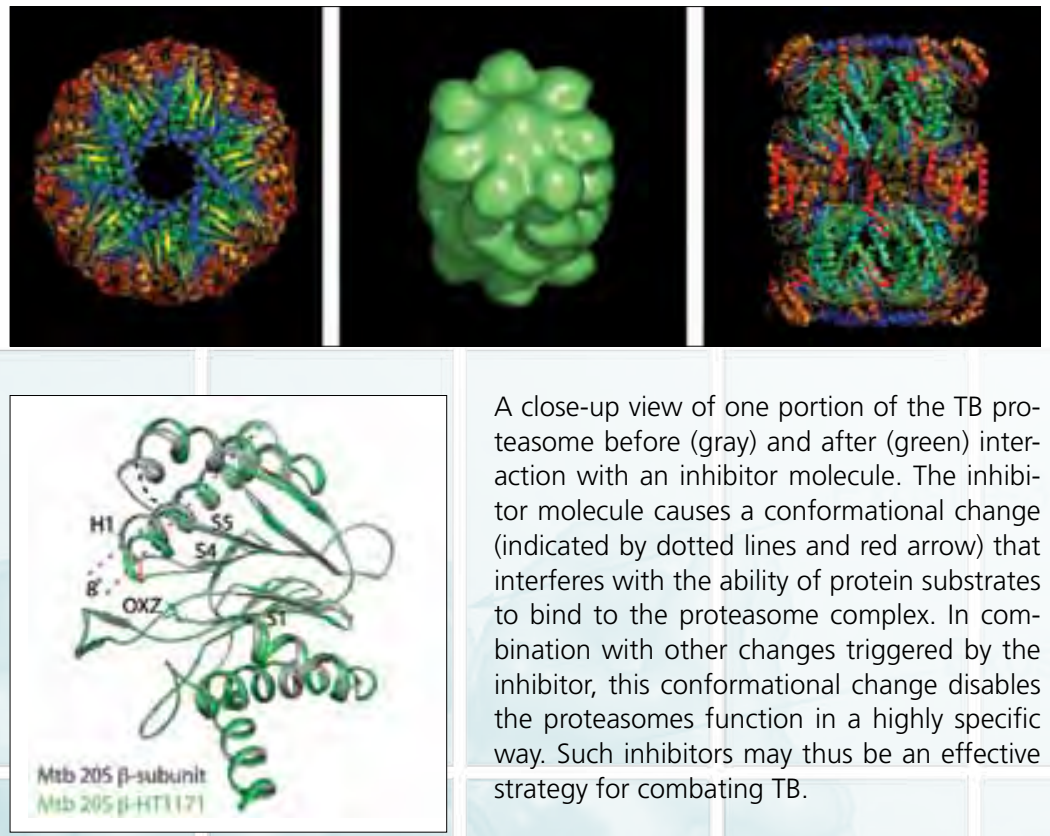

A close-up view of one portion of the TB proteasome before (gray) and after (green) interaction with an inhibitor molecule. The inhibitor molecule causes a conformational change (indicated by dotted lines and red arrow) that interferes with the ability of protein substrates to bind to the proteasome complex. In combination with other changes triggered by the inhibitor, this conformational change disables the proteasomes function in a highly specific way. Such inhibitors may thus be an effective strategy for combating TB.
The TB proteasome structure, shown here from the top, was originally described in a Molecular Microbiology paper in March 2006.

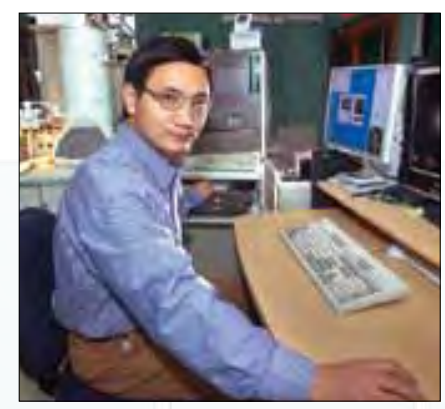

Huilin Li
32 ? 1

Science Highlights 

Disease Research

Minuscule plaques in the brains of mice with Alzheimer's disease contain much less metal than the brains of affected humans, according to a study conducted at the NSLS. This surprising finding could help researchers pinpoint the effect of metal in the human disease.

One of the hallmark features of Alzheimer's diseased brain is amyloid beta $(A \beta)$ plaques, small areas of dense built-up proteins. Previously, researchers have found an abundance of zinc, copper, and iron in the amyloid plaques in human Alzheimer's disease. These metal ions are essential to brain function, but elevated levels in the plaques may catalyze the formation of free radicals, which are toxic to brain cells. However, researchers have found that mice that were bred to develop $A \beta$ plaques don't show the severe neurodegeneration associated with human Alzheimer's disease.

That difference, researchers have guessed, might be attributed to a lower concentration of metal in mouse $A \beta$ plaques.
To investigate, researchers from the NSLS, Stony Brook University, and the University of Chicago used an x-ray fluorescence microscope and Fourier transform infrared microscopy at the NSLS to determine the metal concentration in plaques and surrounding non-plaque tissue taken from mice representing endstage Alzheimer's disease. They then compared the metal levels to previously collected data taken from human brains.

In mice, the plaques only showed an elevation in one type of metal - zinc, up by 29 percent - as compared to the surrounding tissue. But the mouse plaques actually had less copper and iron than in the surrounding tissue. Human $A \beta$ plaques, by comparison, showed a 339-percent increase in zinc, a 466-percent increase in copper, and a 177-percent increase in iron.

Although differences in plaques could be due to a number of factors, this study provides a solid path to follow. If metals turn out to be the culprit of Alzheimer's disease, further research might lead to the identification of targets for drug development or metal-targeted therapy to remove the excess metals from the plaques.

A.C. Leskovjan, A. Lanzirotti, L.M. Miller, "Amyloid Plaques in PSAPP Mice Bind Less Metal Than Plaques in Human Alzheimer's Disease," Neurolmage, 47(4), 1215-1220 (2009).
(A) Thioflavin S-stained PSAPP mouse brain tissue. X-ray fluorescence microprobe images of (B) $\mathrm{Zn}$ and (C) Cu distribution in the same tissue. All scale bars are $5 \mu \mathrm{m}$.

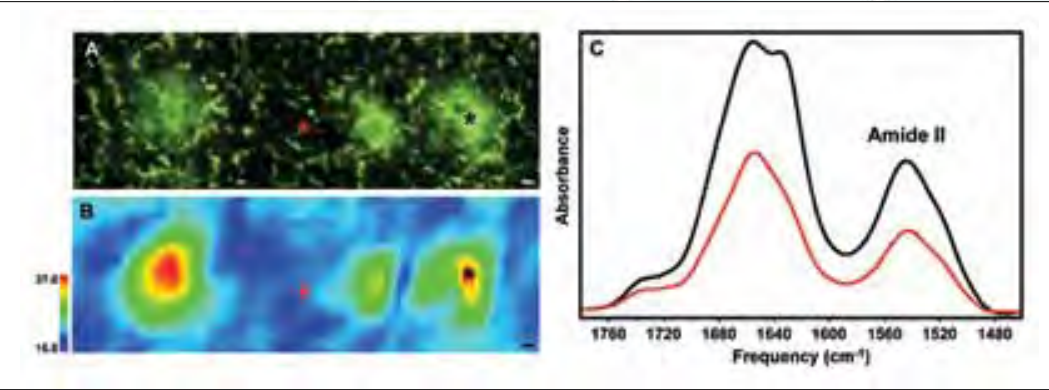

From left, Lisa Miller, Andreana Leskovjan, and Tony Lanzirotti

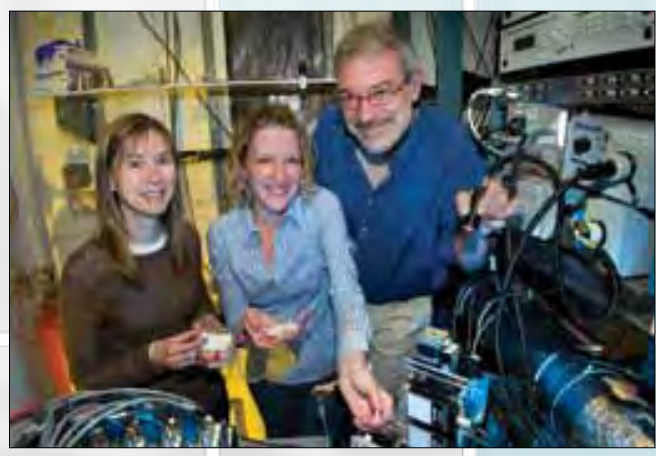




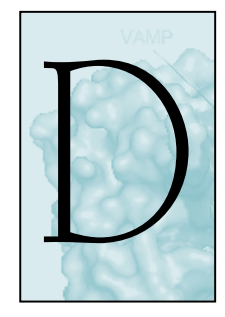

DNA-Based Assembly Line for Precision Nano-Cluster Construction

Building on the idea of using DNA to link up nanoparticles - particles measuring mere billionths of a meter - scientists at Brookhaven National Laboratory have designed a molecular assembly line for predictable, high-precision nano-construction. Such reliable, reproducible nanofabrication is essential for exploiting the unique properties of nanoparticles in applications such as biological sensors and devices for converting sunlight to electricity.

The Brookhaven team has previously used DNA, the molecule that carries life's genetic code, to link up nanoparticles in various arrangements, including 3-D nano-crystals. The idea is that nanoparticles coated with complementary strands of DNA - segments of genetic code sequence that bind only with one another like highly specific Velcro - help the nanoparticles find and stick to one another in highly specific ways. By varying the use of complementary DNA and strands that don't match, scientists can exert precision control over the attractive and repulsive forces between the nanoparticles to achieve the desired construction.

The latest advance, which incorporated small-angle $x$-ray scattering experiments at the NSLS and studies at the Center for Functional Nanomaterials, has been to use the DNA linkers to attach some of the DNAcoated nanoparticles to a solid surface to further constrain and control how the nanoparticles can link up. This yields even greater precision, and therefore a more predictable, reproducible high-throughput construction technique for building clusters from nanoparticles.

Instead of assembling millions and millions of nanoparticles into 3-D nanocrystals, as was done in the previous work, this technique allows the assembly of much smaller structures from individual particles.

M.M. Maye, D. Nykypanchuk, M. Cuisinier, D. van der Lelie, O. Gang, "Stepwise Surface Encoding for Highthroughput Assembly of Nanoclusters," Nature Materials, 8, 388 (2009).

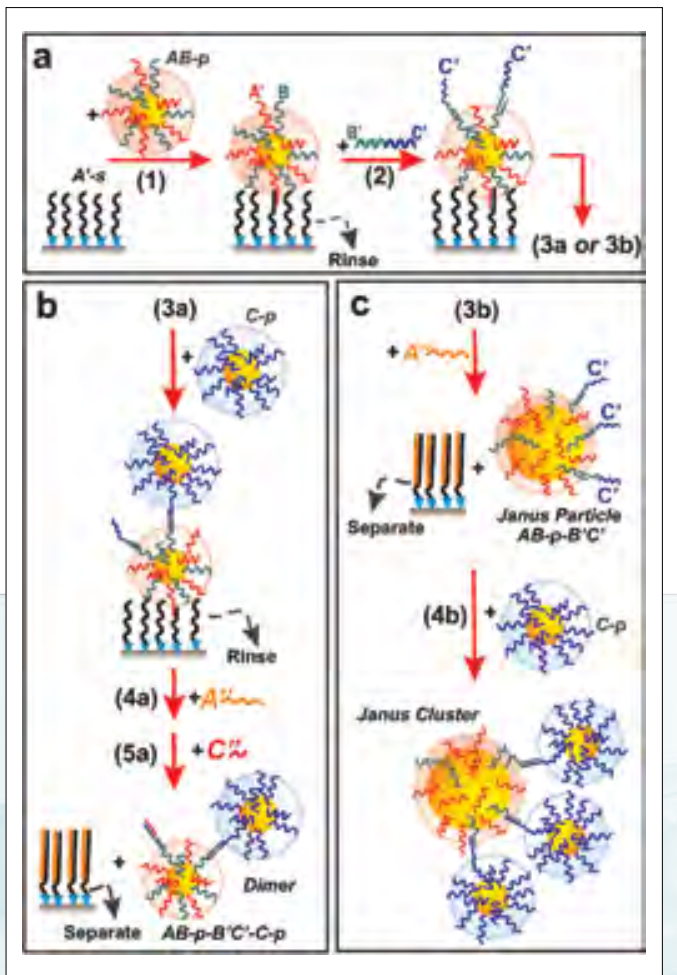

Using DNA to assemble nanoclusters: (a) (1) DNA linker strands (squiggly lines) are used to attach DNA-coated nanoparticles to a surface. (2) Linker strands are attached to the top side of the nanoparticle. (b) (3a) A nanoparticle of a second type with complementary DNA encoding recognizes the exposed linker strands and attaches to the surface-anchored nanoparticle. (4a and 5a) The assembled structure is released from the surface support, resulting in a two-particle, dimer cluster. (c) (3b) Alternatively, the immobilized particles produced in step (a) are released from the surface, leaving the opposite-side linker strands free to bind with multiple particles (4b) to form asymmetric "Janus" clusters

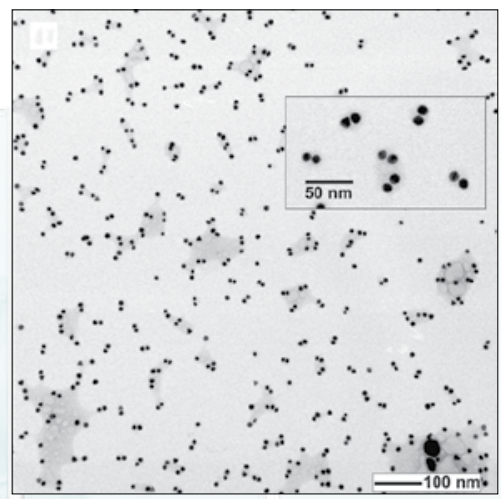

This transmission electron micrograph shows nanoparticle dimers (two-particle clusters) assembled and released through the DNA-encoded solid-support approach. 


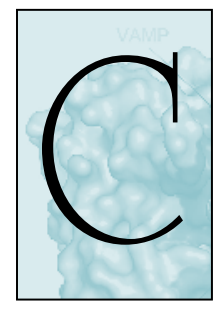

Chemists Reach from the Molecular to the Real World with Creation of 3-D DNA Crystals

Chemists from New York University and Purdue University have created three-dimensional DNA structures, a breakthrough bridging the molecular world to the world where we live.

DNA's double helices form when single strands of DNA - each containing two pairs of complementary molecular components called bases, attached to a molecular backbone - self-assemble by matching the complementary parts. The researchers added "sticky ends" — small cohesive sequences - to these double helices, forming single-stranded overhangs. Where these overhanging sticky ends are complementary, they bind together to link two double helices. By linking together multiple helices, the researchers form a lattice-like structure that extends in six different directions, thereby yielding a 3-D crystal.
This technique allows researchers to organize more matter and work with it in many more ways than is possible with 2-D crystals.

The crystals were analyzed using x-ray diffraction at Argonne National Laboratory's Advanced Photon Source and NSLS beamlines $X 6 A$ and $X 25$. Using a variety of detectors, scientists measure how a beam of intense $x$-rays scatters, or bounces off, the atoms in the sample. The resulting diffraction pattern allows them to reconstruct a 3-D molecular model of the material, showing the positions and relative orientations of the atoms.
A promising application of this approach is in nanoelectronics, where the enhanced flexibility of 3-D components could help manufacturers build parts that are smaller, closer together, and more sophisticated.

The scientists also expect that they can organize biological macromolecules by attaching them to these crystals, which would help in the development of new drugs.

\section{— James Devitt, New York \\ University}

J. Zheng, J.J. Birktoft, Y. Chen, T. Wang, R. Sha, P.E. Constantinou, S.L. Ginell, C. Mao, N.C. Seeman, "From Molecular to Macroscopic Via the Rational Design of a Self-Assembled 3D DNA Crystal," Nature, 461, 74-77 (2009).

Researchers created 3D DNA structures by using single-stranded sticky ends that link double helices in DNA triangles that point in different directions.

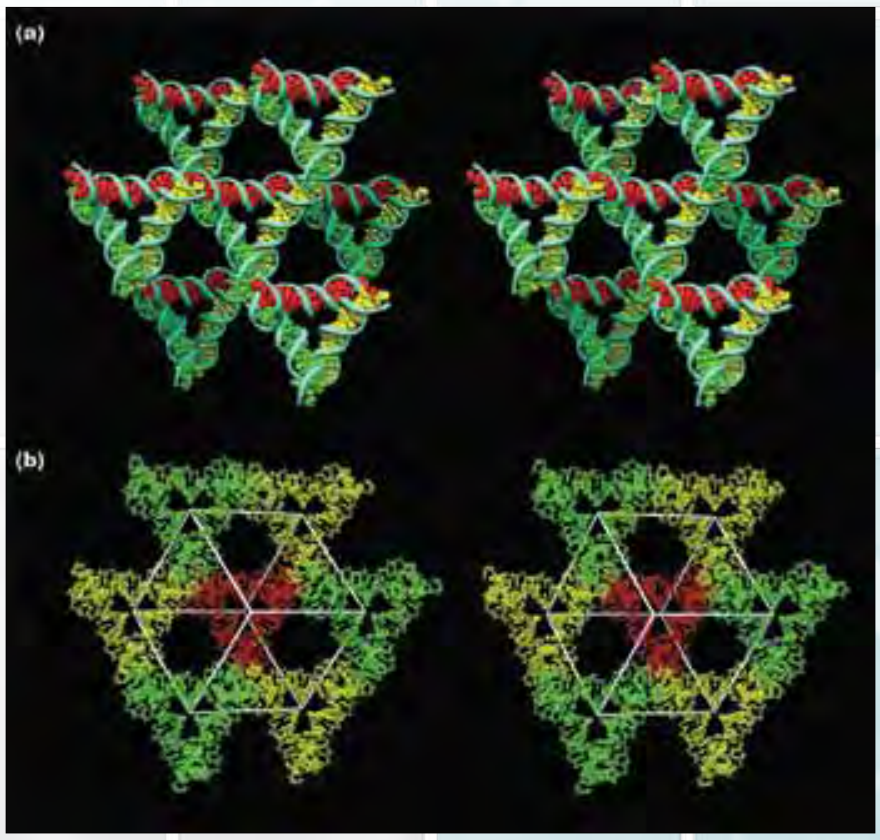




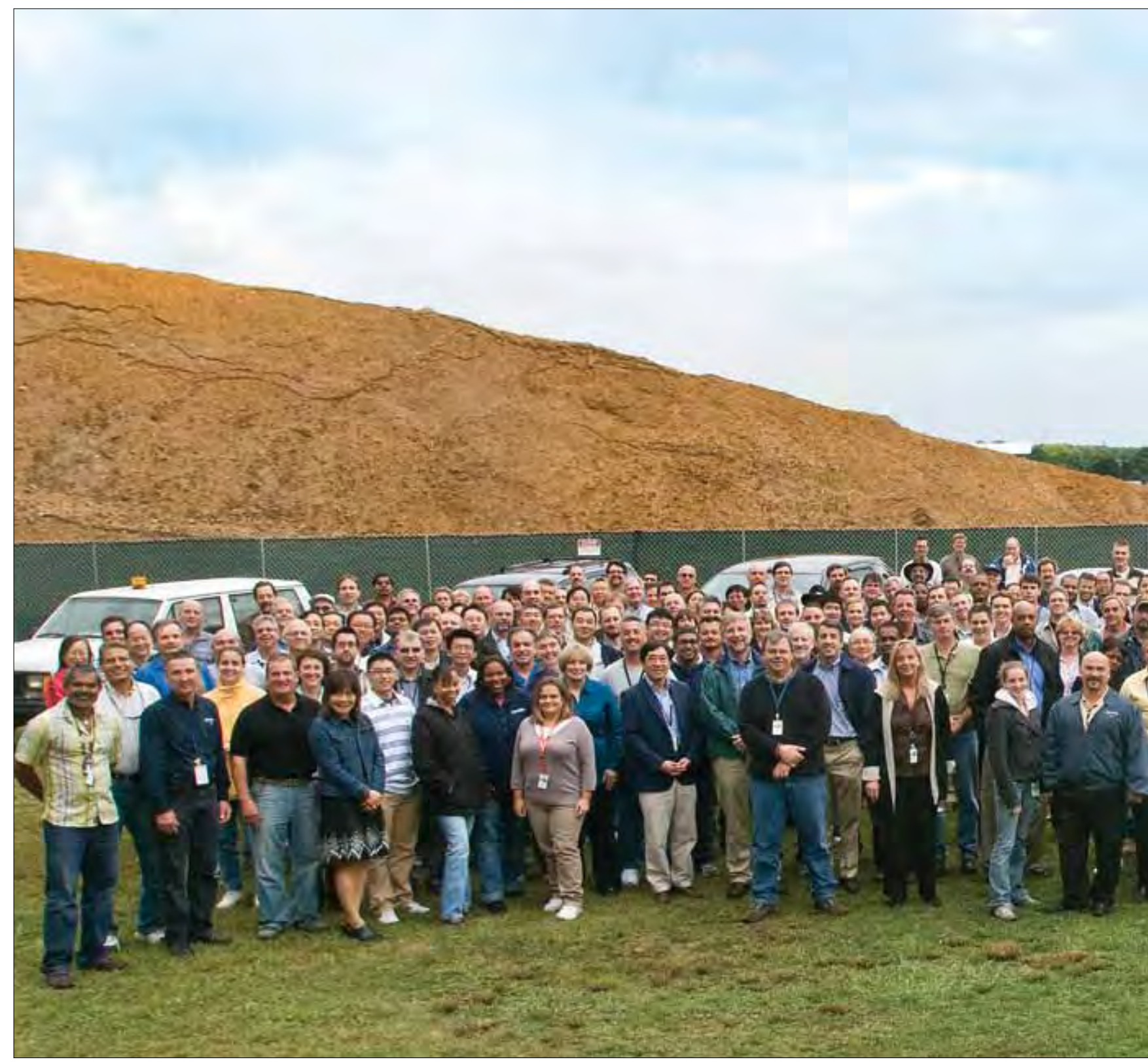

NSLS and NSLS-II staff gather at the Light Sources Directorate Annual Awards Barbeque.

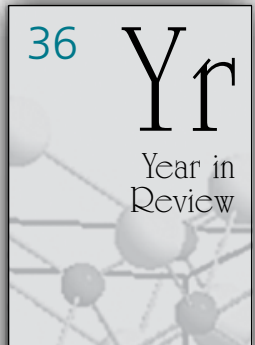




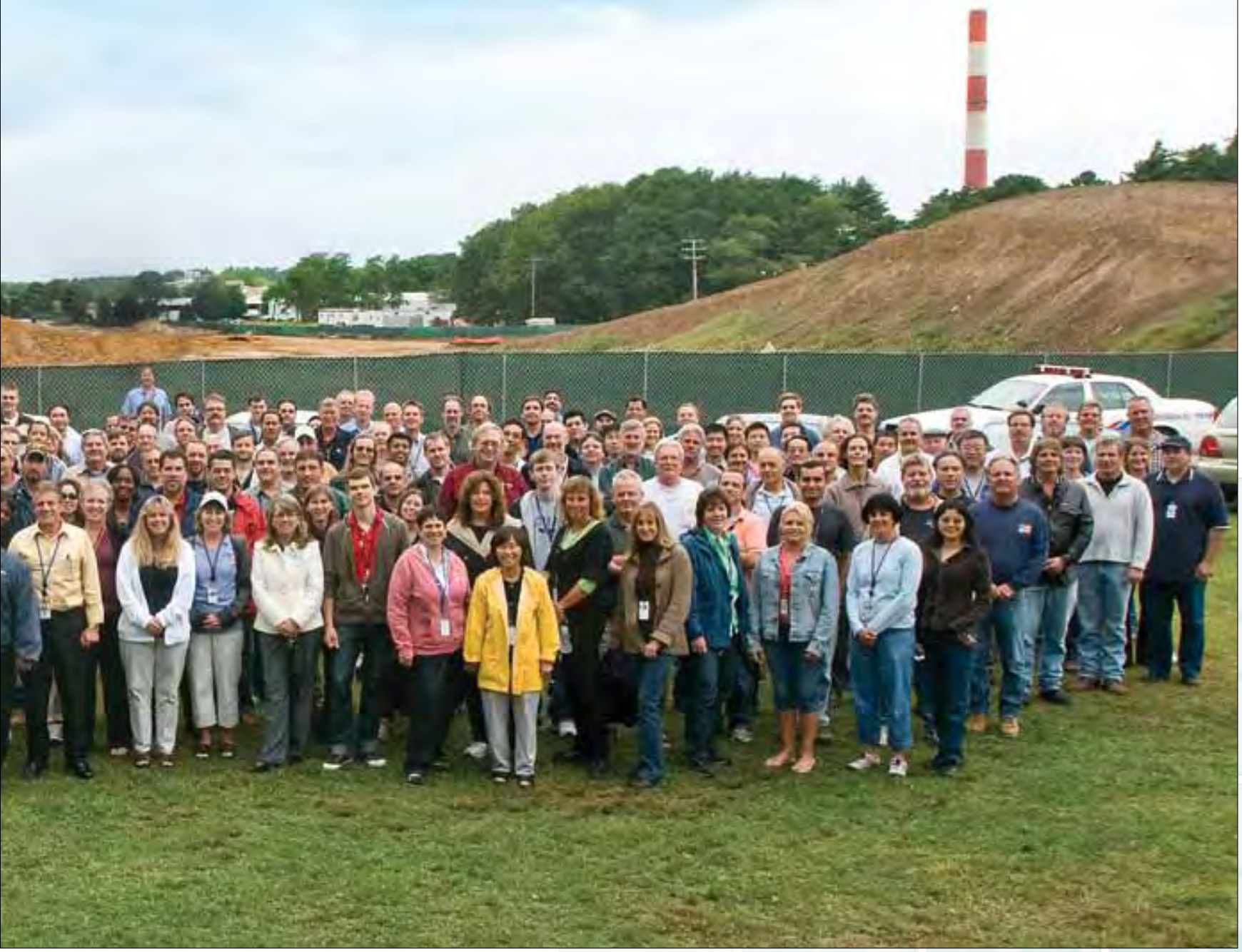

The Light Sources Directorate includes more than 370 scientists, engineers, technicians, and support staff. 


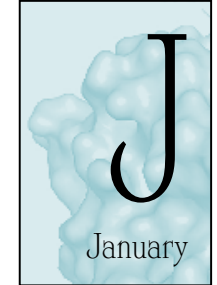

Department of Energy Approves Construction Start of NSLS-II Project

The U.S. Department of Energy grants "Critical Decision 3" (CD-3) status to the NSLS-II, approving the start of construction in fiscal year (FY) 2009 and scheduling completion in FY 2015.

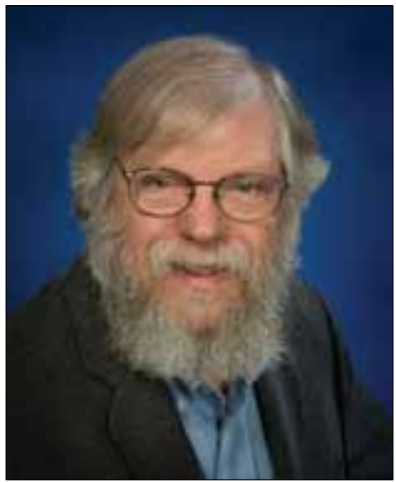

NSLS Physicist Pete Siddons Named APS Fellow

Pete Siddons, an NSLS physicist, is among four Brookhaven scientists to be named Fellows of the American Physical Society, a professional organization with about 46,000 members. Siddons was honored "for his contribution to $x$-ray optics, $x$-ray physics, $x$-ray detectors, and the development of synchrotron radiation instrumentation and experimental techniques."

Brookhaven Lab Receives \$28 Million to Support Crystallography Facility

Brookhaven receives grants from the U.S. Department of Energy (DOE) and the National Institutes of Health (NIH) totaling $\$ 28$ million to support the X-ray Crystallography Research Resource at the NSLS. The grants of $\$ 15$ million from DOE's Office of Biological and Environmental Research and $\$ 13$ million from NIH's National Center for Research Resources will fund five years of operations and research.

College Mini-Semester Students Spend Their Winter Break at Brookhaven Lab

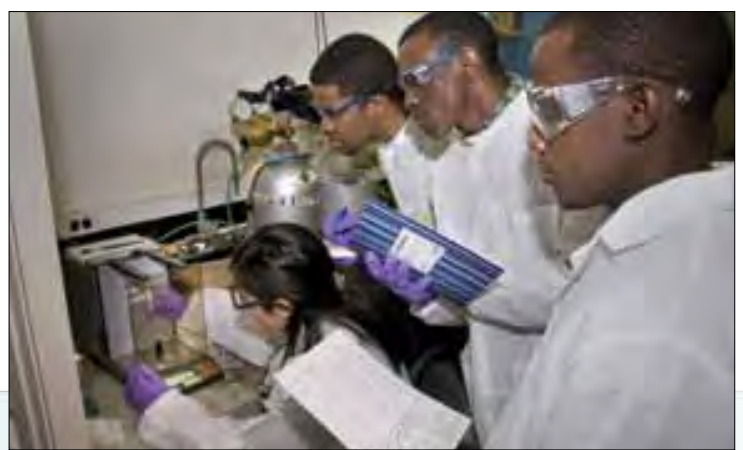

Twenty-two students from 15 colleges spend five days of their winter break at Brookhaven discovering cuttingedge science. The students were enrolled in Brookhaven's College Mini-Semester Program, which included lectures, team research experience, and tours of BNL facilities, including the NSLS.

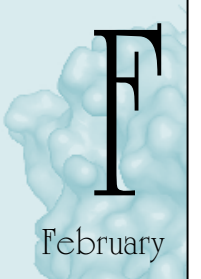

NSLS-II Contract Will Mean Hundreds of Jobs for Long Island

The NSLS-II Project selects Torcon, Inc. to construct the building that will house the accelerator ring, the largest component of the machine. Torcon estimates that 90 percent of the total construction contract cost of more than $\$ 170$ million will be spent directly with Long Island contractors and suppliers.

\section{6th Brookhaven Lecture: Lin Yang}

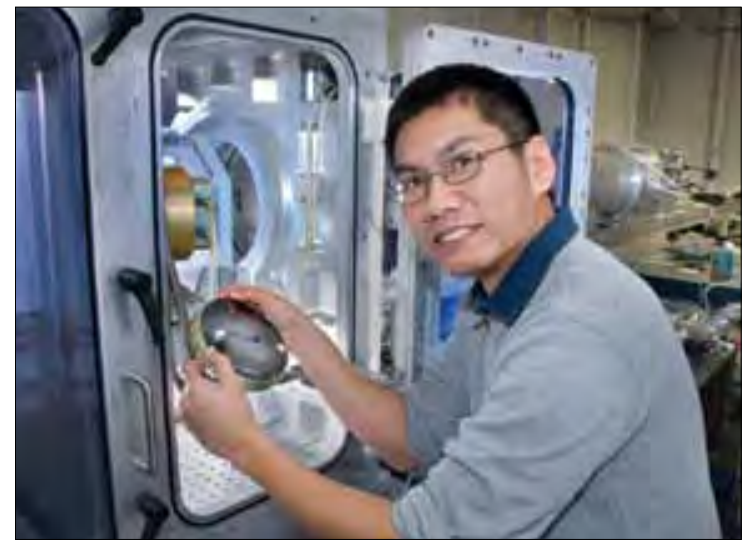

NSLS scientist Lin Yang gives the 446th Brookhaven Lecture, titled, "When Crystallography Won't Show You the Membranes," focusing on a new, unique method to study proteins and lipids within their native environment as they form the essential permeable surface of a cell membrane. 


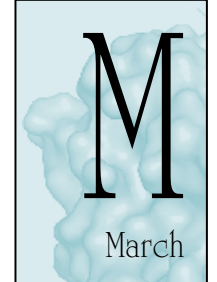

JPSI Workshop: Microelectronics Research Opportunities at the National Synchrotron Light Source The Joint Photon Sciences Institute sponsors its first workshop to bring together researchers from industry, education, and government to share information and form new collaborative projects. The microelectronics-focused workshop, held at Albany Nanotech's Nanofab South, assembled a team of experts in synchrotron techniques and brought it to the "customer" - microelectronics researchers from Sematech, IBM, University of Albany's College of Nanoscale Science and Engineering, TEL, and Intel.

\section{NSLS Physicist Elaine} DiMasi Awarded Tenure Elaine DiMasi, a physicist at the NSLS, is one of eight scientists granted tenure by Brookhaven Science Associates, based on her scientific accomplishments related to ordering at liquid surfaces as well as her research and leadership in the field of biomineralization.

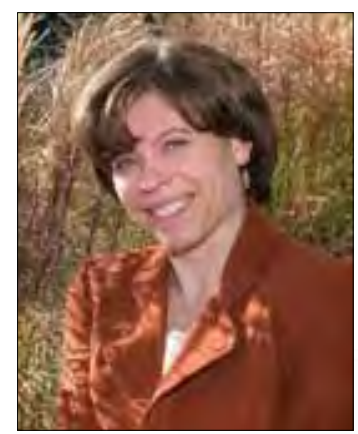

"Brain Week" Web Conference Links High Schoolers with NSLS Researchers

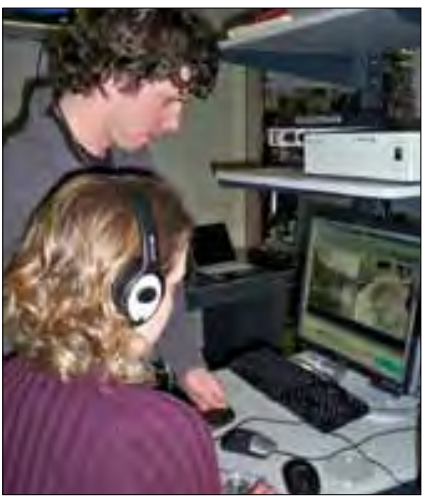

As part of "Brain Week," a group of Sachem East High School students learn - and watch - how synchrotron light is being used to study ailments such as Alzheimer's, Parkinsons, and Lou Gehrig's diseases without stepping foot outside of their classroom. Via web conference, the students talked to and questioned scientists at the NSLS and "toured" a specialized beamline used for biological imaging.

Hendrickson Appointed NSLS-II

Associate Project Director for Life Sciences

Wayne A. Hendrickson, a longtime NSLS structural biology user, university professor at Columbia University, and Investigator with the Howard Hughes Medical Institute, is appointed Associate Project Director for Life Sciences at NSLS-II.

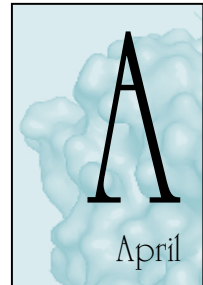

Workshop Breaks New Ground, Introduces Synchrotron Techniques to Glass Community

A Workshop on Applications of Synchrotron Techniques in Glass Research is held at Brookhaven by the National Science Foundation's International Materials Institute for New Functionality in Glass and the NSLS.

Senator Gillibrand Visits the NSLS

U.S. Senator Kirsten Gillibrand is welcomed to Brookhaven Lab during her first visit to Suffolk County since being appointed by Governor David Paterson to the seat formerly held by Hillary Clinton. Accompanied by U.S. Congressman Tim Bishop, and new-

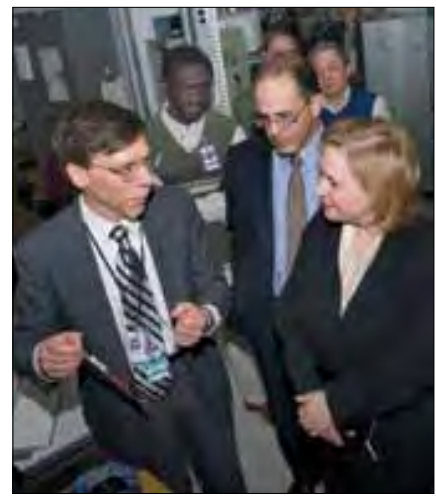
ly elected Brookhaven Town Supervisor Mark Lesko, the Senator toured the PHENIX experiment at the Relativistic Heavy Ion Collider, the National Institute of Standards and Technology beamline at the National Synchrotron Light Source, and electron microscopy and other labs at the Center for Functional Nanomaterials.

\section{RapiData Draws 50 Future}

Crystallographers to the NSLS

About 50 students gather at the NSLS for RapiData 2009, a weeklong crash course designed to introduce participants to the best and latest equipment and techniques for macromolecular x-ray crystallography.

Children Use Synchrotron Forensics,

Detective Techniques to Solve Mock Hit-and-Run

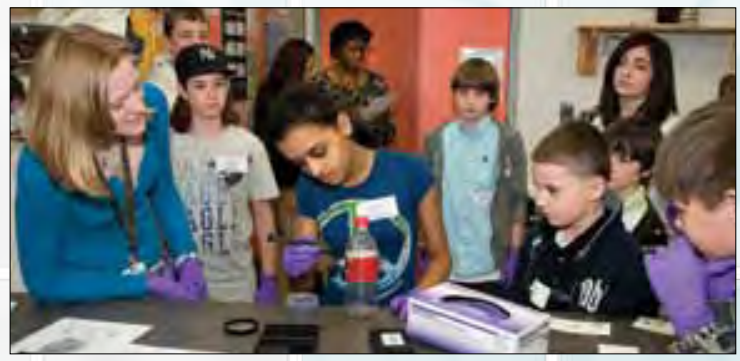

With the help of NSLS researchers and BNL Police, about 50 children of Light Sources Directorate staff and users put together clues to catch the culprit in a hit-and-run case. The "crime," played out as part of the national Take Your Children to Work Day, transformed the students into temporary detectives and forensic scientists as they used synchrotron techniques at the NSLS to illuminate evidence. 


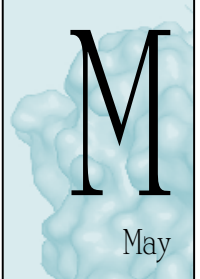

Workshop Highlights New

Opportunities in Hard X-ray

Photoelectron Spectroscopy

The third international workshop on hard x-ray photoelectron spectroscopy (HAXPES) brings together about 100 scientists from 14 countries. The three-day workshop was sponsored by the NSLS, the NSLS-II Project, Brookhaven's Condensed Matter Physics and Materials Science Department, and the National Institute of Standards and Technology.

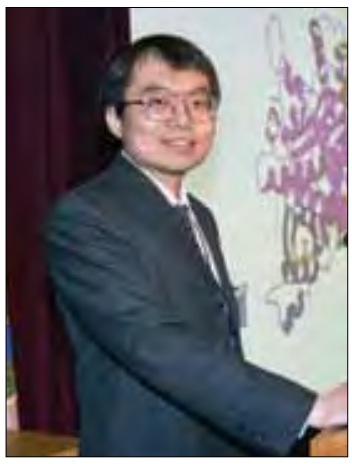

Chuan-Hsiang Huang Receives 2009 Julian Baumert Award

Chuan-Hsiang Huang, a post-doctoral fellow at The Johns Hopkins University School of Medicine, is awarded the 2009 Julian Baumert Ph.D. Thesis Award for his work on solving the structure of a protein frequently mutated in human cancers.

NSLS-CFN Joint Users' Meeting Highlights Boost, Opportunities in Science Funding

About 400 people attend the 2009 joint meeting of the NSLS and Center for Functional Nanomaterials user communities, which focused on the increased support for science in the nation. Plenary speakers included: Laboratory Director Sam Aronson; Harriet Kung, Director of DOE's Office of Basic Energy Sciences; Pedro Montano, Director of the BES Scientific User Facilities Division; Steve Dierker, Associate Laboratory Director for Light Sources; NSLS Chair Chi-Chang Kao; and CFN Director Emilio Mendez.

UEC Community Service Award Goes to Keith Klaus The NSLS Users' Executive Committee awards Keith Klaus, the NSLS Safety Engineer, with the 2009 UEC Community Service Award for outstanding service, innovation, and dedication to users of the NSLS.

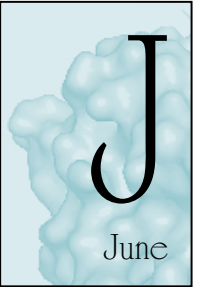

JPSI Workshop: Energy Storage Research Opportunities at the NSLS

About 45 participants attend the "Energy Storage Research Opportunities at the $\mathrm{Na}$ tional Synchrotron Light Source" workshop sponsored by the Joint Photon Sciences Institute and the NSLS.

The NSLS-II Celebration: New Jobs and New Science

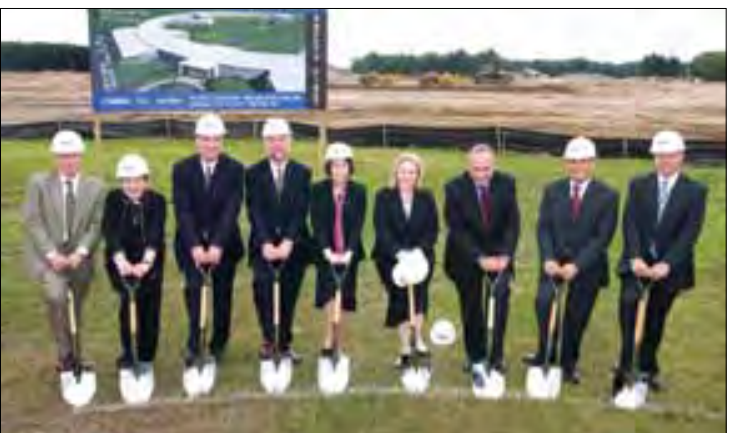

The NSLS-II Project marks the start-of-construction with music and dance performances, food, and remarks from Senators Charles Schumer and Kirsten Gillibrand, Congressman Tim Bishop, and numerous representatives from Brookhaven, the U.S. Department of Energy, Battelle, and Stony Brook University.

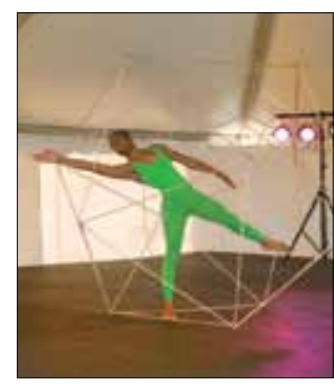

NSLS Conference Room Named in Honor of Former Project Director

Almost 27 years after the dedication of the NSLS, Arie van Steenbergen, the man who helped bring the facility to fruition, receives his own ceremony. Numerous relatives, friends, and colleagues of van Steenbergen, a former Deputy NSLS Department Chairman who died in January 2009, gathered at the NSLS to name Conference Room A in his honor.

\section{First Major Milestone Achieved for Brookhaven's} Next Big Machine, NSLS-II

The development of the magnet girder assembly for NSLS-II, a project requiring almost four years of research and engineering design, is completed when NSLS-II staff confirmed that the magnets' high-precision alignment would survive the process of transporting them from their assembly point to the NSLS-II tunnel. 
First Concrete Poured for NSLS-II Ring Building

The first bits of the NSLS-II ring building start taking shape as the concretepouring process for the new, worldclass facility begins. Once complete, the 400,000 square-foot building will house the accelerator ring, the largest component of the machine.
Third Annual Meeting of INCREASE Consortium Focuses on Heightening Involvement

The third meeting of the Interdisciplinary Consortium for Research and Educational Access in Science and Engineering (INCREASE) stresses the importance of amplifying the participation of faculty and students from minorityserving institutions. Held at the NSLS, the workshop attracted 11 faculty members from 10 institutions to learn how to transform themselves and their students into successful synchrotron users.

Summer Sunday Teaches Science with Gumdrops, Beethoven

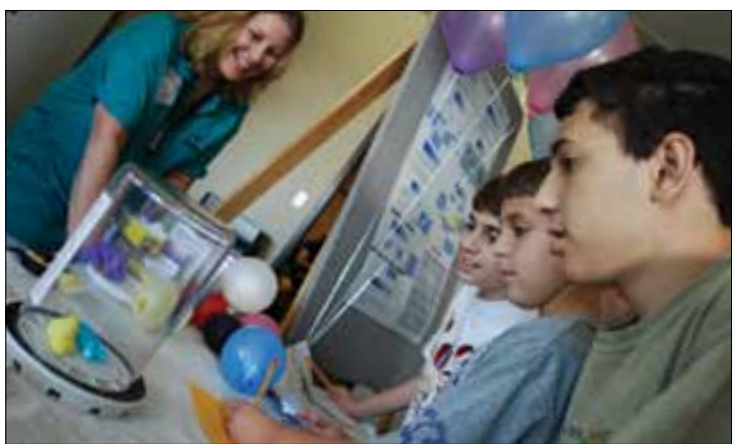

The Light Sources Directorate annual open house, part of Brookhaven Lab's Summer Sundays program, draws a record-breaking number of both visitors and volunteers. A slew of hands-on scientific demos, basic lectures, giveaways, and tours attracted nearly 850 visitors from the local community to the NSLS.

MX Frontiers at the One Micron Scale:

Making the Case for Micro-Beams

The Macromolecular Crystallography (MX) Frontiers at the One Micron Scale workshop is held at Brookhaven to explore structural biology scientific opportunities made possible through the use of micro-beams. More than 100 attendees participated in the workshop, which included one-and-a-half days of lectures, discussions, and a semiformal poster session.

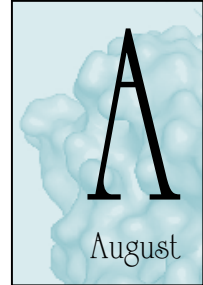

Another First at the NSLS-II

Construction Site

Workers at the NSLS-II ring building construction site complete the first complicated concrete pour for the approximately 19-ft.-tall walls of the Utility Tunnel. The continuous pour was the first of its kind, as previous pours have been for footings and the foundations of footings.
NSLS Summer Students Complete Projects Ranging from Geology to Physics

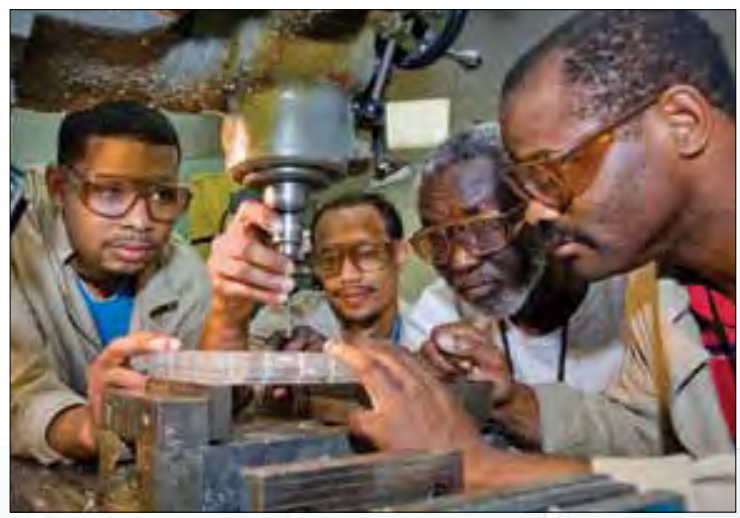

Twenty-seven college students and five professors join the NSLS for the summer, working with scientists and engineers from the department in research fields ranging from geology and environmental sciences to electri-

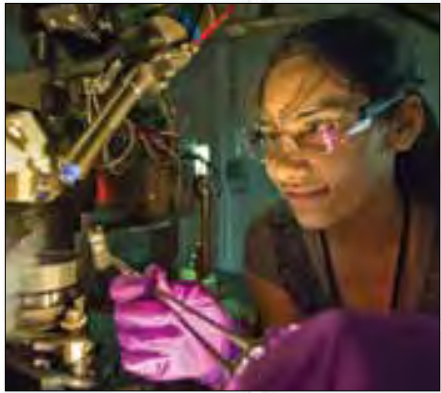

cal and mechanical engineering. In addition to their research projects, students have the opportunity to attend scientific lectures, tour BNL research facilities, and participate in numerous social activities.

July - August 


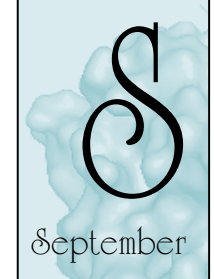

NIH Funding Renewed for Case Center for Synchrotron Biosciences

Funding for the Center for Synchrotron Biosciences (CSB), a consortium that runs five beamlines at the NSLS, is renewed through the National Institutes of Health. The CSB, based at Case Western Reserve University, will receive a five-year, $\$ 4$ million grant to continue the exploration of the structure and dynamics of proteins and nucleic acids.

First Structural Steel Erected for NSLS-II

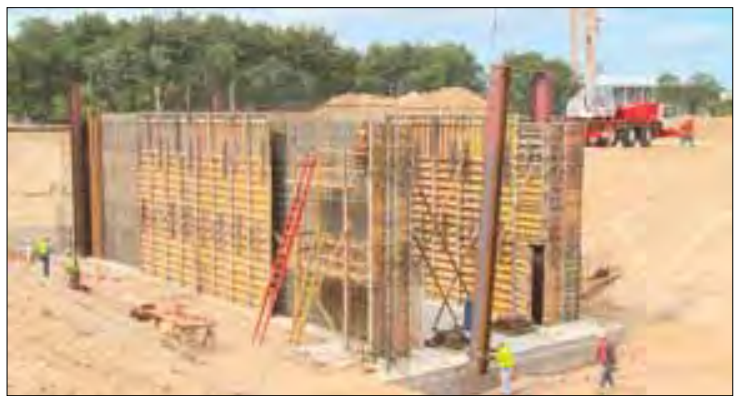

Ten steel columns are incorporated into the ever-growing framework for the NSLS-II — the first structural steel erected for the future 400,000-square-foot facility.

\section{BNL Hosts Workshop on Materials} in Next-Generation Energy Systems

A BNL workshop on the characterization of materials under extreme conditions of next-generation energy systems is organized by BNL's Energy Sciences Technology Department, the NSLS, and the Joint Photon Sciences Institute.

Light Source Employees Honor Year's Achievements, Co-Workers at Annual Picnic

Discounting dark skies and sprinkles, almost 200 Light Source Directorate employees gather for food, drinks, and the chance to reflect upon the past year's accomplishments at the annual picnic and awards ceremony.

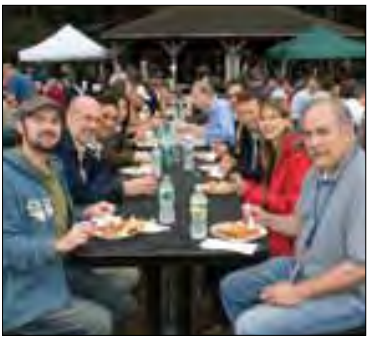

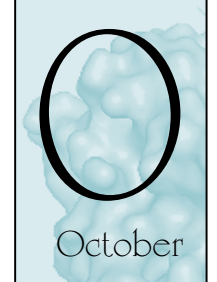

Light Sources Staff Makes Strong Showing at Instrumentation Conference

More than 20 Light Sources Directorate employees attend the 10th international conference on Synchrotron Radiation Instrumentation (SRI) to learn about and present the latest developments in the field.

Contracts Awarded for Production of NSLS-II Storage Ring Magnets

The last of seven contracts for the production of the NSLS-II storage ring magnets is awarded - a significant milestone for the project. The magnets - 750 in total — will be made by vendors in the United States, Russia, China, Europe, and New Zealand.

Seminal Work for 2009 Nobel Prize in Chemistry Conducted at NSLS
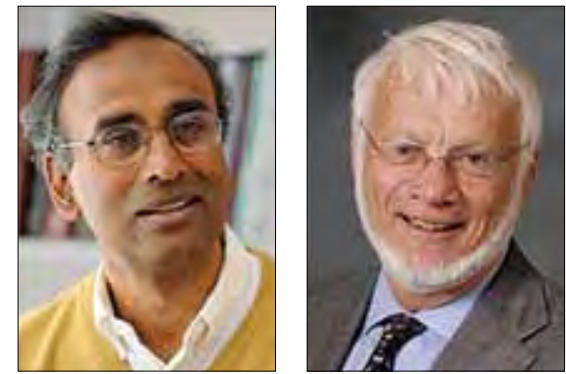

The 2009 Nobel Prize in Chemistry is awarded to three researchers, including long-time NSLS users Venkatraman Ramakrishnan, Medical Research Council Laboratory of Molecular Biology, a former employee in Brookhaven's biology department; and Thomas A. Steitz, Yale University. They shared the prize with Ada E. Yonath, Weizmann Institute of Science, for studying the structure and function of the ribosome.

\section{NSLS Hosts First Training Session} on Solution X-ray Scattering

To learn the ways of solution $x$-ray scattering, about a dozen researchers from eight different institutions come to the NSLS for hands-on training and tips from experts in the field. The inaugural training session was based at NSLS beamline $X 9$, a newly commissioned, undulatorbased beamline that specializes in taking small angle $\mathrm{x}$-ray scattering measurements - data that are very valuable for studying biological macromolecules. 


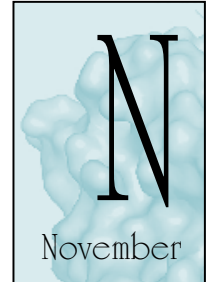

Inscribed Concrete Boulder Found on NSLS-II Excavation Site Sparks Curiosity

Construction workers at the NSLS-II excavation site discover a large concrete "boulder" with writing and a drawing inscribed on it that likely has ties to Camp Upton - the military base that existed prior to the creation of BNL.

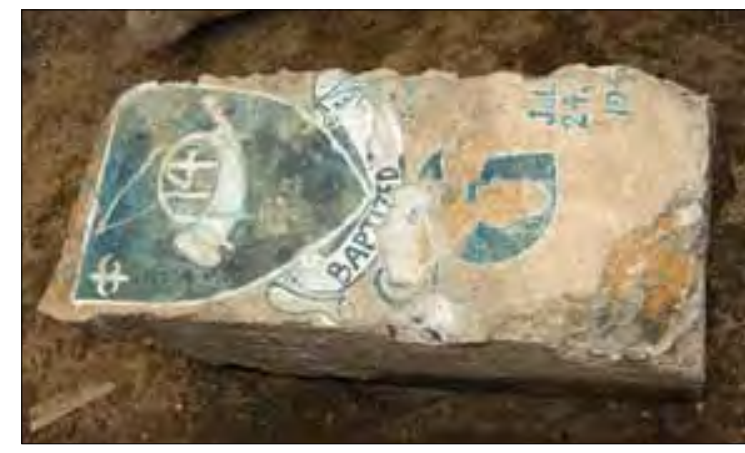

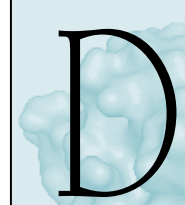

December

NSLS Users Rack Up Numerous Awards Eight NSLS users win a number of prestigious honors. They include: Brookhaven physicist and former NSLS Deputy Chair Samuel Krinsky, winner of the 2008 Free Electron Laser (FEL) Prize; National Institute of Standards and Technology

(NIST) scientists Dean DeLongchamp and Dan Fischer, who received NIST's highest honor, the Departmental Bronze Medal; Delongchamp, Thomas Epps III (University of Delaware), and Jason Graetz (Brookhaven Lab), who were among 100 recipients of the 2009 Presidential Early Career Award for Scientists and Engineers; University of Delaware postdoctoral researcher Matthew Ginder-Vogel, who was awarded a seed grant from the Delaware National Science Foundation Experimental Program to Stimulate Competitive Research (NSF EPSCOR) office; and Bonnie Ann Wallace, a researcher at Birkbeck College, University of London, who won the 2009 Royal Society of Chemistry Interdisciplinary Prize and the 2010 Biochemical Society's AstraZeneca Award.
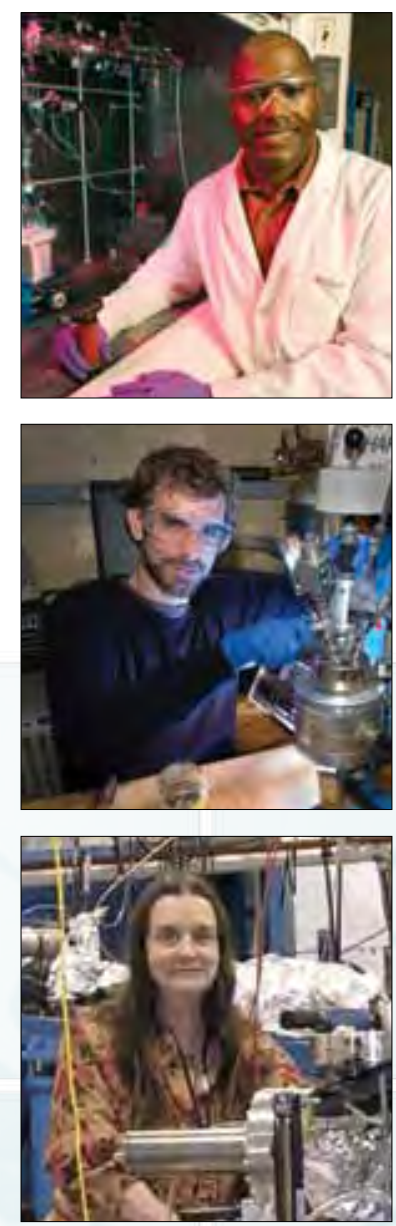

\section{"This boulder has been underground for over 70 years, but the writing on it was quite legible."}

- Tim Green, BNL Cultural and Natural Resources Manager, on the NSLS-II excavation site boulder 

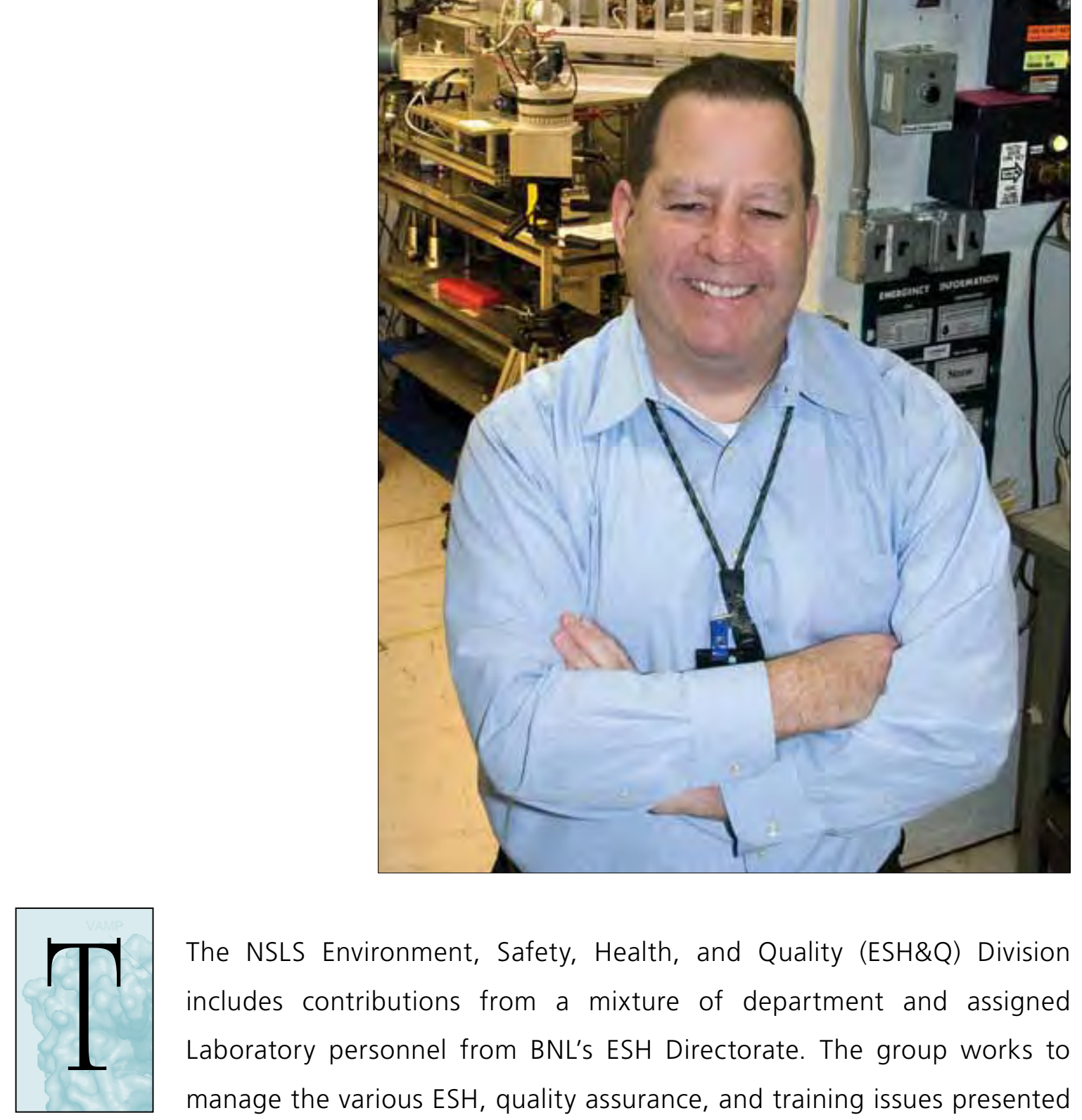

The NSLS Environment, Safety, Health, and Quality (ESH\&Q) Division includes contributions from a mixture of department and assigned Laboratory personnel from BNL's ESH Directorate. The group works to manage the various ESH, quality assurance, and training issues presented by facility and experiment operations.

There is a continued emphasis on integration of ESH\&Q principles into all work at BNL. Laboratory initiatives for 2009 included continued focus on implementation of Human Performance principles into work planning and execution, better communication across directorates for lessons learned and corrective actions needed when an incident or audit uncovers some program deficiency, and on efforts to consolidate resources and improve management efficiency through the directorate's new Blueprint and Leadership Action Plan.

There were a number of significant accomplishments this year at the NSLS. Implementation of Human Performance principles continued as directorate and beamline staff attended training developed for application of Human Performance concepts to facility, beamline, and experimental operations. And hazard analyses were completed for 
each beamline to identify risks and error-likely situations presented by routine work tasks not captured through use of the experiment Safety Approval Forms.

Another major activity of the year was redesigning the Beam Line Operational Safety Awareness (BLOSA) program. BLOSA forms are now better customized to each beamline, and revision control for the new checklists is much improved. The basic information required for all forms was rewritten with redundant or unnecessary information eliminated to allow for a more effective and efficient process.

Management of the set-up laboratories was improved. Much legacy equipment has been discarded. Task definition and risk analyses have been completed for each laboratory, and the steward program is better defined. In addition, a new webpage was established to collect needed information and the Safety Approval Forms were modified to assure review of the work planned for these spaces.

A final significant achievement to note for 2009 is the successful reduction of the risks presented by cryogen use at the NSLS. Through much discussion and analysis, specific personal protective equipment (PPE) requirements for handling cryogens were established to allow for efficient work progress and still provide needed protection, and improvements implemented at the beamlines have led to better control of the oxygen deficiency hazards presented by these materials. A considerable volume of liquid nitrogen and helium is in constant use at the facility and the improvements made toward controlling the risks they present were highly needed.

Tracking of various performance measures shows that all risks are well managed at the NSLS, and 17 audits of the department's ESH\&Q programs yielded few findings and much praise. Workplace inspections continue to find

ardous waste generation remains low. Only three events rose to the level of required reporting and each was minor and efficiently resolved. Unfortunately, there were six injuries at the NSLS during 2009 and two of those resulted in some lost work time. Each was well investigated and corrective actions were taken to reduce the risk of recurrence.

2009 was both a productive and challenging year for the Laboratory and NSLS ESH\&Q programs. Much progress was made, but the accident rate on site continues to be troublesome. Several significant events have illustrated the need for more attention on the controls in place for managing how work is conducted, how work changes are evaluated and documented, and how facili-

"Tracking of various performance measures shows that all risks are well managed at the N\&LS and 17 audits of the department's $\mathrm{E} \& H \& Q$ programs yielded few findings and much praise."

\section{Andrew Ackerman}

Environment, Safety, Health, and Quality Division Head

deficiencies, but the time needed for correction has been reduced. Measured personnel radiation exposures were negligible and haz- ties are used and their configuration maintained. The NSLS ESH\&Q staff is engaged in the Laboratory's efforts to improve these processes and to help develop requirements that fit the needs of the department and the Laboratory. Continued cooperation from everyone will be needed to implement those requirements and continue with an exemplary and safe science program. 

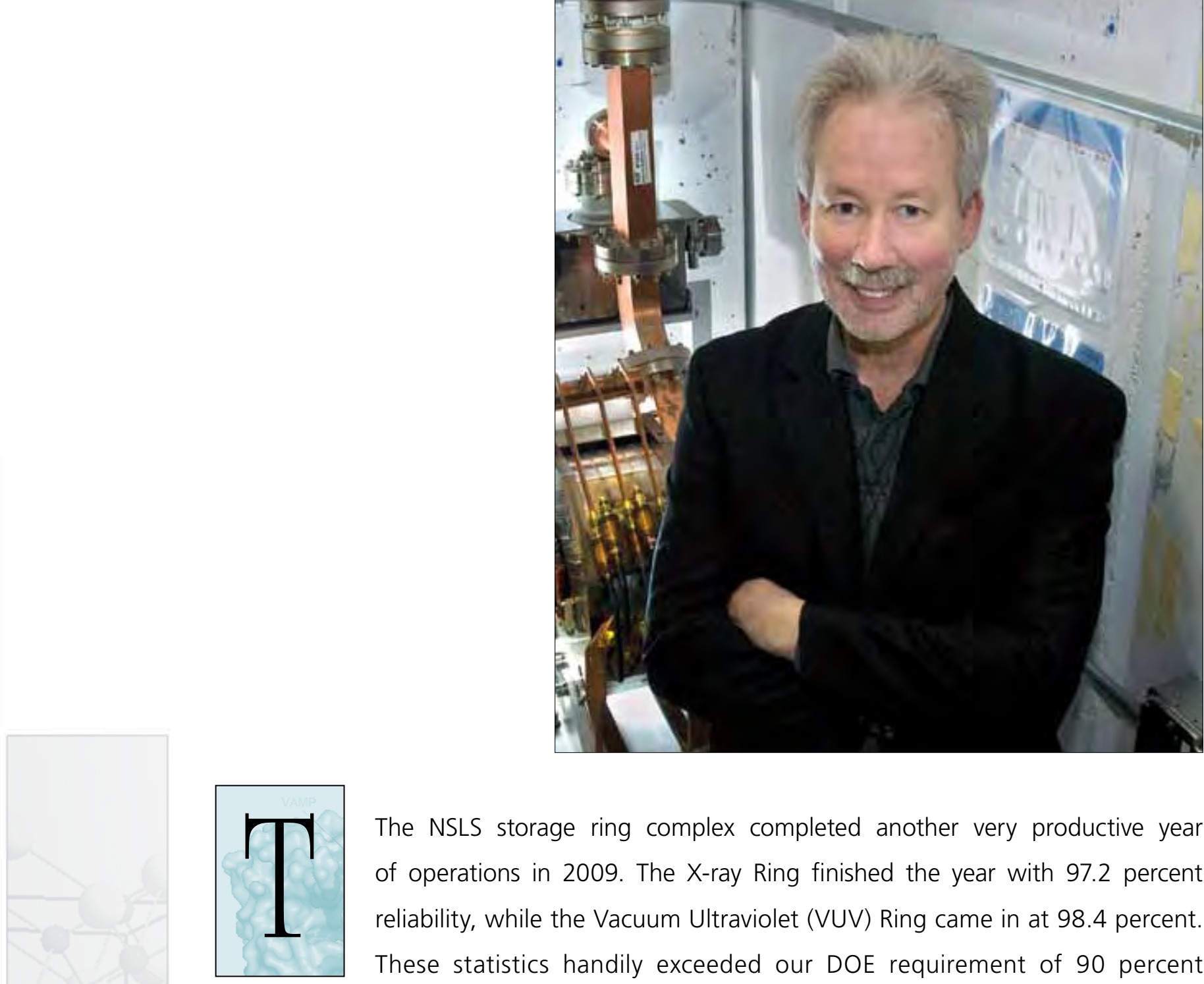

The NSLS storage ring complex completed another very productive year of operations in 2009. The X-ray Ring finished the year with 97.2 percent reliability, while the Vacuum Ultraviolet (VUV) Ring came in at 98.4 percent. These statistics handily exceeded our DOE requirement of 90 percent reliability and even bested the NSLS stretch goal to exceed 95 percent reliability. In addition, reliability in each ring was greater than 95 percent for each month of the year. This exceptional performance can be attributed to planned improvements in some of our critical high- power systems, such as the radiofrequency (RF) system, and enhanced preventive maintenance activities. Mother Nature pitched in a little help by providing a relatively quiet summer season with few power dips.

In the winter 2008 shutdown, the X-Ray RF system 3 was upgraded with a new solid-state $3 \mathrm{~kW}$ amplifier and circulator. Commissioning of this critical component took place in January 2009. The new 3 kW solid-state amplifier replaced an aging tube amplifier. This com- ponent amplifies the $52.88 \mathrm{MHz}$ signal and drives the final $125 \mathrm{~kW}$ stage. Since the electronics in the new amplifier cannot tolerate any reverse power from its load, it is isolated from the $125 \mathrm{~kW}$ amp through a circulator that diverts reflected power to a load resistor.

46 
Following the careful installation of the amplifier, along with extensive modifications to the controls of XRF3, commissioning went very smoothly and we were back to operations on schedule early in 2009.

The $125 \mathrm{~kW}$ amplifier in each of the X-Ray RF systems is tube-based and requires a large power supply to drive the tube. This power supply occupies two racks. The rack that holds the magnetic components of the supply for X-Ray RF system 3 weighs about 3,000 pounds and had to be lowered to the ground from the roof of the building (about 25 feet). This task was carefully planned by our staff along with staff members from the BNL rigging shop, who completed the move flawlessly during the spring shutdown. Although weighing only slightly less, raising the new supply from the ground to the roof was equally challenging

Calendar year 2009 machine activities

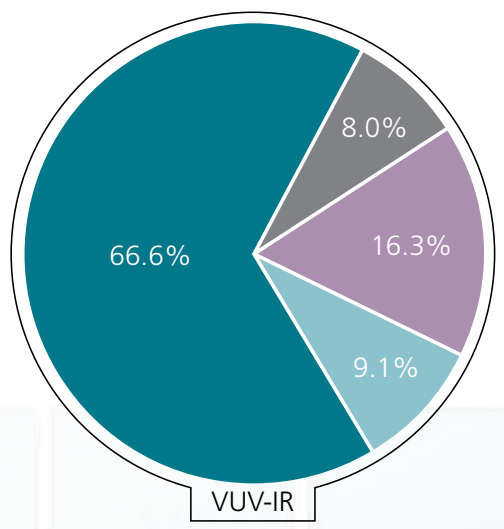

Scheduled Operations

Unscheduled Operations

Maintenance

Other - Studies, Com/Con, Holiday, Injection, Unscheduled downtime, Interlock and went equally well. Commissioning of this device went smoothly at the end of the May shutdown. We expect reliable performance from both of these critical XRF3 devices in the years to come.

\section{Commissioning of}

the new Booster-to-VUV kicker power drivers occurred early in 2009 following their installation during the winter 2008 shutdown. These are the last new drivers scheduled to be installed. Their successful commissioning lays to rest a critical vulnerability that was identified in the 2006 Machine Operations and Reliability Evaluation (MORE). The new supplies use available components and are designed to be modular, promoting
"The NoLs storage ring complex completed another very productive

\section{year of operations in 2009.}

\section{James B. Murphy}

Deputy Chairman for Accelerators and Operations

ease of component replacement in the event of a failure.

January of 2009 saw the final phase of the X9 mini-gap undulator commissioning. We fully tested and commissioned the X9 Active Interlock system, which protects the vacuum pipe from synchrotron light damage by detecting an electron beam orbit outside of a designated window. This crucial system had to be fully operational

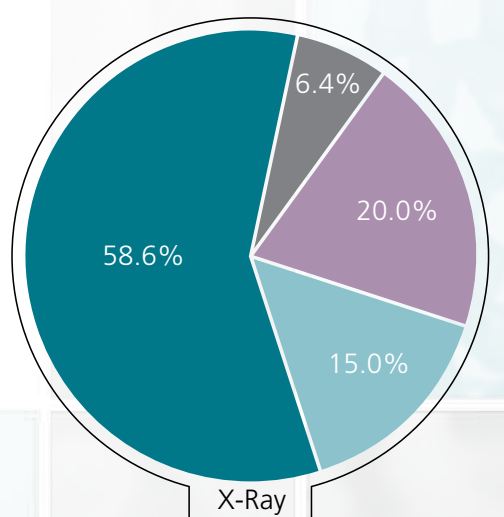

\begin{tabular}{|l|c|c|}
\hline \multicolumn{1}{|c|}{ Other } & VUV/IR & X-Ray \\
\hline Studies & $2.5 \%$ & $5.0 \%$ \\
\hline Com/Con & $2.3 \%$ & $3.8 \%$ \\
\hline Holiday & $2.5 \%$ & $2.5 \%$ \\
\hline Injection & $0.8 \%$ & $1.5 \%$ \\
\hline Unsched. downtime & $1.0 \%$ & $1.6 \%$ \\
\hline Interlock & $0.0 \%$ & $0.6 \%$ \\
\hline
\end{tabular}

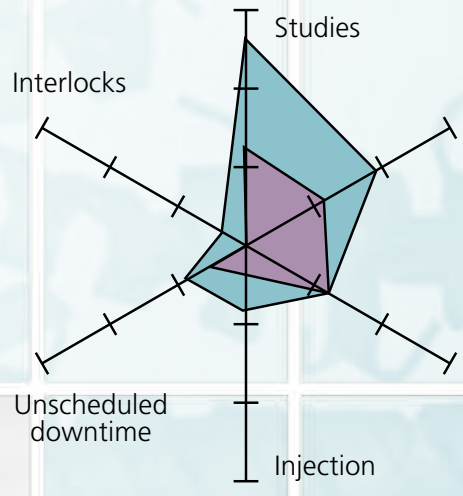

\begin{tabular}{|l|c|c|}
\hline \multicolumn{1}{|c|}{ User Metrics } & VUV/IR & X-Ray \\
\hline Reliability & $98.4 \%$ & $97.2 \%$ \\
\hline Availability & $110.2 \%$ & $107.9 \%$ \\
\hline
\end{tabular}


before the new $\times 9$ beamline can accept the light from the full 300 $\mathrm{mA}$ electron beam. With the Active Interlock system in place and fully functional, the final stages of the beamline commissioning were completed.

Following a vacuum leak at a bellows weld joint in the $\times 27$ front-

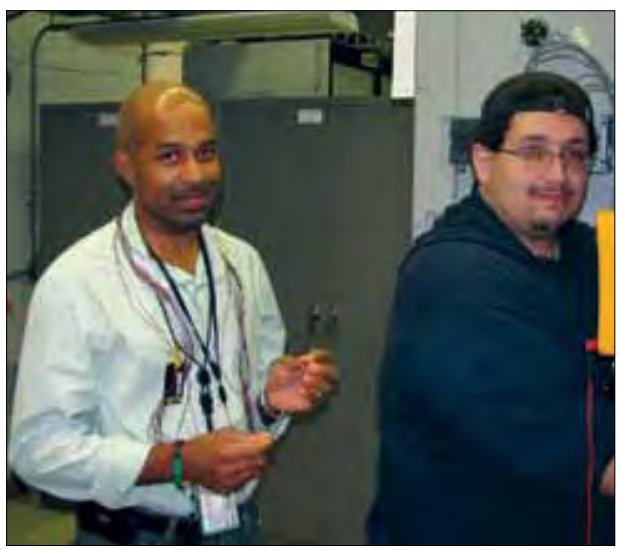

Installing the new booster safety interlock system

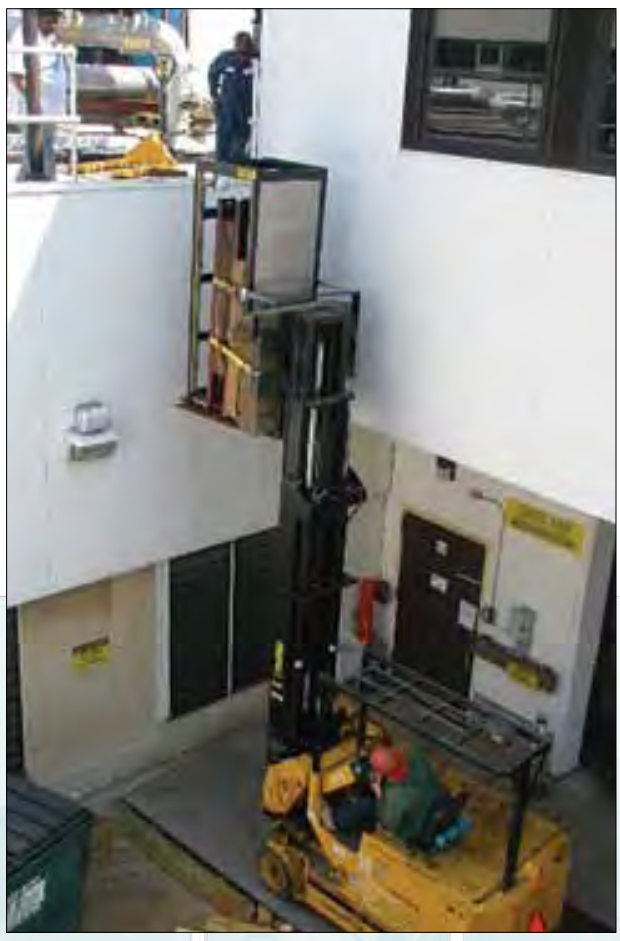

Carefully lowering the old 3,000-pound plate supply end mask early in the year, plans were made to replace the mask with one having additional water cooling and a modified aperture. This mask was successfully installed during the winter shutdown. Diagnostics placed on the mask shows that the new design operated as intended and temperatures on the mask are well below levels that would be of concern.

The issue with high mask temperatures was also discovered on the $X 7$ mask. Plans to replace this mask were made for the winter shutdown, but upon further surveys and studies, a simple horizontal rotation of the mask was attempted to alleviate the problem.
With the full mask replacement task planned for the winter shutdown, we made the rotation during some unscheduled ops at the start of maintenance. The first rotation proved that this plan may work. Following two more rotations, we were satisfied that the temperature at the critical bellows weld dropped significantly and a full replacement would not be necessary.

The installation of the new $\times 17$ hutch occurred in 2009. Work on this new addition to the beamline family began during the spring shutdown with relocation of some electrical panels and wiring and the relocation of a rack of $x$-ray beam-position monitors to the top of the sawtooth to make room for the new hutch and transport enclosure extensions. This work con-
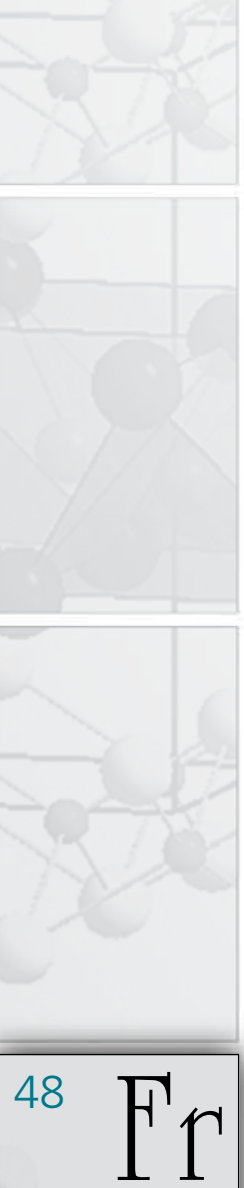

Facility Report

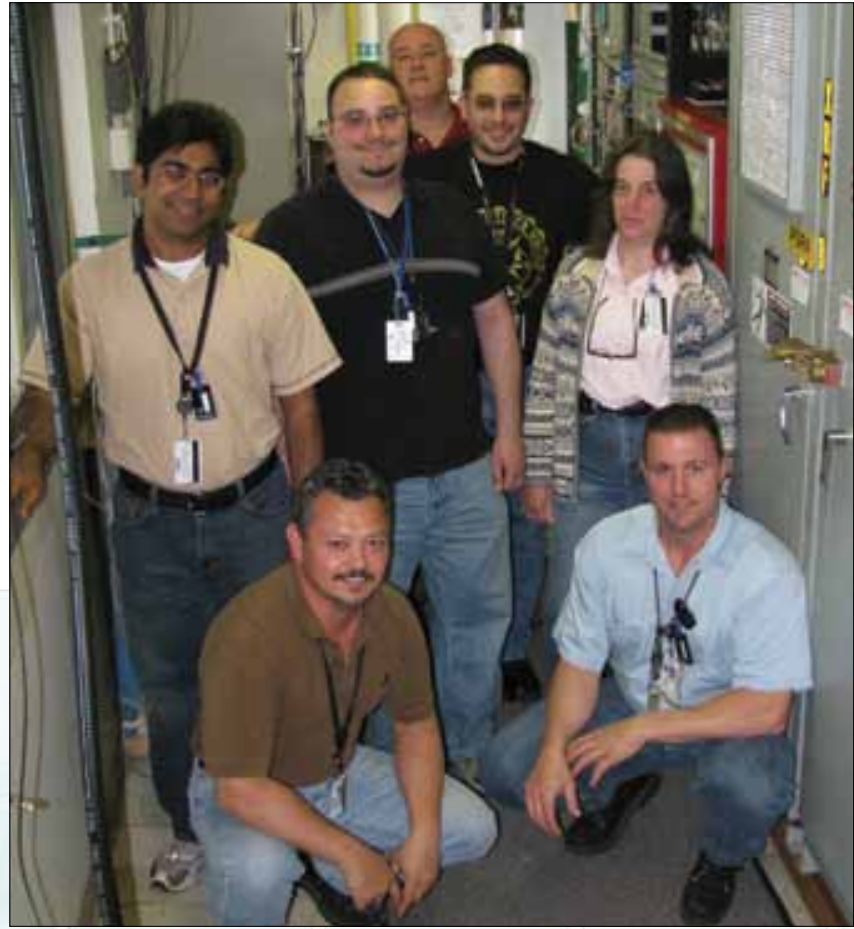

Some of the plate supply team members 
tinued during the winter shutdown when we relocated the $\mathrm{X} 17$ Active Interlock electronics to the top of the sawtooth as well as some rearranging of vacuum equipment. With the area clear, the enclosure vendor came in and installed all of the needed structures according to plan.

An Electrical Equipment Inspection (EEI) deadline to have all electrical items inspected by the end of FY09 was met. In all, about 15,000 items were listed and inspected. Thanks to our team of EEl inspectors, this daunting task was completed by the deadline. Hats off to them for a job well done.

Throughout the year, several projects were completed to improve our operations with equipment upgrades. A new VAT valve controller was designed and commissioned during the spring shutdown. The new system is based on state-of-the-art programmable logic controller (PLC) technology and replaces a 1980s vintage system that simply ran out of available inputs. The new system gives us a user-friendly touch screen interface and is expandable. A new booster safety interlock system was designed and installed during the winter shutdown. Also based on PLC technology, this system uses a special safety PLC that meets the high standards of a personnel safety system.

With an eye toward maintaining robust operations for the full life of

the NSLS, we purchased several pieces of RF and Power Systems equipment to upgrade aging hardware. This included another 3 kW solid-state amplifier and circulator for X-Ray RF system 1, a spare klystron oil tank so that we can keep a hot klystron spare while we test other tubes in our test dock. We also upgraded several $\mathrm{x}$-ray transport line power supplies and a new elliptically polarized wiggler (EPW) feed-forward correction system that is now in development.

\section{X-Ray Ring Injection Improvements with a New Pulsed Trim Magnet}

It has been known for a long time that the X-Ray Ring injection process was not fully optimized. Both the X-Ray and VUV rings share the Booster, which operates at the same current when injecting into either ring. Prior to spring 2009, we were injecting the $\mathrm{X}$-Ray Ring at a rate of 0.2 to $0.4 \mathrm{~mA} / \mathrm{shot}$, when $1.5 \mathrm{maA} / \mathrm{shot}$ should be possible from the Booster. Therefore each re-fill of the X-Ray Ring was taking around 10-20 minutes (the NSLS booster operates at $1.2 \mathrm{~Hz}$ ).
Injection losses were quantified in more detail with new diagnostics, in particular, wall current monitors were instrumented in 2005. From studies of residual activation around the Booster, it was established that a significant amount of Booster beam was lost in a relatively short region around the Boosterto-X-Ray extraction area, where we had limited steering ability. To address this, a compact, C-frame, pulsed trim magnet was designed, built, measured, and installed in the Booster-to-X-Ray extraction line to aid in reducing beam losses during the injection process. The new trim magnet provides about 


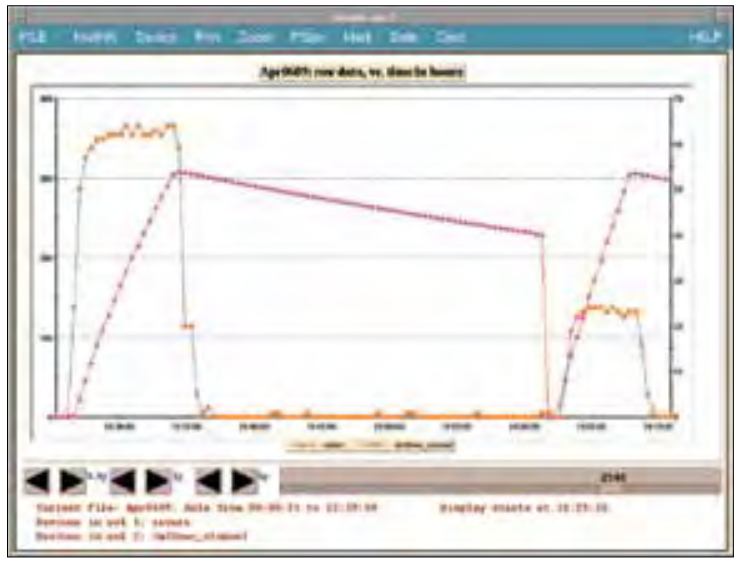

X-Ray Ring beam current in $\mathrm{mA}$ (left axis) and radiation monitor readings (arb. units, right axis) during the $X$-Ray Ring injection with the new trim magnet off and on

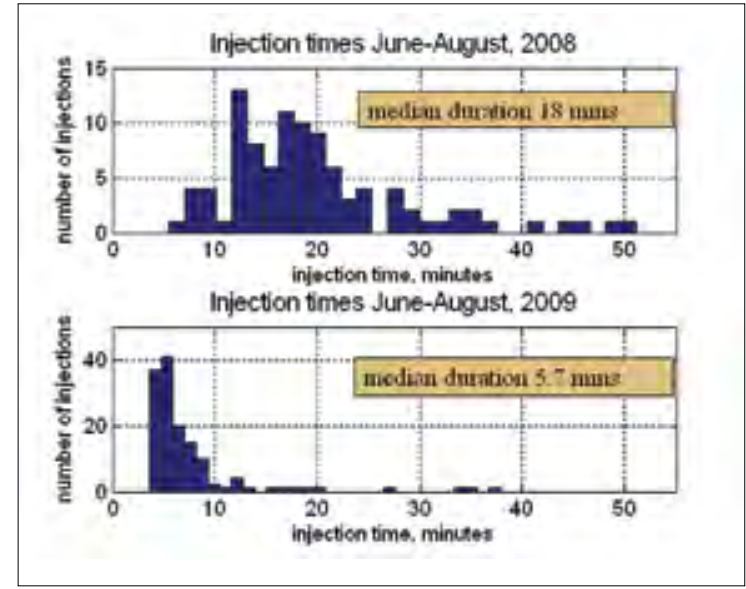

X-Ray Ring injection improvement after pulsed trim magnet installation
1 mrad kick in both horizontal and vertical directions. To allow simple convection air cooling, the trim magnet operates in pulsed mode, powered on only for about $10 \mathrm{~ms}$ during beam extraction.

The effort was spearheaded by Xi Yang of the NSLS Accelerator Physics Group. The magnet was designed by George Rakowsky, built by Mike Lehecka, and measured by Dave Harder of the NSLS Magnet Measurement Group, while the pulsed current supply was implemented by Pete Zuhoski from Electrical Engineering, assisted by electrical technicians Mike Fulkerson and Pete Davila. Installation assistance was provided by the Mechanical Tech Group.

The magnet was installed during the 2008-09 winter shutdown and it has undergone successful commissioning in spring of 2009. The benefits of the new system were quite obvious; in particular, injection rates have gone up and radiation losses in some locations went down. Long- standing records for charge-per-shot have been quickly shattered by a large margin with the new ones now standing at above $1.5 \mathrm{~mA} / \mathrm{shot}$ and (zero to $300 \mathrm{~mA}$ ) X-Ray Ring re-fill in less than 4 minutes. The new trim magnet was put into routine operations right after the spring 2009 machine shutdown, and it has been performing extremely well. With optimized kick settings, average injection rates have tripled, reducing the X-Ray Ring refill time to around 6 minutes. Most importantly, many NSLS users have noticed faster machine re-fills and have commented very favorably on this improvement in machine performance.

\section{Source Development Lab (SDL)}

The Source Development Lab (SDL) at the NSLS is a laser- and linacbased facility dedicated to R\&D on future light source technology and applications. The SDL is the world leader in the development of laserseeded and high gain harmonic generation ( $\mathrm{HGHG)}$ free electron lasers (FELs), which provide fully coherent ultrashort pulse radiation in the IR and VUV regimes. The SDL is an ideal platform to explore new cutting-edge ideas in FEL and highbrightness electron beam R\&D. We have made significant progress in laser-seeded FELs, intense terahertz (THz) application and ultrafast electron diffraction (UED) in 2009. We have successfully demonstrated undulator tapering that will not only improve the laser-seeded FEL efficiency, but also preserve the FEL longitudinal and transverse coherence in the saturation regime.

We continue to explore the unique characteristics of single-cycle intense $\mathrm{THz}$ pulses generated at the NSLS SDL. We demonstrated that an intense single-cycle $\mathrm{THz}$ pulse combined with an electro-optic crystal and a dispersive element can act as a time lens for ultrafast laser pulses. We have compressed an unchirped 165 femtosecond ( $\mathrm{fs}$ ) laser pulse down to about $45 \mathrm{fs}$. We 
have applied the intense $\mathrm{THz}$ pulse for materials studies, successfully observing the threshold for a single $\mathrm{THz}$ pulse to destroy the superconducting state in a thin film superconductor ( $\mathrm{NbN})$.

UED is a promising technique that allows us to observe a molecular structure transition on the time scale less than $100 \mathrm{fs}$. UED has been continuously developed as a complementary technology to an x-ray FEL (XFEL) for probing ultrafast events of ultra-small objects. UED has some advantages over an XFEL in terms of its compactness, the size of its interaction cross-section (10 million times larger than an $X F E L$ ), because it's less damaging to the samples. Our goal is to design, optimize, and experimentally demonstrate a single-shot MeV UED system with an atomic-scale spatial resolution and a time resolution on the order of $100 \mathrm{fs}$. The SDL UED system will be a unique tool for the ultrafast science and beam physics at BNL.

The design of the proposed UED system has been optimized by tracking electrons from the start (photocathode RF gun) to the end (detector), using both a particle tracking code PARMELA and a custom MATLAB code that calculates a scattering intensity distribution by an aluminum sample placed between the photocathode RF gun and the UED detector. We have completed the detailed engineering design of the MeV UED, and all major components are being installed at the SDL.

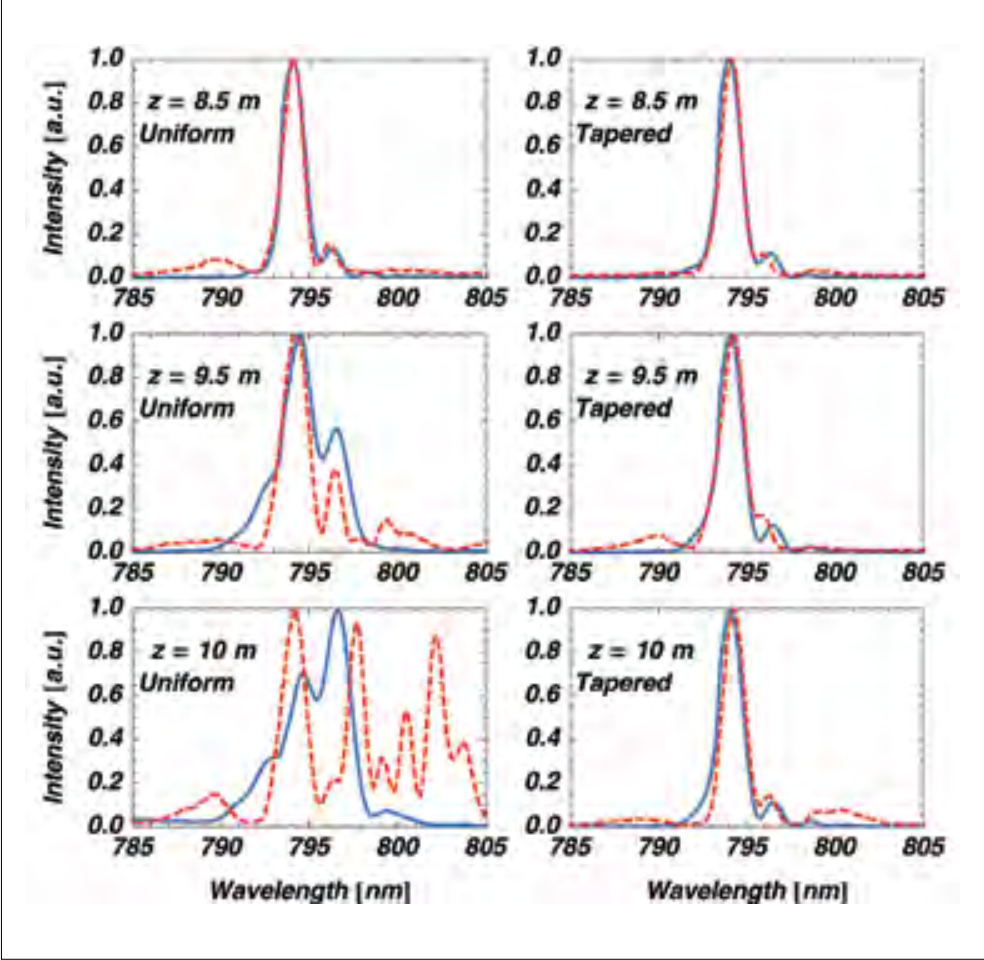

The FEL spectrums at the three different undulator positions for uniform and tapered undulators. The red dashed line and blue solid line represent experimental data and simulation, respectively.

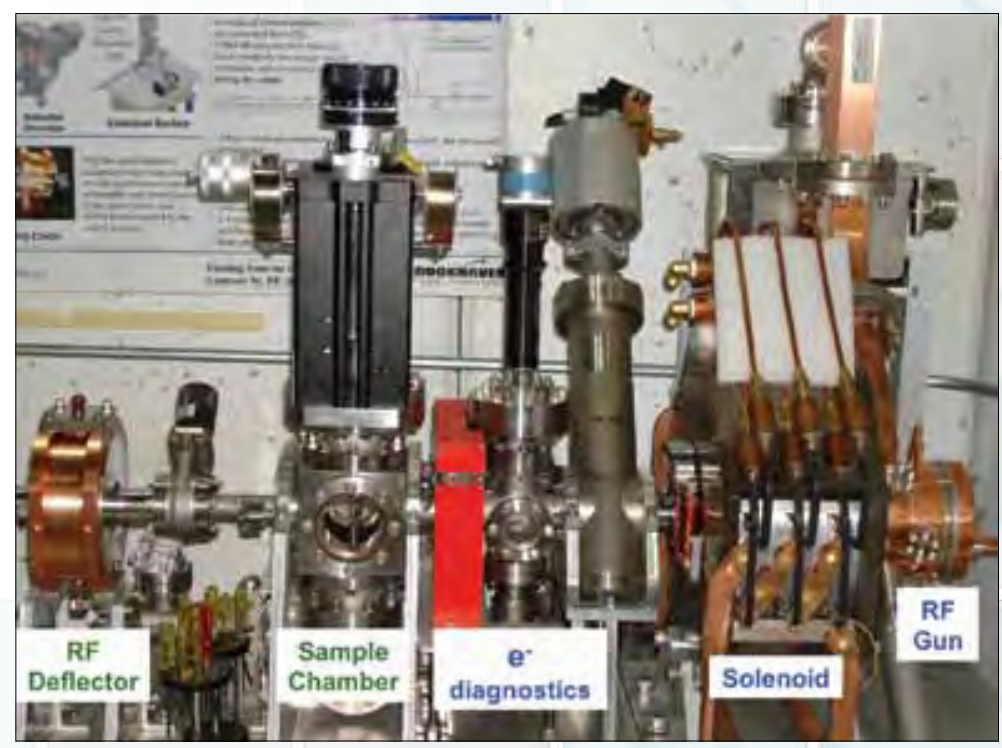

The MeV UED system installed at the NSLS SDL 
nal (PNAS). X9 came into operation using water-cooling of the monochromator's first crystal, resulting in restrictions on the accessible ranges of delivered photon energy (in order to avoid excessive thermal loads on the crystal). To mitigate this, a cryogenic cooling system for cooling the first crystal has been purchased, and its delivery is expected by the end of 2010.

An upgrade of beamline X18A was completed and began to serve users employing diffraction and extended $x$-ray absorption fine structure (EXAFS). Measurements will be facilitated in the future through further upgrades that are underway to permit quick EXAFS (QEXAFS) to be carried out and through a new area detector that is being acquired with American Recovery and Reinvestment Act (ARRA) funds. Also, a HEPA-filtered exhaust system, which will permit nanoscience experiments to be carried out, was implemented in 2009.

An infrared focal plane array (FPA) microspectrometer system designed to work with a large-horizontalcollection-angle infrared beamline, which had been tested and optimized earlier at beamline U4IR, was installed at beamline U10B in 2009 and began to serve users there. This new system was funded by the National Institutes of Health.

Beamline projects that continued in 2009 included the construction of a new endstation for soft $x$-ray scattering at beamline $\mathrm{X} 13 \mathrm{~A}$, and the construction of a new beamline and endstation for pair distribution function measurements at X17A.

Acquisition

of a trans-

mission $x$-ray

microscope

(TXM) was

made pos-

sible through

"In 2O९9, we successfully delivered new beamline ROD projects and expertly supported existing ring and beamline mechanical systems. We have made progress on our first detector system using 3-D integration technology."

\section{Steven Hulbert}

Experimental Systems Division Head

ARRA funds,

and a suitable instrument was speci-

fied and ordered from Xradia by the end of 2009. Simultaneously, the $\mathrm{X} 8 \mathrm{C}$ beamline began to be evaluated as the potential host beamline for this instrument, which is expected to arrive at the end of 2010. When implemented, the TXM will be used for in-situ imaging (including tomographic reconstruction) of materials for energy storage, biofuels, and microelectronics.

Also in 2009, design and acquisition of hardware to permit a remote access capability for diffraction and reflectivity experiments at beamline X20B was undertaken. This capability will be implemented during 2010.

NSLS beamline staff continued to make significant contributions to the design and development of NSLS-II Project beamlines in 2009, albeit at a lower total effort than in 2008 owing to the recruitment by the NSLS-II project of dedicated staff for these beamlines.

For example, with a view to present and future needs to quantify precisely the coherence of highbrightness $\mathrm{x}$-ray beams, NSLS scientists have nano-fabricated a prism array from silicon and carried out a virtual Young's double slit experiment using pairs of such prisms at the Advanced Photon

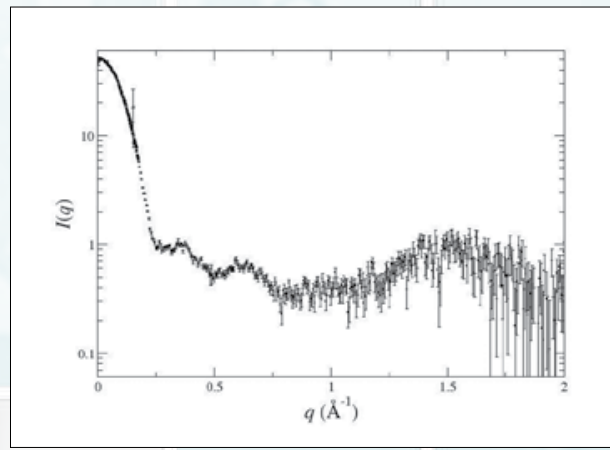

The extended SAXSMAXS range of q coverage in $\mathrm{X} 9$ experiments. The figure shows transmission SAXS/WAXS data from a sample of $3.8 \mathrm{mg} /$ $\mathrm{ml}$ lysozyme solution; the displayed data consist of sets merged from two different detectors (the SAXS detector spans from $q=0.004 \AA^{-1}$ to $q=0.2$ $\AA^{-1}$ and the WAXS detector spans from $q=0.15 \AA^{-1}$ to $q=2.0 \AA^{-1}$ ) 

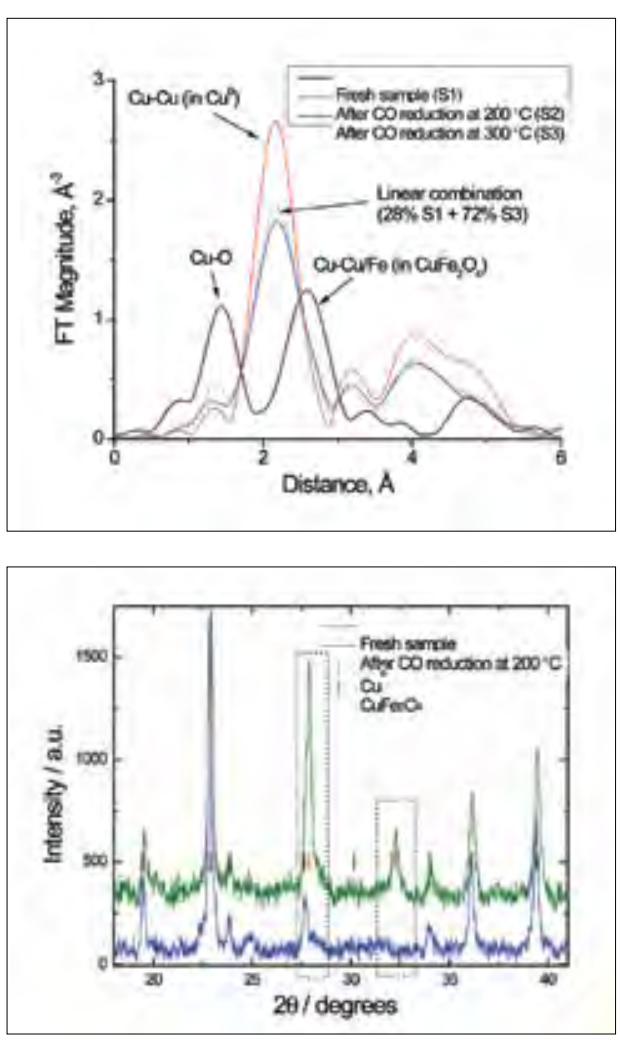

In a demonstration experiment at beamline $\mathrm{X} 18 \mathrm{~A}$, chemical and structural changes accompanying high-temperature reduction of $\mathrm{CuFe}_{2} \mathrm{O}_{4}$ were measured using EXAFS and powder diffraction, respectively, data for which are shown in these figures.

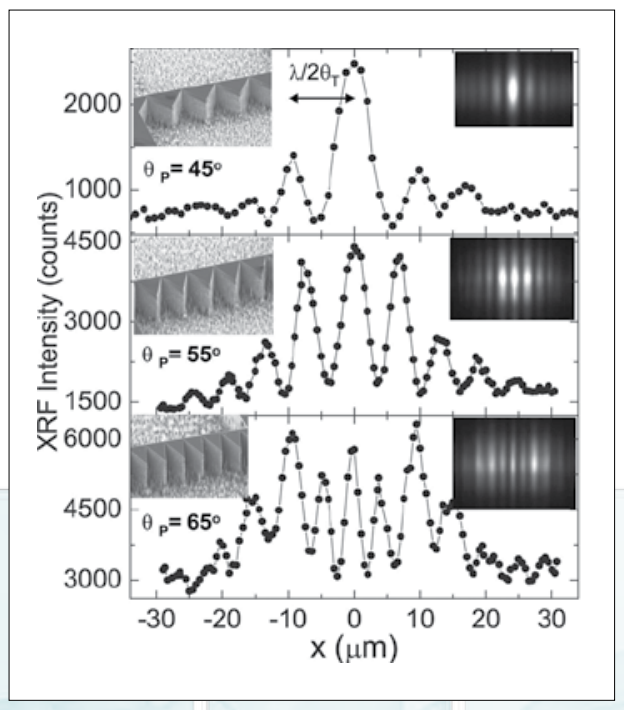

Interference patterns measured for different prism angles of the nano-fabricated silicon prism array, demonstrating their use in a virtual Young's double slit experiment
Source (APS). With this device, interference patterns were measured, and from the visibility of the patterns' fringes, the horizontal and vertical coherence lengths of the $x$-ray beam could be determined and their expected anisotropy could be confirmed.

\section{Detectors}

In 2009, the NSLS Detector Development Group was fully occupied by the fast-imaging detector project for the Linac Coherent Light Source (LCLS), and completing the full-size version (384 pixels) of the Maia rapid spectroscopy system. Good progress has been made, but neither is yet ready for deployment. We expect them both to be completed by midsummer 2010.

We suffered a sad loss of a valuable colleague from Brookhaven's Instrumentation Division. Pavel Rehak was the inventor of the silicon drift detector, which the synchrotron community uses extensively, and was also the inventor of the $\mathrm{x}$-ray active matrix pixel sensors (XAMPS) imaging detector concept, which is the basis of our LCLS devel- opments. He passed away following complications from a stroke. He was a source of inspiration to us all in the detector community and a fount of information on many topics, and is hugely missed.

We have also made progress (with the help of our collaborators from Fermilab and ASH University, Krakow) on our first detector system using 3-D integration technology. This first detector will be designed to bring the enhanced on-pixel processing power provided by 3-D integration to bear on the $x$-ray photon correlation spectroscopy (XPCS) technique. A twolayer application-specific integrated circuit (ASIC) has been designed and is currently being fabricated, providing analog signal conditioning in one layer and sparsified time-stamped readout in the other. This integrated circuit will then be bonded to sensors fabricated at BNL to form a prototype detector. The detector will provide 10 microseconds time resolution and contain a 64-by-64 array of pixels, each 80 microns square. If this prototype is successful, we will then make a second version with resolution in the 10s of nanoseconds. Our dream is to provide on-chip time autocorrelation, but that is for the future. Although XPCS is not a technique much practiced at the NSLS, it will be the main focus of one of the NSLS-II Project beamlines.

Another idea that we are pursuing for the application of 3-D circuit fabrication is the realization of energy-resolving pixel detectors. This is a challenging project, since it requires every detected photon to be 
digitized to high precision, as well as the provision of in-pixel memory to hold the histograms acquired. We are approaching this project in stages, first to develop the analog front end with low noise, but also very low power (since even a microwatt per pixel totals to a Watt when you pack a million of them together!). Then we

need to make a digitizer capable of converting the analog pulses into histogram entries, which must also not consume too much power. Lastly, we need to address the memory needs of such a system. There are many other technical challenges to this project, and it will take some time to bring it to fruition. It is, however, the mostrequested device in any survey of detector needs that we have seen.

\section{Mechanical Systems}

Several major mechanical system activities were undertaken by the Mechanical Systems Section in 2009, contributing significantly to the NSLS by sustaining machine operations and advancing research capabilities. This section's engineers, designers, and technicians also continued developing and implementing preventative maintenance programs and performing emergency repairs on many accelerator and storage ring systems and components.
The major NSLS projects for which the Mechanical Systems Section provided significant support during 2009 include:

\section{$X$-Ray Ring}

It has been known since about 2007 that several $x$-ray beamline front end components are heated well above room temperature by bend magnet radiation that impinges on uncooled surfaces of these components. In December 2008, a vacuum leak developed near one of these overheated areas on the $X 27$ front end mask chamber, requiring remedial action. The mechanical engineering and design groups conducted a thorough engineering analysis via beam tracing and concluded that the cause of this overheating is bending magnet radiation from non-ideal electron orbit positions. A newly designed water-cooled aperture to block this unwanted radiated power was fabricated and installed immediately downstream of the dipole chamber exit flanges and was successful in reducing the $\mathrm{X} 27$ front
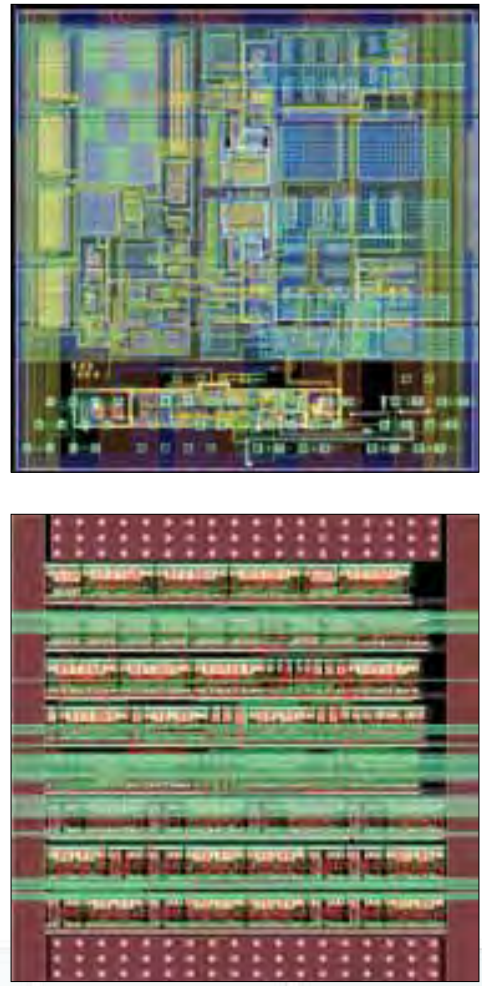

The detailed layout of the circuitry in each pixel on the two application specific integrated circuit (ASIC) layers. The analog circuits are in the layer on the top and the digital hit-finder and sparse readout logic is in the layer on the bottom. These two chips are bonded together to make a 3-D chip. This in turn will be bonded to a third sensor layer.

end temperatures to acceptable values. The $X 7$ front end temperatures, as determined by a remote temperature monitoring system, were even higher than at $X 27$. A similar fix was planned for the $X 7$ front end, to be installed during the December 2009 shutdown. Fortunately, a much less invasive solution consisting of a simple rotation of the $X 7$ mask chamber, was successful. The rotation was able to move any uncooled surfaces inside the $X 7$ mask chamber out of the direct beam path. This obviated the need to vent, pump, and bake the entire $X$ Ray Ring superperiod that includes 
the $X 7$ front end. The remaining front ends that are potentially subject to this heating problem $(X 3, X 11, X 15$, $X 19$, and $X 23$ ) have not shown unacceptably high chamber temperatures, but are being monitored in case this changes.

In addition, the mechanical section addressed a stability problem plaguing one of the radio frequency (RF) systems. The RF cavities' resonant frequencies are maintained via several mechanisms, including coarse control by the water cooling/heating systems and more finely by mechanically driven loop tuners. The ring mechanical group fine-tuned the control valves of the XRF1 system and resolved the mechanical binding problem with its drive shaft, thereby eliminating the temperature jitter in this RF system and the resulting excessive wear on the tuner from overuse in attempting to compensate for this jitter.

\section{VUV Ring}

During the December 2009 maintenance period, three VUV front ends had to be bled up. Two of these ventings were required to solve vacuum problems that developed in the prior running period: (1) a vacuum leak in the actuating bellows of the U4 mask and (2) a malfunctioning front end valve at U10. The third chamber requiring venting was the U12IR mirror chamber, which is connected to the VUV ring chamber, for a planned recoating of the first two (of three) mirrors in the U12IR far-IR spectroscopy beamline. Despite the workload placed upon the NSLS vacuum group by these three concurrent jobs, all were completed successfully.

\section{Transport lines}

In fall 2009, the Booster to X-Ray transport line bending magnet (BXB3HV) coil experienced a water-cooling interruption while still powered, owing to a relay failure in the protection system circuit that resulted in severe damage to the dipole coil and (high resistance) conductivity to ground. During the December 2009 maintenance period, this coil was successfully replaced with a new one to assure continued reliable operation. The NSLS mechanical and electrical groups worked hand in hand to accomplish this delicate repair on schedule.

\section{Utilities}

Utility group responsibilities include maintaining all four machine cooling systems as well as dedicated cooling systems for several insertion devices and seven RF systems, maintaining instrument air and gaseous nitrogen supplies for the machines, beamlines, and endstations, maintaining comfort air conditioning and heating for all of the NSLS facilities, and servicing the Source Development Laboratory's needs. The unscheduled machine downtime in 2009 was remarkably low due to implementation of a vigorous preventive maintenance program and regular upgrading of components.

\section{Vacuum}

The vacuum group embarked on an ambitious plan to unify all of the widespread vacuum readings in a unified global vacuum monitoring system, viewable on-line at http:// vacmon.nsls.bnl.gov/vacmon/NSLSmon.html and on local TV channel 14. Accomplishing this goal required coordinated efforts from almost all NSLS technical groups. The comprehensive, graphically

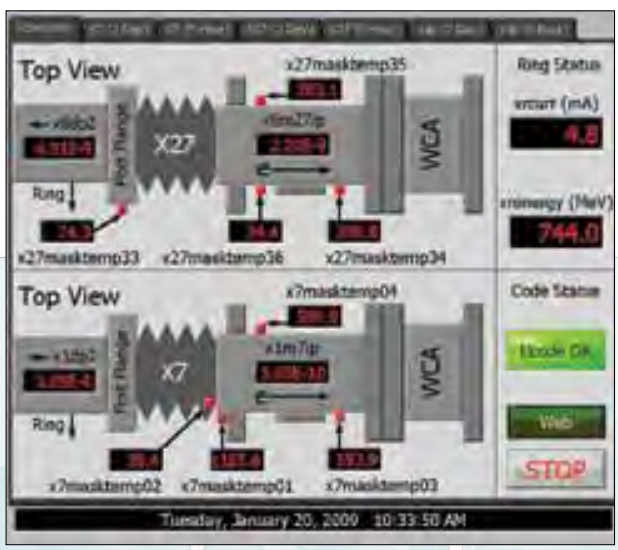

Web page readout of a typical remote temperature-monitoring system

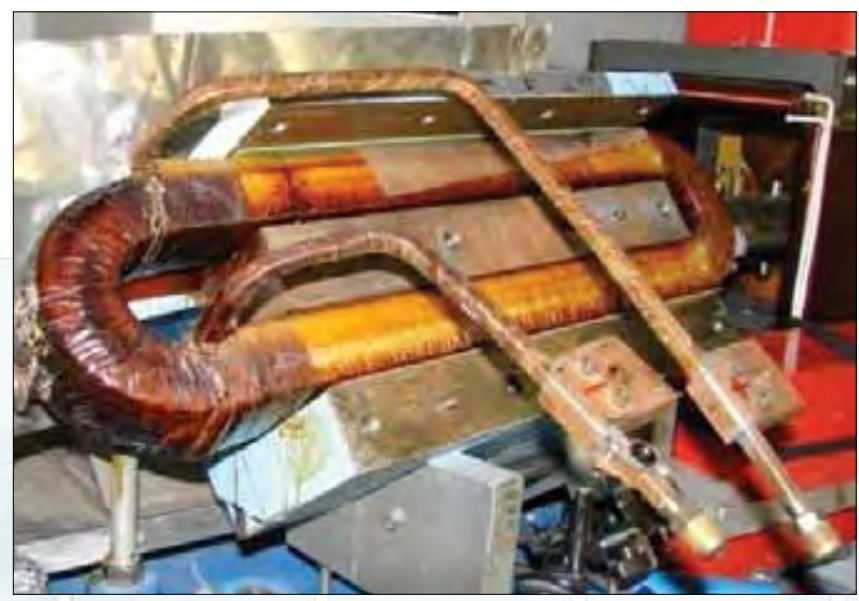

Damaged BXB3HV coil 


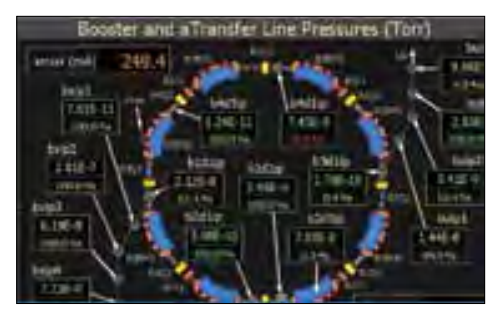

Booster vacuum system

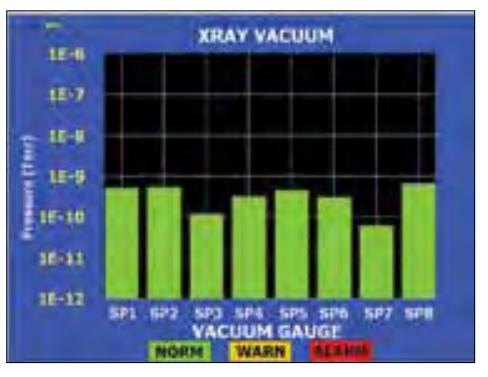

X-Ray vacuum readout

depicted, color-coded layout will help the vacuum group to pinpoint abnormal pressure readings for proactive troubleshooting. In 2010, we will add real-time residual gas analyzer scanning to this global vacuum-monitoring system.

\section{Beamlines}

The engineering and design work for the addition of a new beamline at $X 17 A$ was a large undertaking for the Mechanical Systems Section in 2009. Adding the X17A beamline to the existing X17B and X17C beamline suite required expansion of the small and large X17 transport enclosures on the $\mathrm{X} 16$ side and the addition of a new X17A experimental endstation enclosure (EESE).

Engineering and design of a singlebounce sagittally bent Laue monochromator (511 silicon reflection, Zhong optical design) to diffract and focus a beam of $\sim 70 \mathrm{keV}$ photons into the new X17A beamline was completed in 2009. A novel monochro-

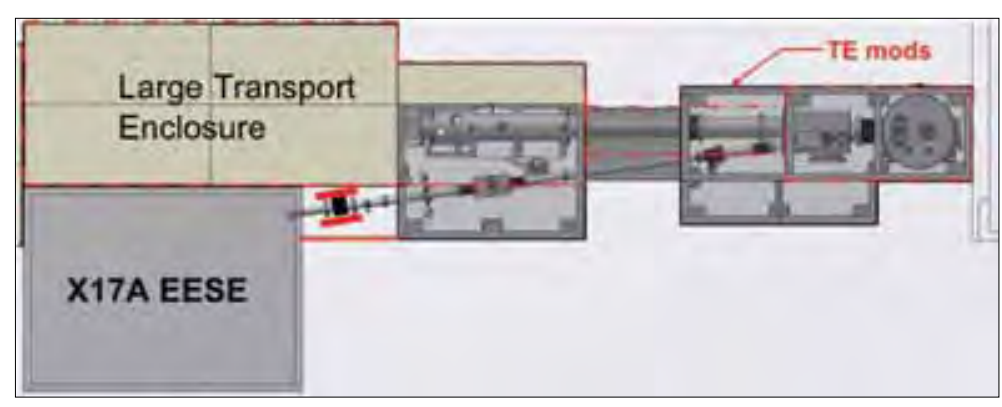

Plan view of $\mathrm{X} 17 \mathrm{~A}$ hutch installation and $\mathrm{X} 17$ transport enclosure modifications

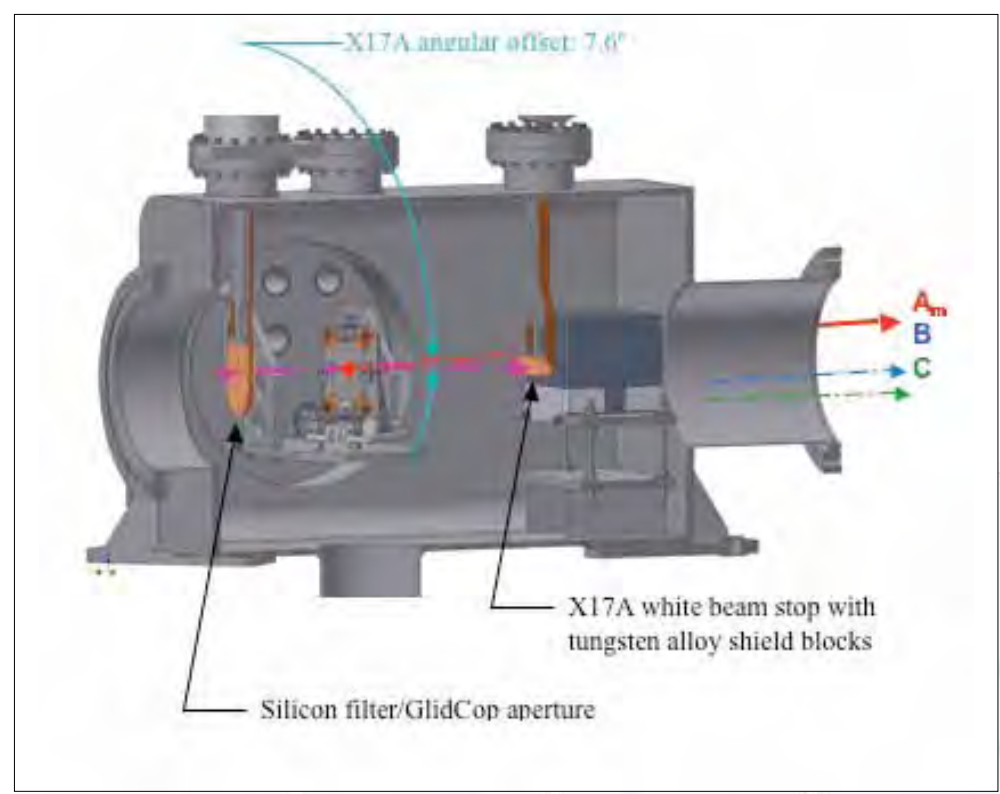

Cutaway elevation view of the X17A monochromator

mator design is being undertaken for this beamline that will utilize two-axis bending of the silicon crystal to simultaneously focus high-energy photons in two orthogonal planes. In order to prove out this novel approach, a test fixture design was designed and fabricated to determine the limits of two-axis bending of the silicon crystal. A patent disclosure was submitted for this novel two-axis focusing monochromator design.

The X17A monochromator includes a water-cooled silicon filter with nine discrete apertures upstream of the silicon crystal, a water-cooled white beamstop, and a tungsten alloy collimator to assure the safety of beamline workers from high-energy $x$-rays. Thermal stress analyses were undertaken to verify that the monochromator would perform appropriately, as well as analyses to determine compliance of its vacuum chamber design with DOE pressure vessel rules.

Also of note during 2009 was the installation of a new HEPA-filtered external exhaust system for beamlines $\mathrm{X} 18 \mathrm{~A}, \mathrm{X18B}$, and X19A for nanoscience research work and beamlines X21 and X22B for endstation equipment requiring external venting. 
our peer-reviewed, web-based proposal system. The proposal is rated based on various scientific criteria, and can remain active for up to six cycles of operations (or about two years). In fiscal year 2009, more than 1,100 requests for beam time were submitted, with nearly half of those requests on new proposals. Beam time is given without charge, as long as the research results are published in open literature. Work that is proprietary in nature is charged on a fullcost recovery basis according to U.S. Department of Energy guidelines.

During fiscal year 2009, hundreds of visitors attended the many workshops, short courses, seminars, reviews, and tours offered at the NSLS. In addition to the annual Joint NSLS/ Center for Functional Nanomaterials (CFN) Workshop in May, 10 other workshops were held, as well as 212 seminars (almost double that of last year!) and 93 tours of the facility.

We instituted some new things this year. In particular, we established an automated notification to request responses to a short survey after a user completes an experimental run. This has helped us increase our response rate tremendously, but more important, it has given us much more feedback than ever before. It has been a challenge to keep up, but we have been able to implement changes to the user experience because of the great suggestions.

In fiscal year 2009, more than 400 different institutions sent over 2,200 users to the NSLS to conduct their research. Of this number, nearly 700 were new users. The majority of us- ers (72\%) come from academic institutions, and a steady 7 percent of users were from industry.

The users who visited in 2009 were characterized by their field of research in different ways. The greatest number works in the life sciences field, with materials sciences studies the second largest group. Considering the number of days spent on experiments - based on running times gathered from experimental Safety Approval Forms, which are required for every experiment - materials sciences studies make up the greatest portion of beam time used. nearly 20 percent were published in premier journals. A publication is considered premier if the journal has an impact factor of 6 or greater (from Journal Citation Report 2005, Thomson Institute for Scientific Information). The table shown on page 60 summarizes publications during the past year. The first column in the table lists the number of publications reported to the NSLS during the 2009 fiscal year (October 1, 2008 through September 30, 2009) and published between 2006 and 2009. Although some of these publications were published earlier than FY 2009, they were not reported to the NSLS
About half of our users are U.S. citizens, and almost 30 percent are women. Nearly one-third of our users are from within New York State, and another third come from locations nearby in the northeastern states.

In 2009, nearly 40 percent of the researchers working at the NSLS were students in undergraduate or graduate studies. About 23 percent of the users were post-doctoral researchers, with faculty members, professional staff, or research scientists making up the balance.

Remaining steady for a few years now, NSLS users and staff published 957 articles in FY 2009. Of these,
"Thanks to a new automated notification system, our end-of-run survey response rate has increased tremendously. It has been a challenge to keep up, but we have been able to implement changes to the user experience because of the great suggestions.

\section{Kathleen Nasta \\ Manager, Information, Outreach, \& User Administration}

until this fiscal year. Thus, they have not been counted in prior years' reports. The second column in the table lists the number of papers published in the 2009 calendar year and reported to the NSLS as of February 28,2010 . These numbers are slightly lower than the fiscal year values because they contain only publications from 2009, and it often takes many months or years to account for user and staff publications. 


\begin{tabular}{|c|c|c|}
\hline & X-Ray & VUV-IR \\
\hline Energy & $2.800 \mathrm{GeV}$ & $0.808 \mathrm{GeV}$ \\
\hline Maximum Current & $300 \mathrm{~mA}$ & $1.0 \mathrm{~A}$ \\
\hline $\begin{array}{r}\text { Photon Critical Wavelength } \\
\text { (Energy) for Dipole }\end{array}$ & $1.75 \AA(7.1 \mathrm{keV})$ & $20.3 \AA(612 \mathrm{eV})$ \\
\hline $\begin{array}{l}\text { Photon Critical Wavelength } \\
\text { (Energy) for X17 wiggler at } 4.2 T\end{array}$ & $0.57 \AA(22 \mathrm{keV})$ & \\
\hline Horizontal Emittance & $62 \mathrm{~nm}-\mathrm{rad}$ & $160 \mathrm{~nm}-\mathrm{rad}$ \\
\hline Vertical Emittance & $0.34 \mathrm{~nm}-\mathrm{rad}$ & $\geq 0.35 \mathrm{~nm}-\mathrm{rad}$ (4 nm-rad in normal ops.) \\
\hline Electron Orbital Period & 567.2 nanoseconds & 170.2 nanoseconds \\
\hline Number of RF Buckets & 30 & 9 \\
\hline Typical Bunch Mode & 30 & 7 \\
\hline Natural RMS Energy Spread & $9.2 \times 10^{-4}$ & $5.0 \times 10^{-4}\left(\mathrm{I}_{\mathrm{b}}<20 \mathrm{~mA}\right)$ \\
\hline RMS Bunch Length & $44 \mathrm{~mm}$ & $5 \mathrm{~cm}\left(\mathrm{I}_{\mathrm{b}}<20 \mathrm{~mA}\right)$ \\
\hline
\end{tabular}

\section{Publications}

\begin{tabular}{l|c|c|} 
& Reported in FY09* & Published in CY09** \\
\hline Journals, peer-reviewed, premier & 176 & 158 \\
Journals, other peer-reviewed & 576 & 500 \\
Journals, non peer-reviewed & 32 & 25 \\
Books / Chapters in Books & 13 & 7 \\
Published Conference Proceedings & 91 & 49 \\
Reports: Technical, Formal, Informal & 6 & 3 \\
Theses / Dissertations & 52 & 19 \\
Patents & 11 & 3 \\
\hline Total Publications & 957 & 764 \\
\hline NSLS VUV-IR User Publications & & 73 \\
NSLS X-Ray User Publications & 91 & 596 \\
NSLS Staff Publications & 742 & 95 \\
\hline Total Publications & 124 & 764
\end{tabular}

* Publications reported to the NSLS from Oct. 1, 2008 - Sept. 30, 2009 and published between 2006 - 2009.

** Publications published in 2009 as reported to the NSLS by Feb. 28, 2010.

\section{0

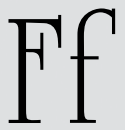

Facility Facts and Figures 
Users by Field of Research

Fiscal Year 2009

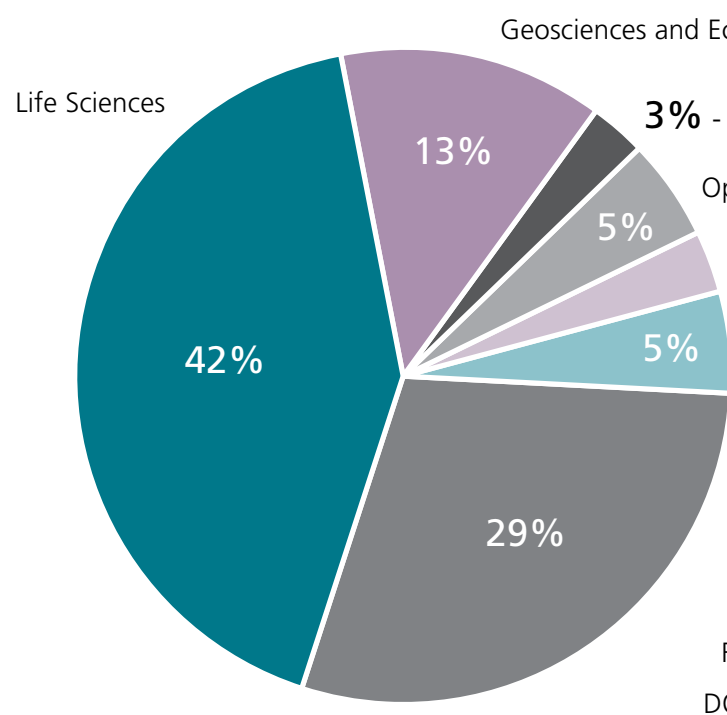

Optical/Nuclear/General Physics

3\% - Unknown

Chemical Sciences

Materials Sciences

Users by Affiliation

Other Labs and Affiliations

Fiscal Year 2009 Industry/Corporate

Federal Agencies (non-DOE) - 2\%

DOE Employees (non-BNL) - 2\%

Geographical User Distribution

Fiscal Year 2009

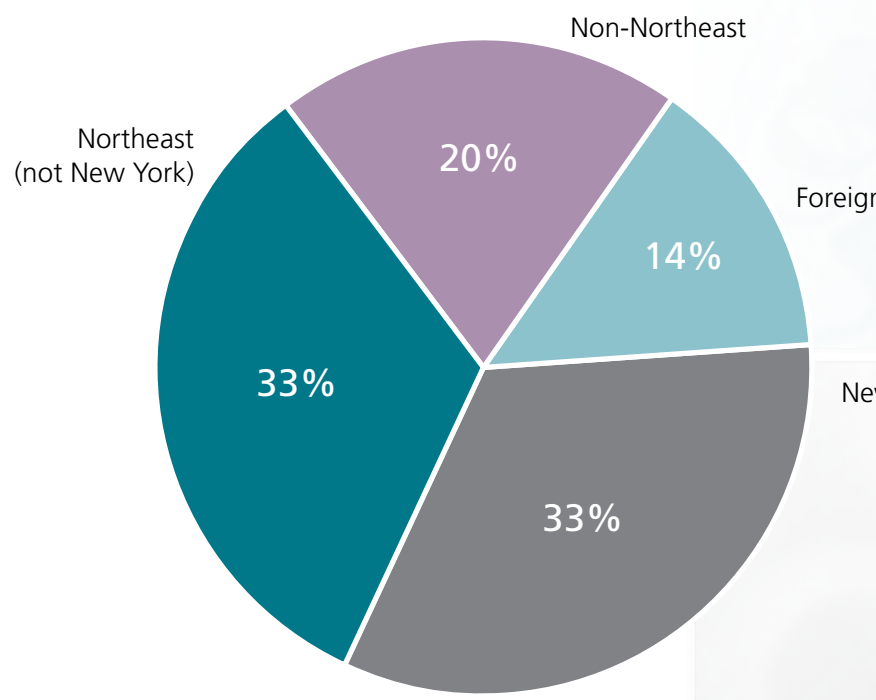

Optical/Nuclear/General Physics

Applied Sciences and Engineering

Academic

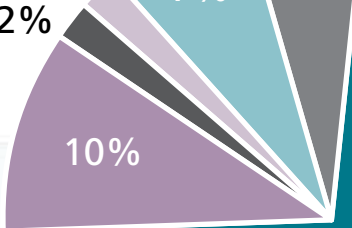

New York Only

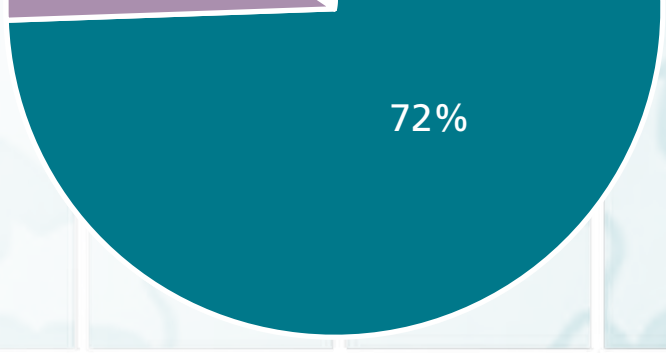

\section{Beamtime Used*}

Fiscal Year 2009

Life Sciences

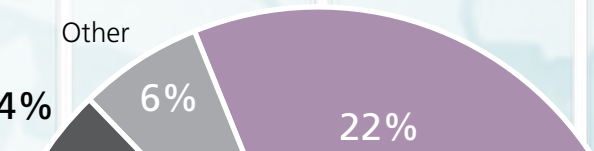

*Based on running times from Safety Approval Forms.
61

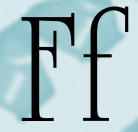

Facility Facts and Figures 


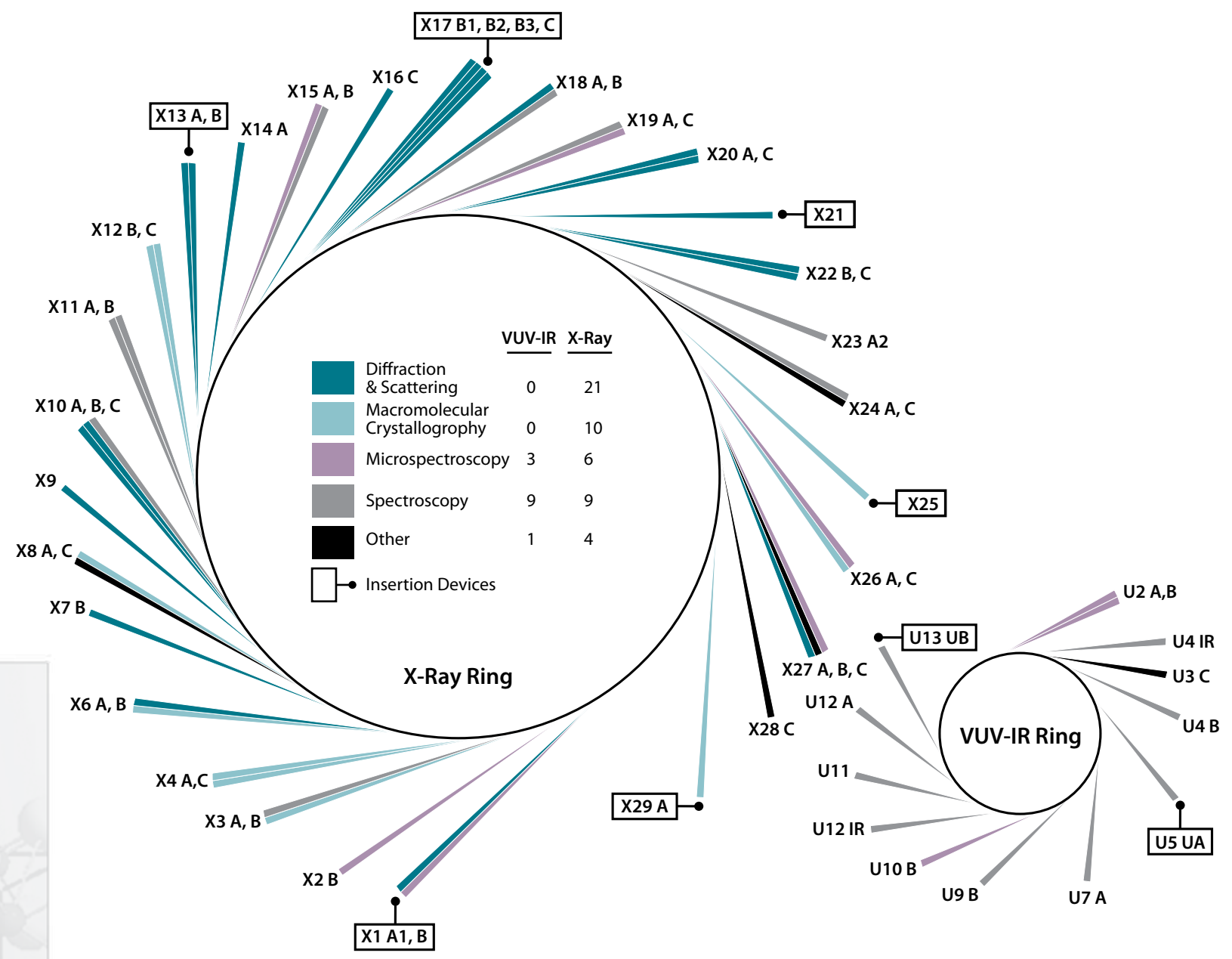

Beamline Status

Beamline Guide Abbreviations

ARPES Photoelectron Spectroscopy, Angle-Resolved

PRT Participating Research Team

DAFS X-Ray Diffraction Anomalous Fine Structure

DEI Diffraction-Enhanced Imaging

EXAFS X-Ray Absorption Spectroscopy, Extended Fine Structure

SAXS Small Angle X-Ray Scattering

STXM Scanning Transmission X-Ray Microscopy

FB Facility Beamline

HARMST High Aspect Ratio Microsystems Technology

IRMS Infrared Microspectroscopy

MAD Multi-Wavelength Anomalous Dispersion

MCD Magnetic Circular Dichroism

NEXAFS Near Edge X-Ray Absorption Spectroscopy

PEEM Photo Emission Electron Microscopy

UPS UV Photoelectron Spectroscopy

UV-CD Ultraviolet Circular Dichroism

WAXD Wide-Angle X-Ray Diffraction

WAXS Wide-Angle $X$-Ray Scattering

XAS X-Ray Absorption Spectroscopy

XPS X-Ray Photoelectron Spectroscopy

XRD X-Ray Diffraction 


\begin{tabular}{|c|c|c|c|c|c|}
\hline Beamline & Source & Type of Research & Energy Range & Type & Organization \\
\hline \multicolumn{6}{|c|}{ VUV-IR Beamlines } \\
\hline U2A & Bend & $\begin{array}{l}\text { IRMS } \\
\text { High pressure research } \\
\text { IR spectroscopy }\end{array}$ & $30-10000 \mathrm{~cm}^{-1}$ & FB & $\begin{array}{l}\text { BNL-NSLS } \\
\text { COMPRES } \\
\text { Carnegie Institution of Washington }\end{array}$ \\
\hline $\mathrm{U} 2 \mathrm{~B}$ & Bend & IRMS & $500-4000 \mathrm{~cm}^{-1}$ & $\mathrm{FB}$ & BNL-NSLS \\
\hline U3C & Bend & Metrology & $50-1000 \mathrm{eV}$ & PRT & $\begin{array}{l}\text { Lawrence Livermore National Laboratory } \\
\text { Los Alamos National Laboratory } \\
\text { National Security Technologies } \\
\text { Sandia National Laboratory }\end{array}$ \\
\hline U4B & Bend & $\begin{array}{l}\text { X-ray reflectivity } \\
\text { X-ray scattering, magnetic } \\
\text { X-ray scattering, resonant } \\
\text { MCD } \\
\text { XAS } \\
\text { X-ray fluorescence spectroscopy }\end{array}$ & $20-1200 \mathrm{eV}$ & FB & $\begin{array}{l}\text { BNL-NSLS } \\
\text { Montana State University }\end{array}$ \\
\hline U4IR & Bend & $\begin{array}{l}\text { IRMS } \\
\text { IR spectrospcopy } \\
\text { Time-resolved spectroscopy }\end{array}$ & $8-20000 \mathrm{~cm}^{-1}$ & FB & $\begin{array}{l}\text { BNL-NSLS } \\
\text { New Jersey Institute of Technology }\end{array}$ \\
\hline U5UA & $\begin{array}{l}\text { Insertion } \\
\text { Device }\end{array}$ & $\begin{array}{l}\text { ARPES } \\
\text { UPS, spin-resolved }\end{array}$ & $15-150 \mathrm{eV}$ & FB & $\begin{array}{l}\text { BNL-NSLS } \\
\text { BNL-CFN }\end{array}$ \\
\hline U7A & Bend & $\begin{array}{l}\text { NEXAFS } \\
\text { XPS }\end{array}$ & $180-1200 \mathrm{eV}$ & PRT & $\begin{array}{l}\text { BNL-Chemistry } \\
\text { Dow Chemical Company } \\
\text { National Institute of Standards \& } \\
\text { Technology }\end{array}$ \\
\hline U9B & Bend & $\begin{array}{l}\text { Time-resolved spectroscopy } \\
\text { UV-CD } \\
\text { UV fluorescence spectroscopy }\end{array}$ & $0.8-8.0 \mathrm{eV}$ & PRT & BNL-Biology \\
\hline U10B & Bend & IRMS & $500-4000 \mathrm{~cm}^{-1}$ & FB & BNL-NSLS \\
\hline U11 & Bend & $U V-C D$ & $3-10 \mathrm{eV}$ & PRT & BNL-Biology \\
\hline U12A & Bend & $\begin{array}{l}\text { XAS } \\
\text { XPS }\end{array}$ & $100-800 \mathrm{eV}$ & PRT & Oak Ridge National Laboratory \\
\hline U12IR & Bend & $\begin{array}{l}\text { IR spectroscopy } \\
\text { Magnetospectroscopy } \\
\text { THz / millimeter wave spectroscopy } \\
\text { Time-resolved spectroscopy }\end{array}$ & $8-600 \mathrm{~cm}^{-1}$ & $\mathrm{FB}$ & BNL-NSLS \\
\hline U13UB & $\begin{array}{l}\text { Insertion } \\
\text { Device }\end{array}$ & $\begin{array}{l}\text { UPS } \\
\text { ARPES }\end{array}$ & $3-30 \mathrm{eV}$ & PRT & $\begin{array}{l}\text { Boston College } \\
\text { Boston University } \\
\text { BNL-Physics } \\
\text { Columbia University }\end{array}$ \\
\hline
\end{tabular}

\begin{tabular}{|c|c|c|c|c|c|}
\hline X1A1 & $\begin{array}{l}\text { Insertion } \\
\text { Device }\end{array}$ & $\begin{array}{l}\text { STXM } \\
\text { NEXAFS }\end{array}$ & $0.25-0.50 \mathrm{keV}$ & PRT & $\begin{array}{l}\text { ExxonMobil Research and } \\
\text { Engineering Co. } \\
\text { Stony Brook University } \\
\text { SUNY@ Plattsburgh } \\
\text { University of Texas@ Houston }\end{array}$ \\
\hline
\end{tabular}




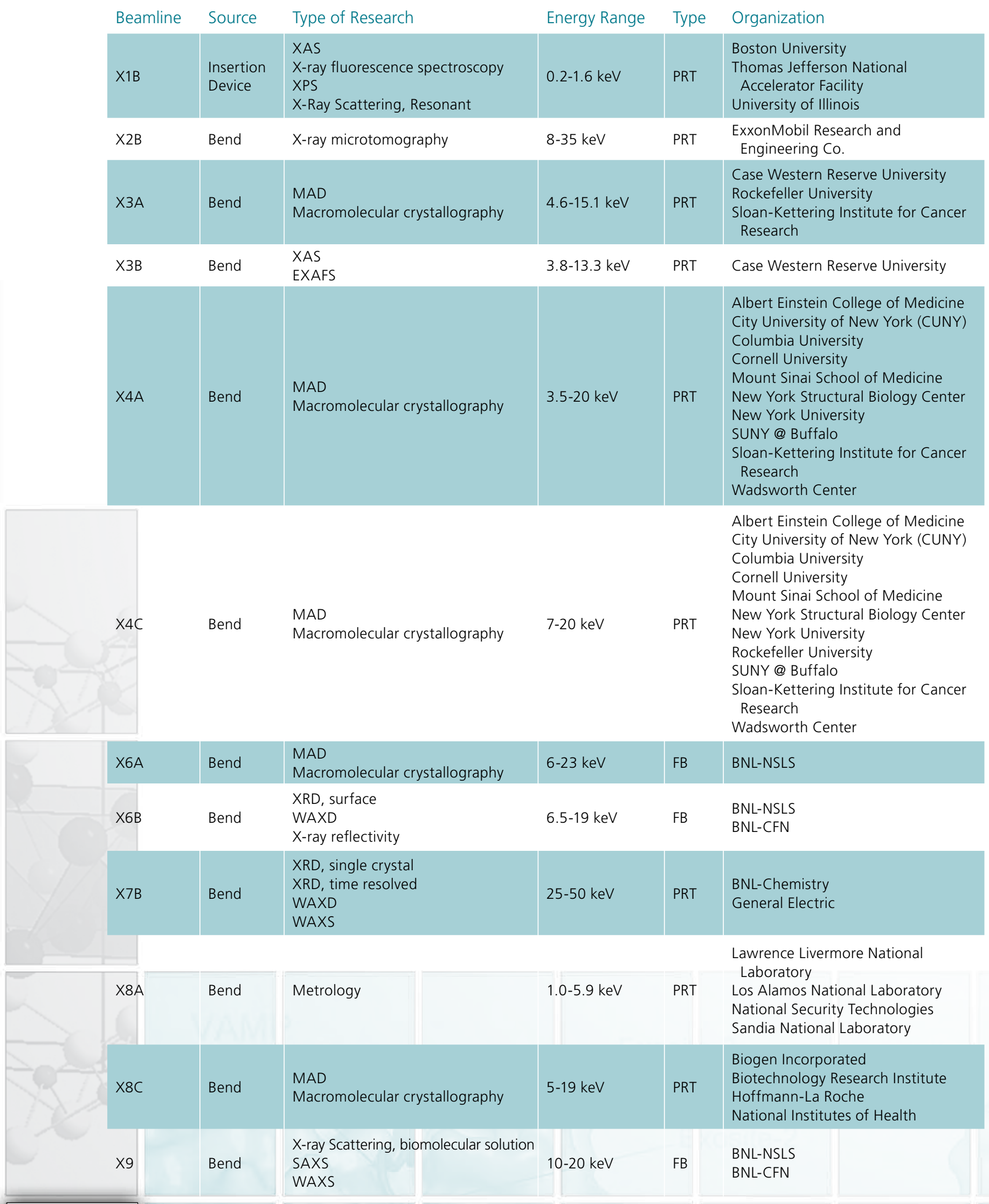

\section{TIf}

Facility Facts and Figures 


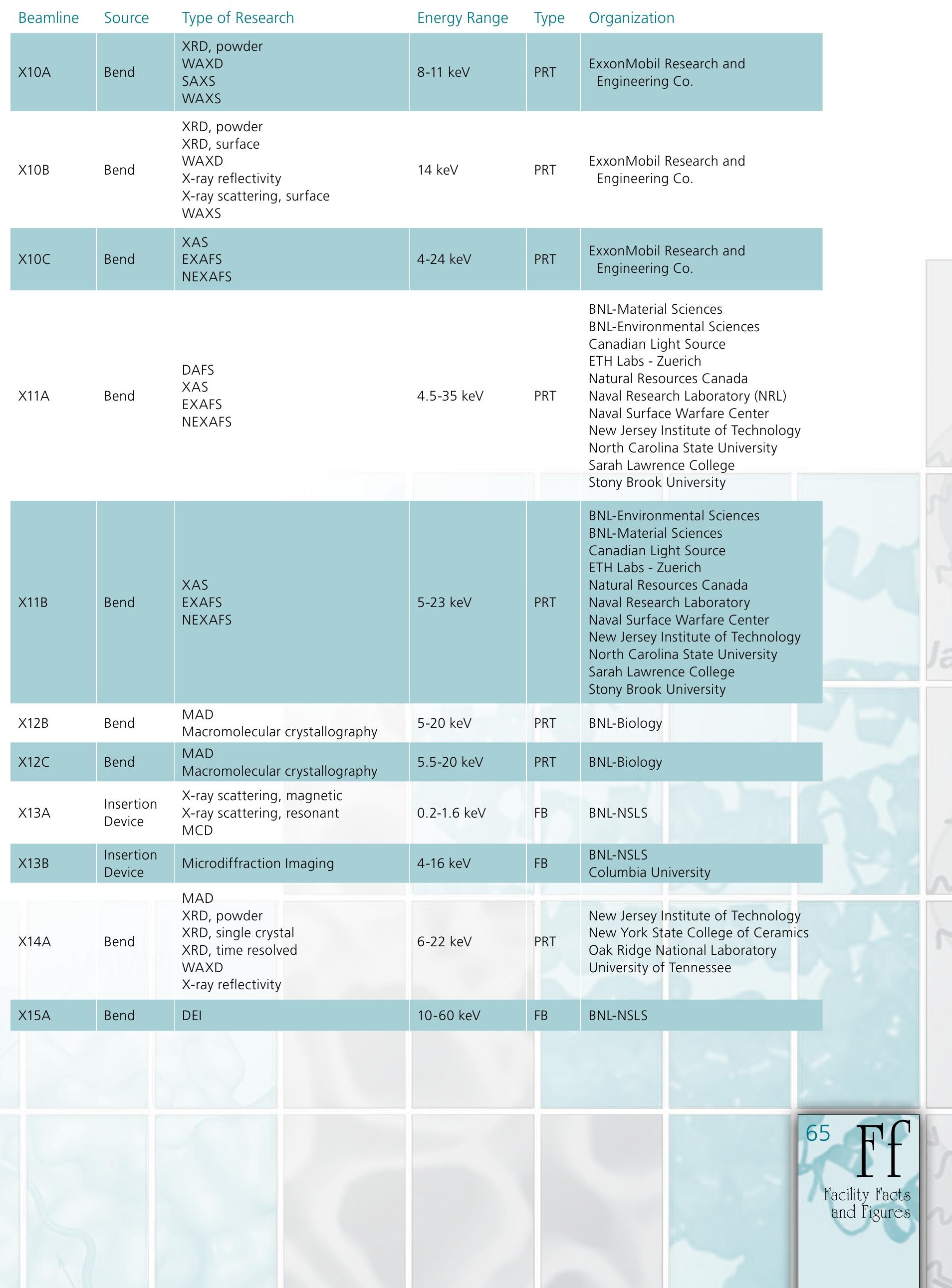




\begin{tabular}{|c|c|c|c|c|c|}
\hline Beamline & Source & Type of Research & Energy Range & Type & Organization \\
\hline X15B & Bend & $\begin{array}{l}\text { XAS } \\
\text { EXAFS } \\
\text { NEXAFS }\end{array}$ & $0.8-15 \mathrm{keV}$ & PRT & $\begin{array}{l}\text { BNL-Environmental Sciences } \\
\text { Corning, Inc. } \\
\text { Georgia Institute of Technology } \\
\text { Lawrence Berkeley National Laboratory } \\
\text { Lucent Technologies, Inc. } \\
\text { Miami University } \\
\text { North Carolina State University } \\
\text { Princeton University } \\
\text { Stony Brook University } \\
\text { University of Delaware } \\
\text { Woods Hole Oceanographic } \\
\text { Institute }\end{array}$ \\
\hline $\mathrm{X} 16 \mathrm{C}$ & Bend & XRD, powder & $6.5-25 \mathrm{keV}$ & PRT & Stony Brook University \\
\hline X17B1 & $\begin{array}{l}\text { Insertion } \\
\text { Device }\end{array}$ & XRD, powder & $20-150 \mathrm{keV}$ & FB & $\begin{array}{l}\text { BNL-NSLS } \\
\text { Rutgers University }\end{array}$ \\
\hline X17B2 & $\begin{array}{l}\text { Insertion } \\
\text { Device }\end{array}$ & $\begin{array}{l}X R D, \text { powder } \\
X R D, \text { time resolved } \\
\text { High pressure research }\end{array}$ & $20-130 \mathrm{keV}$ & FB & $\begin{array}{l}\text { BNL-NSLS } \\
\text { COMPRES } \\
\text { Stony Brook University - Mineral } \\
\text { Physics Institute }\end{array}$ \\
\hline
\end{tabular}

\begin{tabular}{|c|c|c|c|c|c|}
\hline X17B3 & $\begin{array}{l}\text { Insertion } \\
\text { Device }\end{array}$ & $\begin{array}{l}X R D \text {, powder } \\
X R D \text {, single crystal } \\
\text { High pressure research }\end{array}$ & $5-80 \mathrm{keV}$ & FB & $\begin{array}{l}\text { BNL-NSLS } \\
\text { COMPRES } \\
\text { Princeton University } \\
\text { Stony Brook University }\end{array}$ \\
\hline
\end{tabular}

$\begin{array}{lllll} & & & & \text { BNL-NSLS } \\ \text { X17C } & \text { Insertion } & \text { XRD, powder } & \text { COMPRES } \\ \text { Device } & \text { XRD, single crystal } & \text { F-80 keV } & \text { FB } & \begin{array}{l}\text { Princeton University } \\ \text { High pressure research }\end{array} \\ & & & & \text { Stony Brook University }\end{array}$

\begin{tabular}{|l|l|l} 
& XRD, powder \\
& XRD, single crystal \\
& XRD, surface & \\
WAXD & \\
X18A & Bend & $5-25 \mathrm{keV}$ \\
X-ray scattering, surface & \\
WAXS \\
XAS
\end{tabular}

$\begin{array}{llll} & \text { XAS } & & \text { BNL-Chemistry } \\ \text { X18B Bend } & \text { EXAFS } & & \text { BNL-Electrochemistry } \\ & \text { NEXAFS } & 4.8-40 \mathrm{keV} & \text { FB } \quad \text { Oak Ridge National Laboratory } \\ & & & \text { UOP LLC } \\ & & & \text { University of Delaware } \\ & & \text { Yeshiva University }\end{array}$

\begin{tabular}{|c|c|c|c|c|c|}
\hline X19A & Bend & $\begin{array}{l}\text { X-ray scattering, resonant } \\
\text { XAS } \\
\text { EXAFS } \\
\text { NEXAFS }\end{array}$ & 2.1-17 keV & FB & $\begin{array}{l}\text { BNL-NSLS } \\
\text { BNL-Chemistry } \\
\text { BNL-Electrochemistry } \\
\text { Oak Ridge National Laboratory } \\
\text { UOP LLC } \\
\text { University of Delaware } \\
\text { Yeshiva University }\end{array}$ \\
\hline $\mathrm{X} 19 \mathrm{C}$ & Bend & $\begin{array}{l}\text { XRD, surface } \\
\text { X-ray topography } \\
\text { X-ray reflectivity } \\
\text { X-ray scattering, liquid } \\
\text { X-ray scattering, surface }\end{array}$ & $6-17 \mathrm{keV}$ & PRT & $\begin{array}{l}\text { BNL-Instrumentation } \\
\text { Fairfield Crystal Technology, LLC } \\
\text { Kansas State University } \\
\text { Stony Brook University } \\
\text { SUNY @ Albany } \\
\text { University of Illinois @ Chicago }\end{array}$ \\
\hline
\end{tabular}

\section{TIf}

Facility Facts and Figures 


\begin{tabular}{|c|c|c|c|c|c|}
\hline Beamline & Source & Type of Research & Energy Range & Type & Organization \\
\hline$\times 20 A$ & Bend & $\begin{array}{l}\text { XRD, single crystal } \\
\text { WAXD } \\
\text { Microdiffraction Imaging } \\
\text { X-ray reflectivity } \\
\text { X-ray scattering, surface }\end{array}$ & 4.5-13 keV & PRT & IBM Research Division \\
\hline$\times 20 C$ & Bend & $\begin{array}{l}X R D \text {, single crystal } \\
X R D \text {, surface } \\
X R D \text {, time resolved } \\
\text { X-ray reflectivity } \\
\text { X-ray scattering, surface }\end{array}$ & 4-11 keV & PRT & IBM Research Division \\
\hline$\times 21$ & $\begin{array}{l}\text { Insertion } \\
\text { Device }\end{array}$ & $\begin{array}{l}\text { XRD, single crystal } \\
\text { XRD, surface } \\
\text { WAXD } \\
\text { X-ray scattering, magnetic } \\
\text { X-ray scattering, resonant } \\
\text { X-ray scattering, surface } \\
\text { WAXS }\end{array}$ & $6-16 \mathrm{keV}$ & $\mathrm{FB}$ & $\begin{array}{l}\text { BNL-NSLS } \\
\text { Boston University } \\
\text { University of Vermont }\end{array}$ \\
\hline$\times 22 B$ & Bend & X-ray scattering, liquid & $8 \mathrm{keV}$ & PRT & $\begin{array}{l}\text { BNL-CMPMSD } \\
\text { BNL-CFN }\end{array}$ \\
\hline$\times 22 C$ & Bend & $\begin{array}{l}X R D \text {, single crystal } \\
X R D \text {, surface } \\
\text { X-ray reflectivity } \\
\text { X-ray scattering, magnetic }\end{array}$ & $3-12 \mathrm{keV}$ & PRT & $\begin{array}{l}\text { BNL-CMPMSD } \\
\text { Massachusetts Institute of Technolog } \\
\text { Rutgers University }\end{array}$ \\
\hline$\times 23 A 2$ & Bend & $\begin{array}{l}\text { DAFS } \\
\text { XAS } \\
\text { EXAFS } \\
\text { NEXAFS }\end{array}$ & 4.7-30 keV & PRT & $\begin{array}{l}\text { National Institute of Standards } \\
\& \text { Technology }\end{array}$ \\
\hline$\times 24 \mathrm{~A}$ & Bend & $\begin{array}{l}\text { XSW } \\
\text { Auger spectroscopy } \\
\text { EXAFS } \\
\text { X-ray fluorescence spectroscopy } \\
\text { XPS }\end{array}$ & $1.8-6 \mathrm{keV}$ & PRT & $\begin{array}{l}\text { National Institute of Standards } \\
\text { \& Technology }\end{array}$ \\
\hline$\times 24 C$ & Bend & $\begin{array}{l}\text { X-ray reflectivity } \\
\text { UV absorption spectroscopy } \\
\text { XAS }\end{array}$ & $0.006-1.8 \mathrm{keV}$ & PRT & $\begin{array}{l}\text { Naval Research Laboratory (NRL) } \\
\text { SFA, Inc. } \\
\text { Universities Space Research } \\
\text { Association }\end{array}$ \\
\hline$\times 25$ & $\begin{array}{l}\text { Insertion } \\
\text { Device }\end{array}$ & $\begin{array}{l}\text { MAD } \\
\text { Macromolecular crystallography }\end{array}$ & $5-20 \mathrm{keV}$ & $\mathrm{FB}$ & $\begin{array}{l}\text { BNL-NSLS } \\
\text { BNL-Biology }\end{array}$ \\
\hline$\times 26 \mathrm{~A}$ & Bend & $\begin{array}{l}\text { Microdiffraction Imaging } \\
\text { X-ray microprobe }\end{array}$ & $3-30 \mathrm{keV}$ & PRT & $\begin{array}{l}\text { BNL-Environmental Sciences } \\
\text { University of Chicago } \\
\text { University of Kentucky }\end{array}$ \\
\hline $\mathrm{X} 26 \mathrm{C}$ & Bend & $\begin{array}{l}\text { MAD } \\
\text { Macromolecular crystallography }\end{array}$ & $5-20 \mathrm{keV}$ & PRT & $\begin{array}{l}\text { BNL-Biology } \\
\text { Cold Spring Harbor Laboratory } \\
\text { Stony Brook University }\end{array}$ \\
\hline$X 27 \mathrm{~A}$ & Bend & X-ray microprobe & $4.5-32 \mathrm{keV}$ & FB & $\begin{array}{l}\text { BNL-NSLS } \\
\text { BNL-Environmental Sciences }\end{array}$ \\
\hline$\times 27 B$ & Bend & HARMST & $8-40 \mathrm{keV}$ & PRT & $\begin{array}{l}\text { BNL-Nonproliferation \& National } \\
\text { Security }\end{array}$ \\
\hline$\times 27 C$ & Bend & $\begin{array}{l}\text { XRD, time resolved } \\
\text { WAXD } \\
\text { SAXS } \\
\text { WAXS }\end{array}$ & $9 \mathrm{keV}$ & PRT & $\begin{array}{l}\text { Air Force Research Laboratory } \\
\text { National Institutes of Health } \\
\text { Naval Surface Warfare Center } \\
\text { Stony Brook University }\end{array}$ \\
\hline $\mathrm{X} 28 \mathrm{C}$ & Bend & X-ray Footprinting & $\begin{array}{l}\text { Focused White } \\
\text { Beam }\end{array}$ & PRT & Case Western Reserve University \\
\hline$\times 29 A$ & $\begin{array}{l}\text { Insertion } \\
\text { Device }\end{array}$ & $\begin{array}{l}\text { MAD } \\
\text { Macromolecular crystallography }\end{array}$ & $6-15 \mathrm{keV}$ & PRT & $\begin{array}{l}\text { BNL-Biology } \\
\text { Case Western Reserve } \\
\text { University }\end{array}$ \\
\hline
\end{tabular}




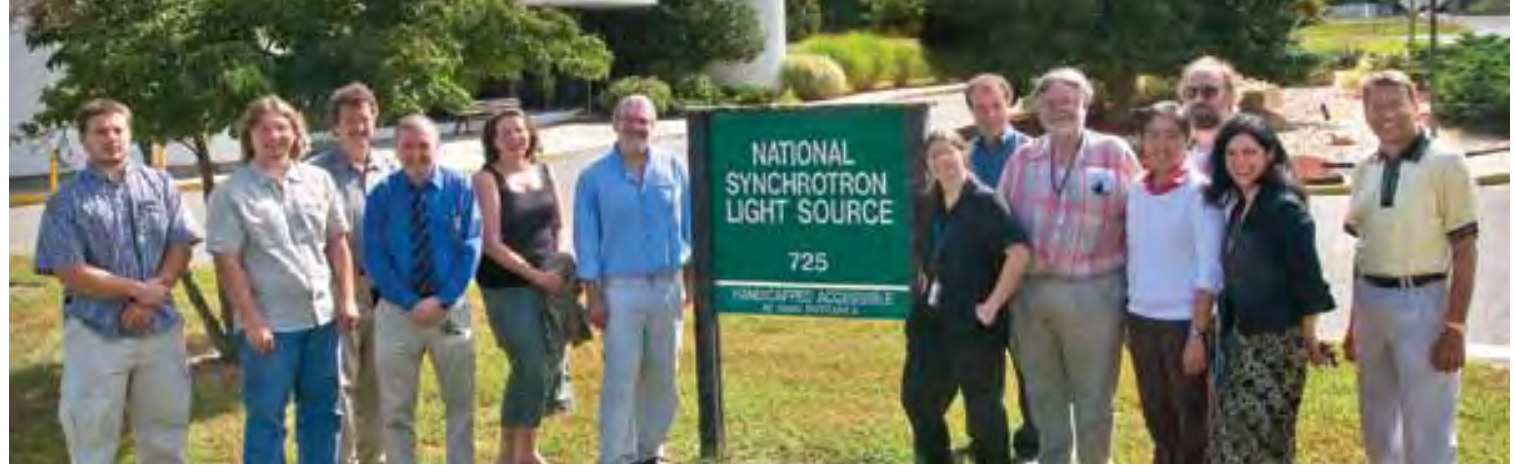

\section{Users' Executive Committee}

The NSLS regularly consults with the Users' Executive Committee (UEC). This committee provides a forum for ongoing, organized discussions between representatives from the NSLS user community in various research disciplines and the management and administration at the NSLS and Brookhaven National Laboratory. The purpose is to communicate current and future needs, concerns, and trends, and to disseminate information about future plans for the NSLS and BNL.

Chair Bruce Ravel, National Institute of Standards and Technology (NIST)

Vice Chair Tony Lanzirotti, University of Chicago

Past Chair John Parise, Stony Brook University (SBU)

Secretary Jean Jordan-Sweet, IBM

General Member Jen Bohon, Case Western University

General Member Dan Fischer, NIST

General Member George Flynn, SUNY Plattsburgh

Ex-Officio Chi-Chang Kao, BNL, NSLS Chair

Ex-Officio Kathleen Nasta, BNL, NSLS Information Outreach \& User Administrator

\section{Special Interest Group Representatives}

Special Interest Group (SpIG) Representatives are listed below. These groups, divided into areas of common concern, communicate with NSLS management through the UEC.

Bio. Crystallography Annie Heroux, BNL, Biology
\& Diffraction

High Pressure Lars Ehm, BNL, NSLS

Imaging Paul Northrup, BNL, Enviro. Sciences

Industrial Users Jean Jordan-Sweet, IBM

Infrared Users Yizhi Meng, SBU

Magnetism Cecilia Sanchez-Hanke, BNL, NSLS NSLS-II Howard Robinson, BNL, Biology

Students \& Post Docs Megan Bourassa, SBU

Time Resolved

Spectroscopy John Sutherland, BNL, Biology

Topography Michael Dudley, SBU

UV Photoemission \& Tony Caruso, University of Missouri at Surface Science Kansas City XAFS Syed Khalid, BNL, NSLS

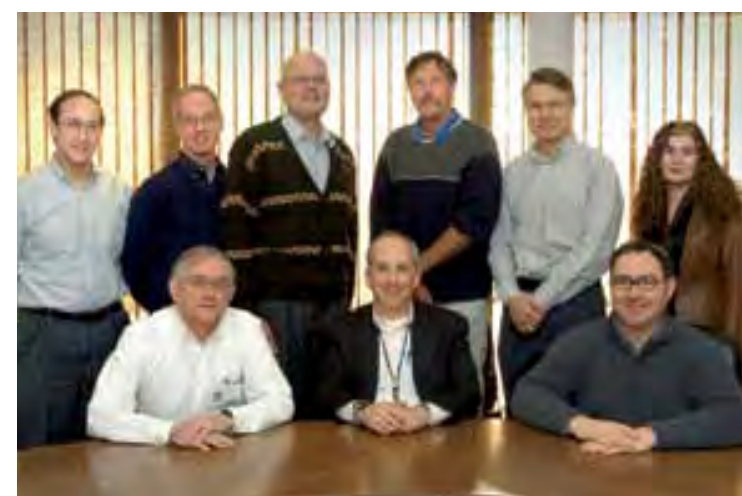

\section{Scientific Advisory Committee}

The NSLS Scientific Advisory Committee (SAC) advises the NSLS Chair and the Associate Laboratory Director for Light Sources on scientific, technical, and policy issues related to the optimization of the scientific productivity of the NSLS.

\footnotetext{
Mario Amzel, Johns Hopkins University

Simon Bare, UOP, LLC

Joel Brock, Cornell University

Tony Heinz, Columbia University

Robert Hettel, Stanford Synchrotron Radiation Laboratoryl SLAC National Accelerator Laboratory

Eric Isaacs (Chair), Argonne National Laboratory

Leemor Joshua-Tor, Cold Spring Harbor Laboratory

James Kaduk, INEOS Technologies

Edward Kramer, University of California, Santa Barbara

Simon Mochrie, Yale University

James Penner-Hahn, University of Michigan

William Thomlinson, Canadian Light Source

John Parise (UEC Chair), SBU
}

\section{Proposal Review Panels}

As part of the peer-review process of GU proposals, the Proposal Review Panels (PRPS) at the NSLS review and rate the proposals within their scientific area. Members are drawn from the scientific community and usually serve a two-year term. Each PRP has an appointed Chair, who is part of the Proposal Oversight Panel or POP, established to review any proposals that might need special attention due to use of multiple techniques or conflicts in scores. The POP has additional appointed members, listed below after the PRP membership.

${ }^{*}=$ Chair of PRP 
Imaging and Microprobes: Biological and Medical Leroy Chapman, University of Saskatchewan Paul Dumas, Soleil Synchrotron Kathleen Gough, University of Manitoba Barry Lai* Argonne National Laboratory Carolyn Larabell, Lawrence Berkeley National Laboratory Irit Sagi, Weizmann Institute of Science Franz Vogt, Argonne National Laboratory Gayle Woloschak, Northwestern University

Imaging and Microprobes: Chemical and Materials Sciences Harald Ade*, North Carolina State University

David Black, Topographix

Darren Dale, Cornell University

Paul Evans, University of Wisconsin Ismail Noyan, Columbia University Mark Rivers, University of Chicago Nobumichi Tamura, Lawrence Berkeley National Laboratory Paul Zschack, Argonne National Laboratory

Imaging and Microprobes: Environmental and Geosciences Don Baker, McGill University

David Black, Topographix

Darren Dale, Cornell University

George Flynn, SUNY @ Plattsburgh

Matthew Ginder-Vogel, University of Delaware

Keith Jones*, BNL, Environmental Sciences

Mark Rivers, University of Chicago

Donald Ross, University of Vermont

IR / UV / Soft X-ray Spectroscopy: Chemical Sciences / Soft

Matter / Biophysics

Daniel Fischer*, National Institute of Standards \& Technology

Mary Gilles, Lawrence Berkeley National Laboratory

Joseph Lenhart, Army Research Laboratory

Robert Lodder, University of Kentucky

Gary Mitchell, The Dow Chemical Company

IR / UV / Soft X-ray Spectroscopy: Magnetism / Strongly

Correlated Electrons / Surface

Robert Bartynski*, Rutgers University

Di-Jing Huang, Synchrotron Radiation Research Center

Jeffrey Keister, SFA, Inc.

Alexander Moewes, University of Saskatchewan

David Mullins, Oak Ridge National Laboratory

Robert Opila, Jr., University of Delaware

Boris Sinkovic, University of Connecticut

Jiufeng Tu, City University of New York (CUNY)

Tonica Valla, BNL, Condensed Matter Physics \& Materials Science

Methods and Instrumentation

Leroy Chapman, University of Saskatchewan

Kenneth Finkelstein, Cornell University

Jeffrey Keister, SFA, Inc.

Ralf Hendrik, Menk Sincrotrone Trieste

Peter Takacs*, BNL, Instrumentation

Macromolecular Crystallography

Steven Almo, Albert Einstein College of Medicine

Alex Bohm*, Tufts University

Olga Boudker, Cornell University

Barnali Chaudhuri, Hauptman-Woodward Medical Research Institute

Ashley Deacon, Stanford Synchrotron Radiation Lab

Annie Heroux, BNL, Biology

Xiangpeng Kong, New York University

Nicolas Nassar, SBU

Peter Prevelige, University of Alabama

Steven Roderick, Albert Einstein College of Medicine

Brenda Schulman, St. Jude Children's Research Hospital
Bianca Sclavi, Centre National de La Recherche Scientifique Hao Wu, Cornell University

Powder / Single Crystal Crystallography

Emil Bozin, Columbia University

Andrew Campbell, University of Maryland

Yu-Sheng Chen, University of Chicago

Przemyslaw Dera, Carnegie Institution of Washington

Thomas Duffy*, Princeton University

Andrew Fitch, European Synchrotron Radiation Facility

Jon Hanson, BNL, Chemistry

James Kaduk, Poly Crystallography, Inc.

Volker Kahlenberg, University of Innsbruck

Peter Khalifah, BNL, Chemistry

Peter Lee*, Argonne National Laboratory

James Martin, North Carolina State University

Wendy Panero, Ohio State University

Stephen Shapiro, BNL, Condensed Matter Physics \&

Materials Science

Peter Stephens, Stony Brook University

X-Ray Scattering: Magnetism / Strongly Correlated

Electrons / Surface

Peter Abbamonte, University of Illinois at Urbana-Champaign

Kenneth Finkelstein*, Cornell University

Peter Hatton, University of Durham

Karl Ludwig, Boston University

Christopher Marrows, University of Leeds

George Srajer, Argonne National Laboratory

Trevor Tyson, New Jersey Institute of Technology

Gerrit Van Der Laan, Diamond Light Source

$X$-Ray Scattering: Soft Matter and Biophysics

Masafumi Fukuto, BNL, Condensed Matter Physics \&

Materials Science

Randall Headrick, University of Vermont

Benjamin Hsiao*, SBU

Huey Huang, Rice University

Thomas Russell, University of Massachusetts

Detleff-Matthias Smilgies, Cornell University

Lei Zhu, University of Connecticut

X-Ray Spectroscopy: Biological, Environmental and

Geosciences

Suzanne Beauchemin, Natural Resources Canada

Martine Duff, Westinghouse Savannah River Co.

Graham George, University of Saskatchewan

Douglas Hunter, Westinghouse Savannah River Co.

Satish Myneni*, Princeton University

Matthew Newville, University of Chicago

Bruce Ravel, National Institute of Standards \& Technology

$X$-Ray Spectroscopy: Chemical and Material Sciences

Simon Bare, UOP

Scott Calvin, Sarah Lawrence College

Anatoly Frenkel, Yeshiva University

Steve Heald, Argonne National Laboratory

Bruce Ravel, National Institute of Standards \& Technology

Jean-Pascal Rueff, Synchrotron SOLEIL

Tsun-Kong Sham, University of Western Ontario

Trevor Tyson*, New Jersey Institute of Technology

\section{Proposal Oversight Panel Members}

Antonio Lanzirotti, University of Chicago Jonathan Hanson, BNL, Chemistry

Stephen Shapiro, BNL, Condensed Matter Physics \&

Materials Science

Peter Stephens, SBU

Subramanyam Swaminathan, BNL, Biology 


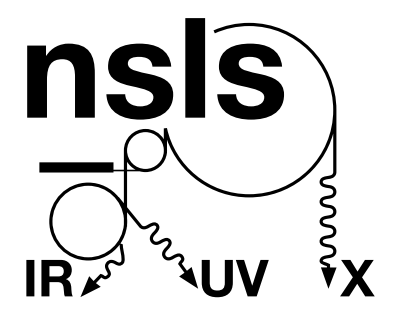

National Synchrotron Light Source

Brookhaven National Laboratory

Upton, NY 11973

www.nsls.bnl.gov

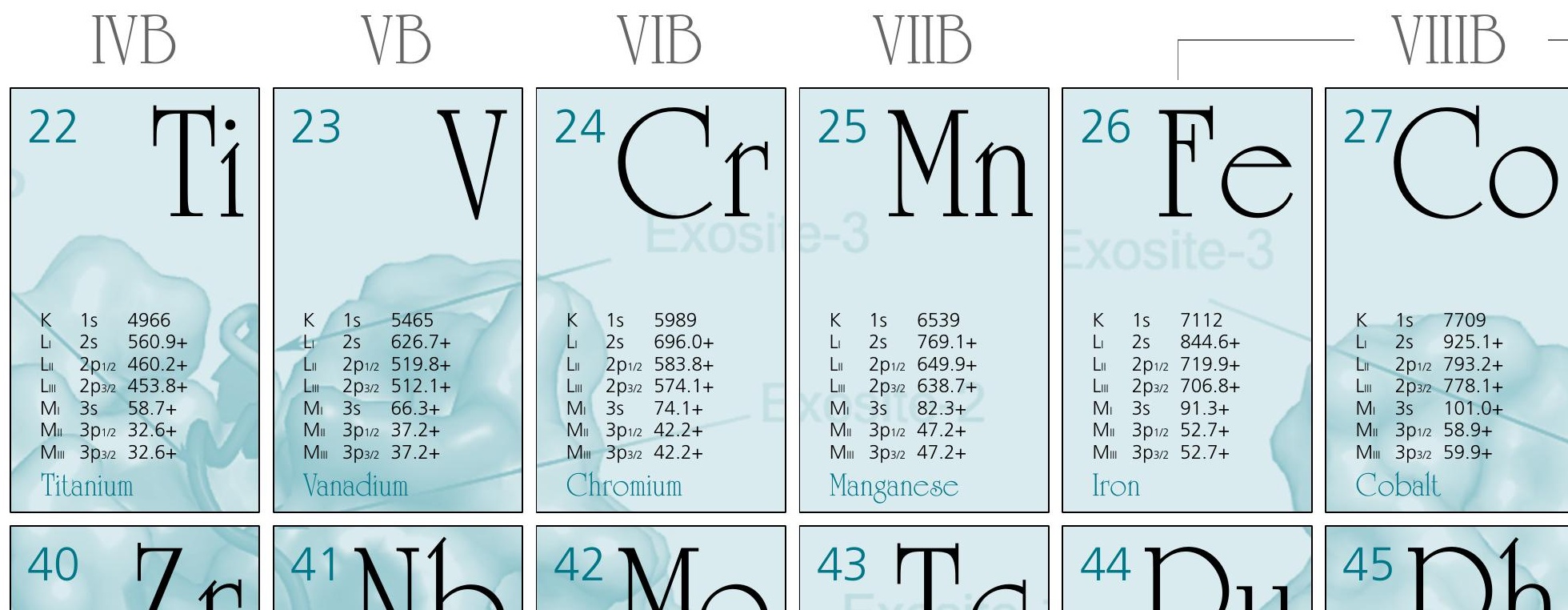

